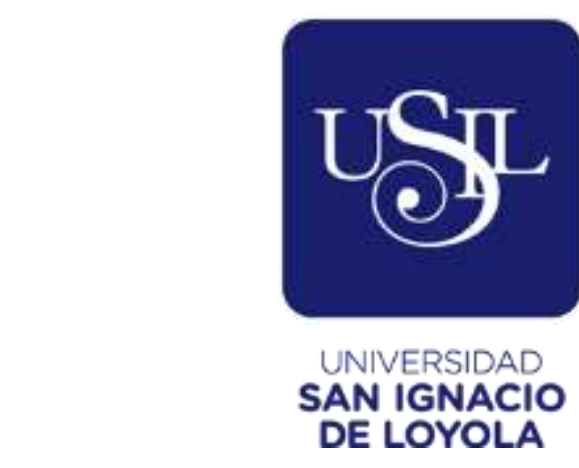

ESCUELA DE POSTGRADO

Maestría en Educación con Mención en Gestión de la Educación

\title{
ESTRATEGIA METODOLÓGICA PARA EL INTERÉS POR EL APRENDIZAJE DEL INGLÉS EN LOS ESTUDIANTES DE ADMINISTRACIÓN DE UNA UNIVERSIDAD PRIVADA DE LIMA
}

Tesis para optar el grado de Maestro en Educación con

Mención en Gestión de la Educación

NATALY FALCON SIFUENTES

Asesor:

Dra. Miriam Encarnación Velázquez Tejeda

Lima - Perú 


\section{Dedicatoria}

Con todo el amor y cariño a mis padres, Oswaldo y Rocío, por su apoyo incansable, por impulsarme a seguir luchando por mis metas y sobre todo por ser mi fortaleza en los momentos más difíciles.

A mi amado hijo André, por ser mi mayor motivación e inspiración para poder superarme cada día y así enfrentar las vicisitudes que nos depara la vida con expectativa de un futuro mejor.

A mi hermana Priscilla, por su apoyo incondicional quien a la par con mis padres, suplen mi ausencia por trabajo y estudio y se preocupan por dar los mejores cuidados a mi hijo en todos los aspectos de su desarrollo emocional y educativo.

A mis profesores, compañeros, amigos en general quienes sin esperar nada a cambio compartieron sus conocimientos, consejos y experiencias de vida, enriqueciendo mi etapa de formación profesional. 
A Dios, por su infinita bondad y sabiduría, por mostrarme lo maravilloso de la vida, no obstante, ciertos momentos difíciles pero que nos alivia y redime siempre con su bondad, mostrándome cada amanecer diferente lleno de oportunidades, siendo la luz que guía mi camino.

A mis padres, hermana y familia en general que de una $u$ otra forma están muy pendientes de mis propósitos, brindándome su apoyo incondicional, protección, motivándome y también corrigiendo mis errores con verdadero amor, principios y valores para seguir creciendo profesionalmente.

A la doctora Miriam Velázquez, por ilustrarme con sus conocimientos, por su paciencia y buena voluntad, cuyo aporte ha fortalecido enormemente mi desarrollo profesional. 


\section{Índice}

$\begin{array}{lr}\text { Resumen } & 8\end{array}$

$\begin{array}{ll}\text { Abstract } & 9\end{array}$

$\begin{array}{ll}\text { Introducción } & 10\end{array}$

$\begin{array}{ll}\text { Problema de la investigación } & 12\end{array}$

$\begin{array}{lc}\text { Preguntas científicas. } & 13\end{array}$

$\begin{array}{ll}\text { Objetivo general. } & 13\end{array}$

$\begin{array}{ll}\text { Justificación teórica, metodológica y práctica } & 15\end{array}$

Metodología de la investigación 16

$\begin{array}{ll}\text { Métodos de investigación } & 18\end{array}$

$\begin{array}{ll}\text { Técnicas e instrumentos para el trabajo de campo } & 20\end{array}$

$\begin{array}{ll}\text { Capítulo I } & 24\end{array}$

Marco teórico $\quad 24$

Antecedentes de las investigaciones $\quad 24$

Fundamentos teóricos sobre el interés por el aprendizaje 32

Fundamentos teóricos y reflexión sobre la estrategia metodológica $\quad 54$

$\begin{array}{ll}\text { Capítulo II } & 61\end{array}$

Diagnóstico o trabajo de campo $\quad 61$

Análisis, interpretación y discusión de los resultados obtenidos con la aplicación de los instrumentos $\quad 62$

$\begin{array}{ll}\text { Capítulo III } & 83\end{array}$

$\begin{array}{lr}\text { Modelación, validación y aplicación de la propuesta } & 83\end{array}$

$\begin{array}{ll}\text { Validación de la estrategia metodológica } & 123\end{array}$

$\begin{array}{lr}\text { Recomendaciones } & 129\end{array}$

$\begin{array}{ll}\text { Referencias } & 130\end{array}$

ANEXO1- MATRIZ METODOLÓGICA 137

ANEXO2- MATRIZ DE CATEGORIZACIÓN 138 
ANEXO 3. INSTRUMENTOS DE RECOLECCIÓN DE DATOS

ANEXO 4. FICHAS DE VALIDACIÓN DE LOS INSTRUMENTOS Y ESTRATEGIA METODOLÓGICA MODELADA

ANEXO 5. ANÁLISIS ESTADÍSTICOS 


\section{Índice de tablas}

Tabla 1. Categorías 14

Tabla 2. Dosificación de la unidad didáctica 2 de la asignatura inglés. 90

Tabla 3. Propuesta de talleres de capacitación metodológica orientada a los docentes. 118

Tabla 4.Expertos que validaron la estrategia metodológica. $\quad 124$

$\begin{array}{ll}\text { Tabla 5.Valoración de las fichas de validación. } & 124\end{array}$

Tabla 6.Sumatoria de valoración interna y externa otorgada por los especialistas. 125

Tabla 7.Resultado total de la valoración interna y externa de la propuesta. 126 


\section{Índice de figuras}

Figura 1. Procesos que intervienen en el aprendizaje. 35

$\begin{array}{ll}\text { Figura 2. Categorías emergentes generales. } & 78\end{array}$

Figura 3. Categorías emergentes que influyen en el problema. 79

Figura 4. Esquema teórico-funcional que representa la estrategia metodológica. 91

Figura 5. Componentes del proceso de enseñanza - aprendizaje.. 100

$\begin{array}{ll}\text { Figura 6. Pasos metodológicos de la actividad de aprendizaje. } & 101\end{array}$

Figura 7. Adaptación del juego Hangman. 106

$\begin{array}{ll}\text { Figura 8. Flashcards. } & 107\end{array}$

$\begin{array}{ll}\text { Figura 9. Ejemplo de anotación en la pizarra. } & 107\end{array}$

$\begin{array}{ll}\text { Figura 10. Tabla de actividad. } & 108\end{array}$

$\begin{array}{ll}\text { Figura 11. Tabla para cierre de actividad.. } & 110\end{array}$

Figura 12. Video de motivación sobre lenguaje para usar al comprar. 110

Figura 13. Identificación de objetos. 112

Figura 14. Valor de los objetos. 112

Figura 15. Cuadro de this, that, these, those. 113

Figura 16. Uso de This, that, these, those. 114 


\section{Resumen}

La investigación tuvo como propósito el diseño de una una estrategia metodológica para contribuir al desarrollo del interés por el aprendizaje del idioma Inglés en los estudiantes de primer ciclo de la carrera de Administración de una universidad privada de Lima. La metodología empleada está enmarcada en el paradigma sociocrítico interpretativo, con un enfoque cualitativo y se materializa en una investigación educacional de tipo aplicada. Durante la realización del trabajo se requirió métodos cuantitativos y cualitativos, lo cual admitió el análisis del problema científico desde diferentes perspectivas. La muestra elegida por muestreo no probabilístico por conveniencia la conforman cuatro docentes de la especialidad de inglés y 40 estudiantes de primer ciclo pertenecientes a la carrera de Administración de una universidad privada de Lima. En el diagnóstico de campo se utilizaron diferentes instrumentos y técnicas, los cuales fueron la entrevista semiestructurada a los profesores, la prueba pedagógica, la guía de observación de clases, y la encuesta a los alumnos, que garantizó la imparcialidad del problema estudiado. En conclusión, se aporta una estrategia metodológica que contribuye a mejorar la práctica pedagógica del educador en el proceso educativo de la asignatura de Inglés, con el propósito de favorecer a que los alumnos desarrollen el interés por el aprendizaje del idioma.

Palabras claves: interés por el aprendizaje, interés, métodos, estrategia metodológica. 


\begin{abstract}
The purpose of the research was to design a methodological strategy to contribute to the development of interest in English language learning among undergraduate students in the field of management at a private university in Lima. The methodology used is framed in the socio-critical interpretative paradigm, with a qualitative approach and is materialized in an applied educational research. During the realization of the work, quantitative and qualitative methods were required, which admitted the analysis of the scientific problem from different perspectives. The sample chosen by non-probabilistic sampling for convenience is composed of four teachers of the English specialty and 40 first cycle students belonging to the career of Administration of a private university in Lima. Different instruments and techniques were used in the field diagnosis, which were the semi-structured interview with the teachers, the pedagogical test, the class observation guide, and the student survey, which guaranteed the impartiality of the problem studied. In conclusion, a methodological strategy is provided that contributes to improving the pedagogical practice of the educator in the educational process of the subject of English, with the purpose of favouring the students to increase their interest in learning.
\end{abstract}

Keywords: interest in learning, interest, methods, methodological strategy. 


\section{Introducción}

Actualmente se considera que el siglo XXI ha sido relevante en cuanto a los cambios que ha traído consigo el proceso de globalización que lleva intrínseco un vertiginoso progreso en las ciencias, así como en la tecnología que ha causado una explosión de información en todas las ramas del saber y un mayor acceso a la misma por las personas a nivel global, regional y local acortando los tiempos y la distancia. (Riopel y Smyrnaiou, 2016).

Ello ha significado un gran reto y un grado de exigencia considerable desde todas las perspectivas y en especial, en los sistemas educativos por la necesidad de transformar el aprendizaje de las disciplinas lingüísticas como es el idioma inglés por su gran demanda social como vía de acceso al mercado internacional. Se evidencia en la práctica que el dominio de esta lengua es cada vez más urgente para la comunicación internacional en el campo cultural y en los negocios, incluso se vincula con prospectos de crecimiento en la economía global y competitividad. En este sentido, el idioma Inglés es una lengua cada vez más usado en la cotidianidad de los individuos, según sea los diferentes escenarios que se le presente en su desempeño. Esta es una de las causas por la cual ha aumentado la demanda de su estudio a escala nacional e internacional, generándose así distintas propuestas de estudio de las instituciones educativas de los distintos niveles educacionales. (Cronquist y Fiszbein, 2017).

En ese sentido, América Latina ha evolucionado de manera significativa en cuanto a la organización de la educación Superior en general y en particular en la enseñanzaaprendizaje del inglés convirtiéndose en un notable objetivo estratégico. Al respecto se han desarrollado estrategias nacionales por el Ministerios de Educación (2012) y los centros formadores como: la creación de programas, que implican cuantiosas inversiones con el 
propósito de expandir el acceso a las oportunidades de aprender el idioma. No obstante, en comparación con otras regiones del mundo, aún hay un bajo nivel de dominio del idioma lo cual se confirma con la ubicación de Perú con 2.34 puntos por debajo del promedio mundial en el English First English Proficiency Index (EF EPI), según datos del año 2016 (Cronquist y Fiszbein, 2017).

Según las investigaciones de López (2016), el Perú exhibe dificultades en lo que respecta al proceso de la enseñanza y aprendizaje de esta materia en el empleo de metodologías tradicionalistas poco activas en la que prevalece la exposición y la reproducción de contenido y los estudiantes asumen un rol de receptores de información; limitándose en el ejercicio del protagonismo de su propio aprendizaje. Tomando en cuenta lo descrito, un aspecto importante a mejorar para lograr los objetivos en los educandos es el interés por el aprendizaje, entendido según Rubinstein, (1977), como las formaciones psicológicas específicas que expresan la orientación afectiva de un individuo hacia el conocimiento de determinados fenómenos, objetos o hechos, manifestando la unidad de lo cognitivo y lo afectivo. Es sabido que la persona que tiene intereses estables y sólidos hacia una actividad, en este caso hacia el aprendizaje de una lengua extranjera lo sentirá como una necesidad y desarrollará los saberes y las habilidades de forma integral como añaden Harackiewicz, y Hulleman (2010).

Se reconoce que en el país la mayoría de las personas y los profesionales en general han estudiado de alguna manera este idioma, principalmente por ser un requisito obligatorio como lo expresa el estudio realizado por el British Council, Educational Intelligence (2015). En este se encuestaron a más de mil peruanos para saber los motivos que los llevó a su estudio. Los resultados señalan que $44 \%$ lo aprendió por ser obligatorio durante la Secundaria, el 25\% expresó por ser un requisito de la enseñanza Primaria y el $40 \%$ afirma que estudió el idioma por ser necesario para ingresar a la universidad. En 
resumen, el 23\%, de los encuestados revelan que aprendieron el idioma Inglés para acceder a las fuentes de información, 10\% para ampliar la red personal y profesional y $3 \%$ para tener una mejor posición social. Al revisar el perfil de la carrera de Administración de una universidad privada de Lima, se precisa que los estudiantes deben recibir una formación bilingüe intensiva con la finalidad de que estén preparados para competir profesionalmente y hacer negocios en el mundo. Los profesionales que egresan tendrán la capacidad de leer y escribir en inglés, realizar trabajos de investigación, elaborar casos y dominar un vocabulario asociado a su carrera. Exigiéndoles lograr un nivel intermedio que corresponde al nivel B1 de acuerdo al Marco Común Europeo.

No obstante, en la praxis pedagógica de dicha asignatura se observa en los educandos un nivel bajo de conocimientos y de las destrezas de escucha, comprensión, expresión oral y lectura de textos sencillos; presentan dificultades en la coherencia y cohesión al construir frases y oraciones de acuerdo a las estructuras gramaticales; reflejan dependencia a la orientación del docente, no se integran por completo en las actividades de la clase mostrando poca disposición por colaborar con sus compañeros y en general, revelan falta de interés y apatía por las actividades de aprendizaje. El problema presentado amerita investigar las causas a fin de contribuir con la solución del mismo. Por lo que se plantea el siguiente problema de investigación:

\section{Problema de la investigación}

¿Cómo contribuir al desarrollo del interés por el aprendizaje del idioma Inglés en los estudiantes de primer ciclo de la Carrera de Administración de una universidad privada de Lima? 


\section{Preguntas científicas.}

¿Cuáles son los fundamentos teóricos del desarrollo del interés por el aprendizaje del idioma Inglés en los estudiantes de primer ciclo de la carrera de Administración de una universidad privada de Lima?

¿Cuál es el estado actual del desarrollo del interés por el aprendizaje del Inglés en los estudiantes de primer ciclo de la carrera de Administración de una universidad privada de Lima?

¿Cuáles son los criterios teóricos, metodológicos y prácticos que sirven de base a la modelación de la estrategia metodológica para contribuir al desarrollo del interés por el aprendizaje del idioma Inglés en los estudiantes de primer ciclo de la carrera de Administración de una universidad privada de Lima?

¿Cómo validar por criterios de expertos la efectividad de la estrategia metodológica modelada para contribuir al desarrollo del interés por el aprendizaje del idioma Inglés en los estudiantes de primer ciclo de la carrera de Administración de una universidad privada de Lima?

\section{Objetivo general.}

Diseñar una estrategia metodológica para contribuir al desarrollo del interés por el aprendizaje del idioma Inglés en los estudiantes de primer ciclo de la carrera de Administración de una universidad privada de Lima.

\section{Objetivos específicos o tareas de investigación.}

Sistematizar los fundamentos teóricos que contribuyen al desarrollo del interés por el aprendizaje del idioma Inglés en los estudiantes de primer ciclo de la carrera de Administración de una universidad privada de Lima. 
Diagnosticar el estado actual del desarrollo del interés por el aprendizaje del idioma Inglés en los estudiantes de primer ciclo de la carrera de Administración de una universidad privada de Lima.

Determinar los criterios teóricos, metodológicos y prácticos que sirven de base a la modelación de la estrategia metodológica para contribuir al desarrollo del interés por el aprendizaje del idioma Inglés en los estudiantes de primer ciclo de la carrera de Administración de una universidad privada de Lima.

Validar por criterios de expertos la efectividad de la estrategia metodológica modelada para contribuir al desarrollo del interés por el aprendizaje del idioma Inglés en los estudiantes de primer ciclo de la carrera de Administración de una universidad privada de Lima.

\section{Categorías y subcategorías apriorística.}

Tabla 1.

Categorías y subcategorías apriorísticas

\section{Categorías apriorísticas}

Interés por el aprendizaje:

Es un proceso de formación psicológica particular que orientan la actividad del ser humano hacia el conocimiento de determinados fenómenos, objetos o hechos, que se presentan entre lo afectivo y lo cognitivo; prevalece la orientación afectiva, como formación motivación a la orientación de la personalidad que interviene por su trascendencia consciente y por su fuerza de atracción emocional (Rubinstein, 1977).

\section{Estrategia metodológica:}

Se orienta al proceso de enseñanza- aprendizaje a partir del profesionalismo del docente para conducir el aprendizaje desde un sistema de métodos con la intención de problematizar, dialogar, reflexionar y valorar el contenido de la enseñanza donde los estudiantes son protagonistas conscientes de las transformaciones que alcanzan en las formas de pensar, sentir y hacer. (Velázquez, 2014).

Fuente: Elaboración propia (2020)

\section{Subcategorías apriorísticas}

Base conceptual

Base procedimental

Base actitudinal

Exigencias de la enseñanza- aprendizaje

Sistema de métodos

Rol del docente

Rol del estudiante 


\section{Justificación teórica, metodológica y práctica}

\section{Teórica.}

El estudio aborda una problemática de particular importancia referida al interés por el aprendizaje del inglés una lengua extranjera que cada vez alcanza más notoriedad en la sociedad a nivel general por ser una lengua de carácter internacional. La problemática científica identificada se argumenta y fundamenta de forma holística a partir de las categorías y subcategorías apriorísticas como es el interés por el aprendizaje del inglés desde la enseñanza- aprendizaje en las aulas universitarias. El fin es sistematizar los referentes teóricos que fundamentan la problemática científica tratada por los autores principales del tema objeto de estudio como (Rubinstein, 1977, Díaz y Hernández 2010, Castellanos et al, 2007,Addine, 2015y Tobòn, 2015), que estudian el comportamiento de la personalidad, los métodos de enseñanza y los fundamentos didácticos que incide en el comportamiento de los educandos en el aprendizaje visto a la luz de distintos especialistas (Tobón, 2009; Velázquez, 2014, Addine, 2015), que le permitieron a la investigadora tener una percepción teórica extensa para afrontar el diagnóstico de campo y modelar la propuesta de solución a la problemática.

\section{Metodológica.}

El proceso de investigación posibilitó modelar una estrategia metodológica fundamentada en los referentes científicos de la estimulación e interés por el aprender, la didáctica y la lingüística que se ponen a disposición de la comunidad docente. El propósito es orientar la praxis del docente en la clase mediante un conjunto de métodos comunicativos, problémicos, heurísticos, investigativos y lúdicos a fin de favorecer el interés de los alumnos por el aprendizaje del idioma en el proceso educativo. En este sentido, la 
estrategia metodológica que se aporta constituye una herramienta de carácter metodológico que en manos de los docentes es una guía para orientar la enseñanza- aprendizaje.

\section{Práctica.}

El fenómeno denominado como globalización acortó tiempos y distancias, realidad que exige de la educación estudiantes motivados en cuanto a la adquisición de habilidades y conocimiento de una segunda lengua como es el Inglés, que por su relevancia en la formación profesional y el acceso a la información internacional debe estimularse el interés por su aprendizaje en los educandos. Por ello es imprescindible que la clase sea de calidad para poder afianzar las habilidades comunicativas y motivar a los estudiantes por aprender de manera significativa y con altos niveles de motivación. En ese sentido, el proceso investigativo contribuye a la práctica pedagógica, como producto científico una estrategia metodológica, que orienta al educador en cuanto a la estimulación del interés por el aprendizaje, específicamente del inglés en los alumnos que se concretará en los conocimientos, y las habilidades idiomáticas de esta lengua.

\section{Metodología de la investigación}

\section{Tipo y diseño de investigación.}

El trabajo de investigación se circunscribe al paradigma socio-crítico interpretativo, con un enfoque cualitativo y corresponde a una investigación educacional de tipo aplicada. Según Sánchez y Reyes (2015), este estudio se distingue por su atención en la utilización de los conocimientos teóricos a situaciones específicas y a los resultados prácticos que de ella desprenden. Y tiene como fin profundizar en los conocimientos para hacer, actuar, construir y proponer el cambio a partir de una propuesta de orden teórico- práctico a partir de la aplicación de los métodos del nivel teórico y los empíricos. Así pues, la presente investigación se ajusta al paradigma sociocrítico-interpretativo, porque tiene una base 
empírica y analítica, además se centra en la participación de los actores educativos para la solución de problemas propios de ese contexto. Igualmente, el enfoque de este estudio es cualitativo que según Hernández, Fernández y Baptista (2014), se fundamenta en la recopilación y posterior análisis de datos de tipo cualitativo para lograr la afinación de las preguntas de investigación o plantear nuevas preguntas durante la fase interpretativa, se trata de un proceso circular, que va de lo específico a lo general y luego a lo específico, fortaleciendo la teoría por medio de la experiencia.

El tipo de investigación es aplicada educacional, la cual implica un proceso de búsqueda de soluciones al problema de estudio, que tienen como base la planificación, su sustentación en el método científico, dicho proceso se ejecuta durante las distintas fases de la acción educativa y puede concebirse como un proceso educacional en sí mismo, pues está enmarcado en su acción. En este caso en particular, este estudio se planteó contribuir a solucionar el problema del interés por el aprendizaje del inglés, basado en modelación de una estrategia metodológica. El diseño del estudio es no experimental, sobre el que Hernández et al. (2014) afirman que, se trata de los estudios en los que no se manipula las categorías deliberadamente, de modo que únicamente se observan los fenómenos en el entorno real en el que ocurren, con el fin de analizarlos. En ese sentido, el presente trabajo de investigación es no experimental, porque el fenómeno del interés por el aprendizaje de inglés fue observado directamente en la universidad, que es el lugar donde esta categoría se desarrolla, y el estudio será naturalista, sin manipulación de las categorías. Asimismo, el estudio es transversal porque se recolectaron los datos de estudio en un momento único.

\section{Población, muestra y muestreo.}

La población del estudio está integrada por 14 docentes de la especialidad de Inglés y por 346 alumnos de primer ciclo pertenecientes a la carrera de Administración de una universidad privada de Lima. 
La unidad muestral del estudio tomada por muestreo de tipo no probabilístico intencional, la conforman cuatro profesores de inglés y 40 alumnos de primer ciclo pertenecientes a la carrera de Administración de una universidad de Lima privada.

\section{Las unidades de análisis.}

Está formada por educadores, alumnos, las fuentes documentales y los normativos documentos de la carrera de Administración de una universidad privada de Lima.

\section{Métodos de investigación}

\section{Métodos teóricos.}

Este trabajo de investigación se realizó mediante la aplicación de diferentes métodos teóricos, los cuales se precisan como los que consienten descubrir en el objeto de estudio de la investigación las relaciones esenciales, y las cualidades esenciales. Utiliza los procesos de análisis, abstracción, deducción, síntesis e inducción, viabilizando la interpretación conceptual de los datos (Fabregat, Castañeda y Díaz, 2017). A continuación, se detalla cada uno de los empleados en este estudio con detalle:

\section{Método histórico-lógico.}

Según Cerezal y Fiallo (2005), este método es utilizado para la búsqueda de investigaciones internacionales, regionales, y nacionales, que sirvan como antecedentes para un estudio preciso y lo enlacen con la trayectoria investigativa de cada categoría de estudio. En la esta investigación, se usó el método histórico-lógico, para desarrollarlos antecedentes y la revisión histórica del desarrollo teórico sobre la categoría principal interés por el aprendizaje del inglés, estos datos fueron de provecho para construir en la discusión de los resultados, al final de todo el proceso de investigación.

\section{Método analítico-sintético.}

Como Rodríguez y Pérez (2017) destacan, el método analítico sirve para descomponer la categoría apriorística en subcategorías, para poder analizar cada una de manera 
independiente, mientras el método sintético sirve para el fin opuesto, volver a componer las subcategorías en una sola categoría, esto para su comprensión general. En este estudio, se empleó el método analítico-sintético específicamente para el análisis de las bases teóricas y en la información recolectada en la fase de aplicación de los instrumentos, y para colaborar con la profundización y el enriquecimiento del marco teórico, mediante el establecimiento de conclusiones sobre las categorías de estudio.

\section{Método inductivo-deductivo.}

Para Martínez (2014) dicho método favorece un proceso inductivo, donde las relaciones establecidas parten de lo particular para la construcción de postulados generales; y luego propiciando el proceso opuesto, dando el grado de circularidad a las investigaciones con enfoque cualitativo. En la presente investigación, se empleó el método inductivo-deductivo para realizar el planteamiento de la formulación de la teoría de sustento las categorías y subcategorías de análisis, igualmente que para guiar la base de la metodología y epistemología vinculada a la estrategia modelada basada en el aprendizaje desarrollador para favorecer el interés por el aprender inglés.

\section{Método de la modelación.}

Rodríguez y Pérez (2017) reflexionan entorno a que este método posee una función especialmente heurística, debido a que colabora con el descubrimiento de relaciones y cualidades inéditas sobre el objeto estudiado. En esta investigación, se manejó el método de la modelación para la creación de la estrategia metodológica basada en el aprendizaje desarrollador para contribuir al desarrollo del interés por el aprendizaje del inglés en los estudiantes de primer ciclo de la carrera de Administración de una universidad privada de Lima. 


\section{Método matemático.}

El método matemático, según criterios de Eyssautier (2006), admite explicar y además interpretar los resultados del estudio, luego de aplicar los instrumentos de recolección de información, con fórmulas o teoremas matemáticos. Para esta investigación, se usó el método matemático para el procesamiento de la información sobre el análisis porcentual vinculado a la aplicación de los instrumentos. Este método, facilitó la obtención de conclusiones sobre la investigación y la discusión de resultados.

\section{Método estadístico.}

Por otra parte, Eyssautier (2006), señala que el método estadístico sirve para valorar datos cuantitativos, incluso los que se derivan de investigaciones cualitativas, dichos datos obtenidos son interpretarlos y analizarlos, mediante fórmulas estadísticas, que le dan validez a la investigación. Para este estudio, se utilizaron los estadísticos descriptivos de frecuencia, y su representación en tablas y figuras, para verificar las respuestas más frecuentes a los instrumentos aplicados y su categorización.

\section{Técnicas e instrumentos para el trabajo de campo}

\section{Observación a clase a docentes.}

Según Cerezal y Fiallo (2005), es una apreciación directa, atenta, racional y planificada de los sucesos vinculados con los objetivos del estudio, en circunstancias habituales, con el fin de encontrar una explicación del objeto de estudio. Se aplicó con la intención de corroborar el grado de conocimientos que utilizan los educadores al guiar el proceso educativo de la asignatura Nivelación Inglés para valorar el grado de interés que propician los docentes en la enseñanza del idioma inglés. Para esto, el instrumento utilizado fue una guía de observación de clase. 


\section{Entrevista semiestructurada a los docentes.}

Cerezal y Fiallo (2005) indican que consiste en una conversación profesional previamente planificada entre el entrevistador y los entrevistados. Se caracteriza por la obtención de información confiable acerca de los sucesos y opiniones. De este modo, se aplicó para conocer sus criterios acerca de las actitudes que demuestran los estudiantes con relación al aprendizaje del idioma inglés durante el proceso de enseñanza- aprendizaje. Para ello, se usó una guía de entrevista semiestructurada.

\section{Encuesta a los estudiantes.}

Es una técnica fundada en procedimientos estandarizados de investigación mediante la cual se acopia y analiza una serie los datos de la muestra, a través de ella se puede obtener información variada (Anguita, Labrador y Campos, 2003). En esta investigación se utilizó como instrumento un cuestionario que se aplicó a los estudiantes participantes del estudio, con el uso de una escala tipo Likert.

\section{Prueba pedagógica a los estudiantes.}

Cerezal y Fiallo (2005), indican que se utilizan con la finalidad de diagnosticar el estado de los conocimientos, costumbres y capacidades de los individuos en una situación definida. Se caracterizan por que permite conocer la efectividad de la enseñanza, controlar el proceso docente y evaluar el beneficio de los estudiantes sobre una asignatura en específico. En esta investigación, se llevó a cabo con la finalidad de evidenciar el nivel de conocimientos y las destrezas comunicativas que poseen los educandos en la asignatura Nivelación Inglés. Se usó como instrumentos un cuestionario de ejercicios de comprensión lectora, gramaticales y de expresión escrita.

\section{Análisis documental.}

Para, Cerezal y Fiallo (2005), es la técnica que recoge datos documentales de fuentes escritas primarias o documentales. Estudia detalladamente los documentos que forman 
fuentes de datos relacionados con las variables estudiadas. En este caso, se manejó para ejecutar la inspección de documentos normativos, las consultas y documentos bibliográficos que facilitaron la fundamentación del estudio y la elaboración de la propuesta metodológica. Los instrumentos empleados es una guía de análisis documental, fichas textuales y de resúmenes.

\section{Juicio de expertos.}

De acuerdo a Hernández et al. (2014), esta técnica trata de contactar a un grupo de expertos, específicamente en el objeto de estudio, con el propósito de que faciliten su opinión objetiva y profesional, sobre la calidad de un producto de la investigación o un instrumento. Se empleó en el estudio para validar la efectividad de la estrategia metodológica modelada para contribuir con el desarrollo del interés por el aprendizaje de la asignatura inglés en los estudiantes de primer ciclo de la carrera de administración de una universidad privada de Lima. Como instrumento se utilizaron dos fichas de evaluación interna y externa.

\section{Novedad científica.}

Se bosqueja con los referentes teóricos sobre las categorías y subcategorías sobre el interés por el aprendizaje del inglés y la modelación de la estrategia metodológica como fruto del estudio que es un instrumento teórico y metodológico para los profesores al direccionar el proceso educativo del inglés en alumnos de administración en una universidad privada de Lima.

\section{Estructura de la tesis.}

El trabajo se desarrolla mediante la sección de la introducción y tres capítulos:

Capítulo I: Muestra las categorías y subcategorías apriorísticas basadas desde enfoques holísticos mediante la implementación del método histórico lógico, que permitió 
realizar un análisis de la forma que ha progresado en el campo el objeto y adjudicarse perspectivas conformes a la problemática que le proporcionan firmeza científica al estudio y ultima con la matriz de categorización.

Capítulo II: Concierne al diagnóstico de campo que permitió verificar el actual estado de la problemática investigada. A raíz del procesamiento y triangulación de los datos recolectados en la praxis pedagógica. Asimismo, se identificó las categorías emergentes generales sobre el interés por el aprendizaje del Inglés.

Capítulo III: Se muestra la estrategia metodológica que se modeló y que aporta fundamentos socioeducativos, psicológicos, curricular y pedagógicos; dosificación de una unidad didáctica, asimismo dos clases modelos; además la propuesta de talleres de capacitación orientados a los educadores para ayudar a su desempeño y la validación de la efectividad de la misma a través del criterio de especialistas, para su ejecución práctica en la universidad donde se encuentra la problemática especificada. 


\section{Capítulo I}

\section{Marco teórico}

\section{Antecedentes de las investigaciones}

Existe variedad de estudios que son análogas a esta en cuanto a problemática y categoría apriorística, que se presentan a continuación, tanto en el ámbito internacional como nacional.

\section{En el ámbito internacional.}

Suryasa, Adhitya, y Werdistira (2017), presentan un artículo científico para la revista Journal of Social Sciences and Humanities, con el objetivo investigar la motivación de los alumnos en el aprendizaje del Inglés como segundo idioma. La metodología de la investigación es cuantitativa de nivel descriptivo y diseño no experimental. La muestra formada por 30 estudiantes del Pritchard English Academy. Como instrumento usó un cuestionario que se adaptó de Attitude Motivation Test Battery (AMTB). Concluye que los estudiantes están altamente motivados por el aprendizaje del Inglés. Esto revela que la motivación instrumental es un factor significativo entre los estudiantes.

Alzubaidi, Aldridge, y Khine (2016), presentan un artículo científico para la revista Environ, con el objetivo investigar las percepciones de los estudiantes sobre el entorno de aprendizaje y su influencia en su motivación y autorregulación en el aprendizaje del Inglés como segundo idioma a nivel universitario en Jordania. La metodología empleada es cuantitativa con un nivel descriptivo. La muestra involucra a 994 estudiantes, provenientes de 13 escuelas de tres facultades (Humanidades, Ciencias de la salud e Ingeniería) de una universidad de Jordania. Como instrumento aplican dos cuestionarios una para evaluar las percepciones de los estudiantes sobre el aprendizaje y otra para evaluar la motivación y la autorregulación de los educandos por el aprendizaje del Inglés como segundo idioma. Concluye que los estudiantes tienen probabilidades de alcanzar mayores niveles 
de motivación y autorregulación en las clases donde tienen oportunidades de formar amistades y son solidarios de uno al otro, asimismo, cuando el profesor crea entornos de aprendizaje donde los estudiantes tienen la oportunidad de interactuar, y hacer actividades donde el idioma se conecte con aspectos de la vida real.

Urbina (2016), presenta una investigación en la Universidad Nacional Autónoma de Nicaragua, con el objeto de analizar las concepciones psicológicas que contribuyen a la motivación por aprender el idioma Inglés en educandos del V año de Farem-Estelí. La metodología aplicada es de enfoque mixto, aunque predomina el cualitativo. La muestra conformada por 307 estudiantes tomados 182, pertenecientes a cursos sabatinos y 125 del turno nocturno y 7 docentes. Como instrumento se aplica una encuesta a estudiantes, una entrevista a docentes y a estudiantes. Concluye que las metodologías activas estimulan la motivación en los estudiantes e influyen en la mejora de la comunicación entre los participantes, así como en la fluidez en la práctica de la lengua extranjera.

Drbseh. (2015), presenta un artículo científico para la revista International Journal of Scientific and Research Publications, que tiene por objetivo investigar la situación de los países árabes del Oriente Medio acerca de la motivación y la actitud de los estudiantes hacia el aprendizaje del Inglés. La metodología es de enfoque cuantitativo, con un nivel descriptivo, con un diseño no experimental. La muestra constituida por 139 educandos, a los cuales se les administra un cuestionario. Las conclusiones destacan que es alta la motivación de los estudiantes de países árabes para aprender inglés, sin embargo, se encuentra un grupo con bajo nivel de motivación y actitud, porque aluden que va en contra de su cultura, es así como el autor señala que se debe promover la enseñanza efectiva del inglés, a partir de las necesidades y expectativas de los estudiantes.

Grande (2015), presenta una investigación con estudiantes universitarios de primer semestre del Tecnológico de Monterrey, México, con el propósito de conocer cómo 
incentivar a los estudiantes por aprender el idioma Inglés. La metodología empleada es cualitativa. La muestra elegida por muestreo intencional, la integran 17 alumnos del aula de Inglés I, provenientes de distintas profesiones, y nueve maestros. Como instrumentos se aplica: observación, entrevista, encuesta y autoevaluación que aportan brindando un estado real del problema. Concluye que la clave para motivar a los estudiantes se encuentra en la sensación de éxito que estos puedan experimentar; asimismo indica que el estudiante debe ser consciente del tipo de estudiante que es y, usar la estrategia de aprendizaje que le favorezca. Enfatizando así en la importancia del proceso de metacognición en el aula.

\section{En el ámbito nacional}

Campos (2016), presenta una tesis en la Universidad Cesar Vallejo de Lima, con el objetivo de determinar la relación entre la motivación y el aprendizaje del idioma inglés en estudiantes del nivel $\mathrm{v}$ de un centro de idiomas, 2016. El abordaje metodológico es cuantitativo, correlacional. La unidad muestra está conformada por 84 educandos del nivel $\mathrm{V}$ de un centro de idiomas. El instrumento contemplado es un test de aprendizaje del idioma Ingles. Las conclusiones arrojaron que hay correlación significativa entre la motivación y el aprendizaje del idioma inglés en estudiantes del nivel v de un centro de idiomas, lo que indica que la motivación tiene influencia en el aprendizaje de una lengua extranjera como el idioma.

Valentín (2017), presenta una tesis en la Universidad Nacional del Centro del Perú de Huancayo, con el objetivo determinar diferencias esenciales de motivación para estudiar inglés, según sexo, edad, carrera y procedencia, en los estudiantes de la Facultad de Educación. El abordaje metodológico fue cuantitativo, con un nivel descriptivo, comparativo y un diseño no experimental. La muestra la integran 280 estudiantes de educación, para la recolección de la información se aplica como instrumento un 
cuestionario denominado AMTB (Attitude/Motivation Test Battery). Las conclusiones señalaron que la motivación para el estudio del Ínglés en los alumnos de Educación es baja, prevaleciendo la motivación extrínseca. Asimismo, se encuentra relación directa y significativa entre la motivación para el estudio del inglés y la edad.

Chauca (2018), presenta una tesis en la Universidad Nacional de San Agustín de Arequipa, planteándose como objetivo mejorar la motivación intrínseca y el aprendizaje del idioma Inglés aplicando el enfoque CLIL. La metodología es de enfoque cuantitativo, con un nivel descriptivo, y diseño cuasi experimental. Es así, como la muestra conformada por 59 alumnos y se utiliza como instrumento el cuestionario. Las conclusiones muestran que el enfoque CLIL donde se vincula el aprendizaje del idioma inglés con aspectos de su carrera, efectivamente mejora tanto la motivación como el aprendizaje del idioma inglés en los estudiantes.

López (2016), presenta una tesis en la Universidad de Piura, cuyo objetivo es demostrar cómo el uso de videos auténticos podría cumplir una función importante en la reducción y hasta en la eliminación de signos que muestren falta de motivación en los estudiantes de la Universidad San Ignacio de Loyola al realizar las actividades aplicando los saberes gramaticales del idioma. La metodología es de enfoque cualitativo, con un diseño experimental. La muestra integrada por dos grupos (experimental y control) de 20 estudiantes cada uno de la Universidad San Ignacio de Loyola, quienes estudian la asignatura de Inglés. Para la recolección de la información al grupo experimental se tomaron distintos tipos de videos; mientras que al grupo control se les pidió realizar los ejercicios de sus libros siguiendo las indicaciones del docente. Las conclusiones señalan que hay gran contraste entre los grupos, principalmente: la disminución de los signos de aburrimiento o falta de motivación y la mejora en los ejercicios gramaticales de los alumnos del grupo experimental. 
Cruz (2015), realiza una tesis de maestría en la Universidad San Ignacio de Loyola de Lima, con el fin de diseñar una propuesta para el desarrollo del interés por los ejercicios físicos en alumnos de la provincia de Cajatambo. La metodología utilizada se basa en el enfoque cualitativo de tipo aplicada proyectiva. La muestra seleccionada intencionalmente la integra un directivo, 13 estudiantes y tres docentes. Aplica como instrumentos: guía de observación a clases y entrevistas a los profesores, encuesta y pruebas pedagógicas. Concluye con la modelación de la propuesta orientada al interés por el aprendizaje de los alumnos, partiendo de la ejecución de los métodos que promueven un aprendizaje socializador, reflexivo, y cooperativo donde el docente es un mediador, capaz de integrar la práctica con la teoría en un ambiente de o confianza y exigencia por alcanzar los propósitos de cada actividad.

La revisión de las investigaciones realizadas ha servido para potenciar la visión del presente estudio y corroborar cómo la problemática ha sido materia de análisis en distintos países, niveles de educación y desde distintos puntos de vista. La sistematización del contenido metodológico y teórico, así como los instrumentos utilizados fortalecen el conocimiento de la autora sobre el objeto, sin embargo, no se ha constatado el problema sobre el interés por aprendizaje del Inglés en el nivel universitario, por lo que es preciso en la presente investigación ahondar en dicha perspectiva para proponer una estrategia metodológica a fin de contribuir a la solución del problema.

\section{Bosquejo histórico sobre la enseñanza-aprendizaje del Inglés en el Perú}

En Perú, el mes de junio del año 1938, se considera como fecha del nacimiento de la Fundación del Instituto Cultural Peruano-Norteamericano (Icpna), para dar apertura a las incipientes acciones para el estudio del inglés en el país. En este sentido, es importante comenzar con una reseña histórica que hace referencia al proceso educativo del idioma 
inglés en el Perú, el cual, se presenta en tres grandes bloques a partir del año 1970 hasta el año 2015, para poder tener una mayor comprensión de los enfoques, cambios, y reformas que han ocurrido en el contexto nacional.

\section{Primera etapa de 1970 a 1989}

En este periodo se enseñaba el inglés solamente en la educación secundaria, con una carga horaria de tres horas por semana, fue una época marcada por la escasez de profesores con título universitario de idiomas, razón por la cual esta asignatura fue relegada por algunos años, en comparación con otras asignaturas, por ende los institutos y universidades comenzaron a ofertar la carrera profesional de idiomas, en este periodo, el Ministerio de Educación no facilitaba capacitación a los docentes para mejorar el dominio lingüístico del inglés (De la Puente, 2015).

Motivo por el cual, los docentes instituyeron como metodología única la enseñanza de este idioma con métodos tradicionales, básicamente conductista que concibe el aprendizaje de una lengua en términos de estímulo y respuesta, operante condicionado y refuerzo, lo que resultaba en alumnos que luego de cinco años de estudios secundarios obtuvieran conocimientos y habilidades limitadas del inglés, y al ingresar a la universidad volvían a estudiar inglés en calidad de principiantes. En el caso de los colegios privados, siempre han asignado más horas de clases para esta asignatura y seleccionaban educadores con el perfil requerido (Vanden, 2013).

En el año 1973, el sistema educativo tuvo una reforma definida mediante la Ley General de Educación aprobada con Decreto Ley 19326-72, la cual estipulaba que los idiomas extranjeros debían enseñarse sin que constituyan un factor de imposición cultural. En algunas ciudades, varias instituciones ofertaron la enseñanza de los idiomas alemán, francés, e inglés, resalta el caso de la ciudad de Trujillo, porque la Universidad de Trujillo dictaba la especialidad de Idiomas Extranjeros, al igual que en Iquitos, donde en el año 
1981 se implementó la especialidad de Idiomas extranjeros en la Universidad Nacional de la Amazonía Peruana (Vanden, 2013).

\section{Segunda etapa de 1990 a 1999}

En este periodo destaca que, el Ministerio de Educación y el British Council, realizaron un convenio denominado "Mejoramiento de la enseñanza de inglés en los colegios públicos secundarios del Perú"; el cual contribuía al mejoramiento lingüístico, así como de habilidades pedagógicas, lográndose que docentes estudiaran en Gran Bretaña Administración de la Enseñanza del Inglés, no obstante, en este período aún no había la aspiración de tener la enseñanza del inglés como una política de Estado, destaca que era difícil obtener información actualizada de fuentes bibliográficas en inglés, lo cual es un impedimento lingüístico para los profesionales y estudiantes de educación básica y universitaria (Vanden, 2013).

A partir del año 1998, el Ministerio de Educación implementó programas como la Nueva Secundaria, el Plan Nacional de Capacitación Docente, el Programa Nacional de Formación en Servicio, entre otros, los mismos se orientaban a desarrollar habilidades pedagógicas en los docentes, por lo que, en esta etapa, se dio mayor atención al mejoramiento del desempeño docente y por consiguiente los docentes del área de inglés fueron mejorando considerablemente en cuanto a su capacitación. Aunque se seguían implementando métodos de enseñanza y aprendizaje tradicionalistas, que priorizaban las habilidades orales sobre las escritas, el uso del diálogo como la forma de presentación por excelencia; énfasis en la ejercitación y la memorización mecánica, tanto a nivel escolar como universitario (De la Puente, 2015).

\section{Tercera etapa de 2000 a 2015}

Este bloque caracterizado por la calidad de la enseñanza del Inglés es de mejoría progresiva en todos los niveles educativos, porque ahora hay docentes de idiomas 
calificados, además, hay una política de atención a esta área, el Ministerio de Educación proporciona textos para que los alumnos y los profesores los incorporen en su programación de las respectivas sesiones de aprendizaje. Sin embargo, aún hay un vacío estructural de contenidos que atiendan los requerimientos del Marco Común Europeo, por otra parte, la cantidad de horas determinadas continúan siendo de dos a tres horas de clase por semana, a diferencia de las instituciones privadas donde los directivos han incluido dentro de su propuesta más horas de clase de inglés a la semana, no obstante, es insuficiente para atender los niveles de dominio de este idioma (De la Puente, 2015).

Por su parte, los procesos de enseñanza - aprendizaje de la disciplina se han fortalecido en gran medida, así como la aplicación de métodos basados en el constructivismo y la innovación didáctica. Al calor de la afluencia de estudiantes interesado por el estudio de esta lengua y como respuesta a la Ley Universitaria N. 30222 (2014), se priorizan los programas de estudio y de capacitación docente en esa búsqueda de fomentar una mejor comprensión y desarrollo de la enseñanza - aprendizaje universitaria donde el empleo de recursos audiovisuales y redes sociales para el tratamiento y activación del aprendizaje y el perfeccionamiento de las destrezas comunicativas integrando los saberes adquiridos concatenados a los nuevos, las experiencias cotidianas destacando la lengua como medio de comunicación (De la Puente, 2015).

En resumen, el bosquejo histórico proporciona una visión general de la evolución histórica de la enseñanza-aprendizaje del idioma en el país. Se aprecia que se inició de manera muy rudimentaria, con carencias en la capacitación de docentes y la aplicación de métodos tradicionalistas y el conductismo, que paulatinamente han cambiado con una enseñanza ajustada a las exigencias de los recursos didácticos que incluyen las tecnologías, aunque todavía persisten problemas como: falta de incremento de horas clase por semana, necesidad de aplicar métodos activos que promuevan el pensamiento y las habilidades 
comunicativas, así como estimular el interés y la motivación por el aprendizaje en los estudiantes para que no exista esa actitud de aprobar una materia sin que exista una aprendizaje significativo.

\section{Fundamentos teóricos sobre el interés por el aprendizaje}

Al revisar las diversas fuentes especializadas salta a la vista que el aprendizaje es un proceso psicológico, individual, social, complejo y dialéctico que ha sido analizado por distintos especialistas de tendencias y formación teórica diversas. De lo necesario que resulta realizar una reflexión de sus fundamentos por autores clásicos como contemporáneos en materia de educación.

Uno de los psicólogos clásicos, como Piaget (1947), para quien el aprendizaje es un proceso que adquiere sentido en situaciones de cambio, por lo que aprender forma parte de adaptarse a dichos cambios, la teoría de Piaget postula la dinámica de la adaptación, mediante los procesos básicos de asimilación y acomodación, siendo la asimilación la manera como se recibe un estímulo del medio ambiente a nivel de la sociedad y la acomodación, contiene una modificación de la sociedad actual en respuesta a las demandas del contexto. Por lo tanto, mediante la asimilación y la acomodación se reestructura mentalmente el aprendizaje a lo largo del desarrollo de la vida. No obstante, esta postura se considera limitada, debido a que solamente reconoce el valor del pensamiento y el aspecto cognitivo en base a la edad o el tiempo (Babakr, Mohamedamin y Kakamad, 2019).

Una postura que reconoce la implicancia de la esfera afectiva del individuo en el aprendizaje es la de Ausubel (1983), teórico del aprendizaje significativo, el cual se considera como, un proceso personalizado y activo, donde el estudiante aprende a conectar los conocimientos previos con la nueva información, puntualiza que la nueva información debe estar adecuadamente organizada, para que pueda ser asimilada y entendida. En este sentido, el estudiante se hace consciente de lo que aprende, y comprende su importancia, 
porque es capaz de relacionar su vida y su realidad, para posteriormente asumir una postura en cuanto al aprendizaje, aplicarlo y a su vez darle sentido (Agra, et.al., 2019).

Otro psicólogo que aportó una teoría integral del aprendizaje, es Vygotsky (1962), al señalar que el aprendizaje es un proceso intrapersonal e interpersonal, que vincula tanto lo social como lo individual. Resalta que es por medio del aprendizaje que se produce la relación entre el sujeto y el objeto, en una instancia, y del sujeto con los demás sujetos, en otra, asimismo, el estudiante debe apropiarse del conocimiento, siendo este activo. Estos argumentos teóricos, dan una mirada holística del aprendizaje, en el que se incluye el aspecto cognitivo, volitivo, afectivo, y emocional (Shabani, 2016).

En este sentido, Vygotsky (1962), añade que el desarrollo no puede separarse de su contexto social y cultural, así, la función es social y el proceso a través del cual se convierte en una función interna se conoce como internalización, siendo el papel de la mediación social en el proceso de internalización fuertemente enfatizada en la teoría sociocultural, siendo el centro de la mediación la intersubjetividad, que es descrita como el establecimiento de entendimiento entre el aprendiz y el tutor, asimismo, es una perspectiva compartida entre un experto y un aprendiz en la resolución de problemas, de donde surge la zona de desarrollo próximo, que busca que el docente proporcione tareas de aprendizaje y de resolución de problemas interesantes y culturalmente significativas (Shabani, 2016).

Por su parte, la neurociencia aporta nuevos hallazgos al proceso de aprendizaje, en ese sentido Mora (2017), precisa el aprendizaje es la construcción del estudiante, desde un nivel social y personal, que se lleva a cabo de la mano de la disposición para aprender y la presencia de una figura educativa que está para guiar el proceso, es decir, un educador, asimismo, asevera cómo interviene la motivación, lo afectivo y lo volitivo en la concentración y el interés en el proceso aprendizaje. 
Asimismo, diferentes estudios de esta ciencia han probado que la motivación, y las emociones positivas predisponen de manera favorable a la persona para alcanzar o desarrollar un aprendizaje consciente, sólido y significativo. Según, Mora (2017) la emoción es el secreto ingrediente del aprendizaje y la relación cognición-emoción es sólida, específico al diseño funcional y anatómico del cerebro.

Desde estas perspectivas, el aprendizaje contribuye al desarrollo integral del educando, al enfatizar en la esfera intelectual, procedimental y en las actitudes que al integrarse en el tratamiento del contenido en la clase estimulan el desarrollo del educando, de esa manera se concibe el aprendizaje como proceso social, individual, cooperativo, significativo y consciente, que requiere de la motivación, el interés del estudiante y devienen en exigencias de la enseñanza - aprendizaje.

Esta concepción social e integral del aprendizaje responde al aprendizaje desarrollador, que según Castellano et al. (2007), es aquel que garantiza en el individuo la apropiación activa y creadora de la cultura, propiciando el desarrollo de su autoperfeccionamiento constante, de su autonomía y autodeterminación en íntima conexión con los necesarios procesos de socialización, compromiso y responsabilidad social.

Desde esta mirada teórica, el sujeto aprende de forma individual, social, reflexivo, significativo y activo, que se pone a prueba en la actividad de aprendizaje que es mediado principalmente por el docente, a través de la orientación, dirección y comunicación, tomando en cuenta las necesidades de los alumnos como sujeto activo en un contexto determinado donde se desenvuelven, desde su singularidad, potenciando así su desarrollo integral de la personalidad. Esta teoría describe que en el proceso intervienen otros aspectos relevantes, que los educadores deben manejar para optimizar la enseñanza, se muestran en la figura 1. 


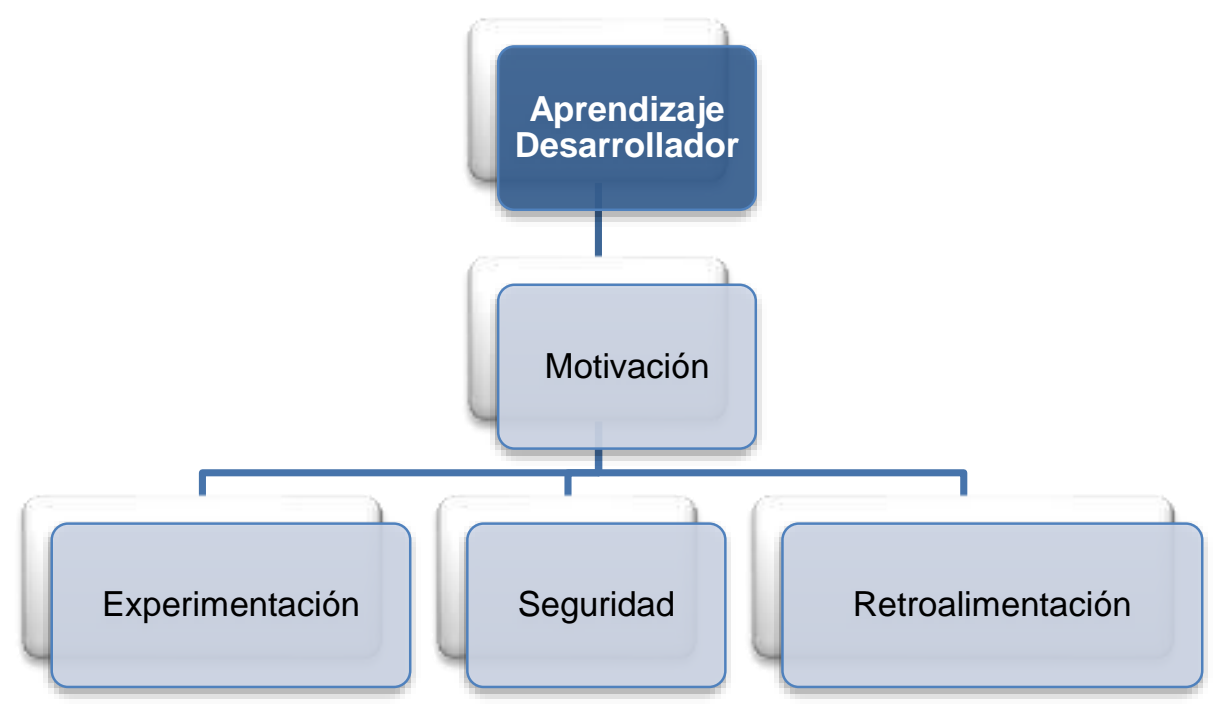

Figura 1. Procesos que intervienen en el aprendizaje.

Fuente: Elaboración propia (2020).

Como se representa, la motivación es un proceso intrínseco al aprendizaje porque estimula y potencia el interés, la concentración y comprensión del estudiante, activándolo a pensar, asimilar, procesar, comprender, y construir el saber de una manera efectiva y significativa que luego aplica en la solución de problemas y se interesa para seguir aprendiendo. En varias oportunidades, se ha mencionado que el alumno debe ser activo y una de las claves es la experimentación, el dinamismo, por lo que amerita el hacer por medio de la interacción, y exploración (Rico, 2013).

De esa manera se constata que el aprendizaje como proceso psicológico requiere del sujeto el activismo, que socialice con sus iguales en ambientes de seguridad y comunicación para que gane en comprensión, libertad y confianza, para intervenir, preguntar, dar puntos de vistas en el proceso propio del aprendizaje. El ambiente educativo debe caracterizarse por la comunicación y comprensión para que se puedan alcanzar aprendizajes conscientes y sólidos. Por su parte, la retroalimentación, forma parte de la evaluación y el refuerzo de logros de los alumnos para mantener niveles adecuados de motivación (Rico, 2013).Tomando en cuenta el análisis realizado, el aprendizaje es un 
proceso complejo donde intervienen factores cognitivos, afectivos, volitivos y emocionales, que se deben conocer y dominar para desde la perspectiva docente y del educando optimizar el proceso educativo para alcanzar las metas previstas, tanto a nivel personal, como educativo.

\section{Reflexiones epistemológicas sobre el interés por el aprendizaje}

En el campo del proceso de aprender, la motivación, el interés y la concentración del aprendiz, son aspectos psicológicos que son el centro de atención en los estudios de diversas disciplinas de la ciencia, pero de manera particular de la psicología.

En cuanto a la personalidad se tiene argumentos teóricos y aportes de distintos psicólogos como, Vygotsky (1962), quien postula que, para conseguir el desarrollo integral de la personalidad, la persona transita por diversas etapas como por ejemplo los periodos etarios, desarrollo físico y psicológicos, donde se dan una variedad de cambios que influyen en su conducta. Por tanto, los psicólogos tratan de comprender la relación entre el crecimiento y la variación en las capacidades intelectuales que intervienen en la conducta, debido a que como es sabido la personalidad varía en cada persona destacando en la formación de la misma, las interacciones de los sujetos entre sí y sus relaciones sociales.

En este sentido, González et al. (2004), asevera que el desarrollo del individuo responde principalmente a la experiencia subjetiva, y el desarrollo de la personalidad responde a la experiencia histórico-social con la que entra en contacto el ser humano mediante las relaciones sociales, por lo tanto, el proceso educativo está mediado en gran parte por la dimensión social del aprendizaje, debido a que el alumno se adueña de los conocimientos que ha producidos a lo largo del tiempo de manera sistemática, interviniendo a su vez la intencionalidad, motivo por el que la educación como fenómeno social tiene una influencia decisiva en el desarrollo de las maneras de pensar, y actuar de cada persona. 
Distintos psicólogos conciben la personalidad desde variadas posiciones ideológicas y teóricas, entre estos destaca la perspectiva de Parks, Gilad y Bardi (2003) quienes visualizan la personalidad como la organización sistémica, y estable de las diversas formaciones psicológicas, que participan de forma activa en las funciones reguladoras del comportamiento, siendo la persona quien ejerce dichas funciones. En este sentido, la personalidad configura una variación de rasgos que distinguen a un individuo de otro, a pesar que es el resultado de las interacciones sociales, pero la individualidad es única e irrepetible y que el desarrollo del sujeto es el resultado de la experiencia históricosocial que vivencia un individuo en sus relaciones sociales (Alzubaidi, et al. 2016).

Es importante destacar que los componentes de la personalidad se van desarrollando en paralelo durante el desarrollo evolutivo del individuo en palabras del psicólogo peruano Ortiz (2008), como es principalmente el temperamento, el intelecto y el carácter. Enfatiza que el temperamento implica diferencias individuales en la reactividad y la autorregulación, en los dominios de afecto, actividad y atención, los rasgos temperamentales de los niños se manifiestan de forma temprana, tienen una fuerte base neurobiológica y son relativamente estables en el tiempo y las situaciones, las investigaciones se ha centrado principalmente en las siguientes dimensiones del temperamento: a) la primera infancia: emocionalidad positiva, nivel de actividad, miedo, ira / frustración, sociabilidad, orientación atencional; b) la segunda infancia: control, es decir, la capacidad de inhibir una respuesta dominante para realizar una respuesta subdominante.

Por otra parte, la inteligencia se desarrolla igualmente durante la niñez, desde la consciente cognición, cuando la actividad primordial es el estudio, así la persona se vincula con el proceso cultural y social de su ambiente, afín con el desempeño personal. Asimismo, 
el carácter, se desarrolla con la actividad emocional y se expresa con el comportamiento y las relaciones sociales (Alzubaidi, et al. 2016).

En este sentido, se afirma que la personalidad es un conjunto de configuraciones psicológicas únicas y singulares de cada persona que se muestran de forma clara en su comportamiento de manera irrepetible, estas disposiciones pueden alcanzar un grado de óptimo desarrollo, no obstante, no son rígidas, sino relativas, y dependen de las circunstancias como la relación con el contexto, el tiempo, la cultura entre otros factores.

La conducta es una manera de actuar que está en cambio permanente siendo un proceso interno, que repercute en la propia persona y, por ende, los otros y el medio sociocultural donde está inmerso el sujeto. Lo afirmado, tiene un gran valor heurístico para la praxis docente que deberá reconocer las necesidades y potencialidades de los sujetos para orientarlos, motivarlos y desarrollar el interés según las necesidades personales y del contexto (González, 2003; Ortiz, 2008 y Rico et al; 2013).

Un aspecto que orienta la personalidad es la motivación, entendida según Robbins y Judge (2017), como un proceso psicológico que incentiva al sujeto a actuar a partir de las influencias, las relaciones y las experiencias entre lo externo y lo interno. En ese sentido, suele definirse como los procesos con los que cuenta un individuo, a nivel de intensidad, dirección y persistencia del esfuerzo para alcanzar una meta. Por otra parte, la motivación general está relacionada con el esfuerzo hacia cualquier objetivo, que refleja el interés singular en el aprendizaje.

Este dinamismo, envuelve otros mecanismos, que se van produciendo entre el estímulo y la respuesta, allí existe un abanico de posibilidades que se dan a partir de la motivación del individuo por dar una respuesta al estímulo. En ese caso, se presenta la teoría de Abraham Maslow (1954), quien postula la teoría de la motivación, donde explica que el comportamiento humano, se da más allá de la simple relación entre el estímulo y la 
respuesta, del cual surge la jerarquía de las necesidades humanas. Específicamente, este teórico expresa que una necesidad que está satisfecha, deja de ser una necesidad y que el organismo está dominado por las necesidades insatisfechas (Legault, 2016).Sobre la motivación, González (2008) manifiesta que está formada por una serie de procesos psíquicos que tiene el rol autónomo y activo de la personalidad, en su permanente determinación y transformación con la actividad externa, sus fines y estímulos, están conducidos a cumplir con las necesidades del individuo, y, por consiguiente, ajustan el fin (la meta), así como la fuerza o movilización del comportamiento, lo que se expresa a través de una actividad motivada.

A partir de esos argumentos, se comprende que la motivación se expresa en el plano interno particular de la personalidad, y que se manifiesta a través de actividades particulares del sujeto dentro de una determinada situación contextual. Dicho comportamiento es orientado y ajustado con la finalidad de cumplir con una necesidad determinada que responde también a lo social, como precisan Ortiz (2008) y Froufe (2011).

Aunado a ello, se comprende que la motivación se fundamenta en componentes o estructura intrínsecas y extrínsecas, los cuales contribuyen a que el sujeto le dé una jerarquización a las necesidades a fin de que sean constantemente dinámicas e influyentes sobre los procesos del pensamiento, las habilidades, la voluntad, los afectos, las conductas y las emociones y pensamientos de los seres humanos.

La motivación intrínseca es el motivo de llevar a cabo una acción cuando no existe una recompensa externa de por medio. Las acciones se ejecutan por su propio interés o por la satisfacción personal que deriva de su realización. Esta motivación es propia del individuo, se encuentra bajo control y puede auto reforzarse. Es decir, cuando un sujeto disfruta al realizar una determinada tarea se impulsa una motivación intrínseca positiva. Asimismo, las emociones positivas que no tienen alguna relación con el contenido de la 
tarea también podrían influenciar positivamente en la motivación intrínseca (González, 2003, González (2008), Ortiz, 2008, y Rico et al, 2013). Por su parte la motivación extrínseca proviene del exterior para iniciar o persistir en una acción. Son los acontecimientos externos los que generan la motivación extrínseca, a tal punto, que en la mente de la persona se crea un medio para un fin, en donde el medio es la conducta y el fin resulta ser alguna consecuencia interesante (Legault, 2016).

Desde otro punto de vista, la motivación intrínseca alude a las circunstancias en donde el individuo ejecuta determinadas actividades por la voluntad que siente de hacerlo, libremente de si existe o no alguna recompensa. Contrariamente, la motivación extrínseca, responde a circunstancias en donde el individuo se involucra en tareas que tienen una finalidad instrumental o por motivos externos a la misma tarea, por ejemplo, el recibir una recompensa. Desde estas perspectivas, se entiende que la motivación intrínseca es una característica interna del individuo que lo moviliza y estimula de manera consciente según sus necesidades y le produce regocijo, sin esperar recibir una recompensa a cambio y podría lograrse a través de la autodeterminación, la curiosidad, la comprensión, el desafío, y el esfuerzo que exprese el individuo (Legault, 2016).

Respecto a la motivación por el estudio, Robbins y Judge (2017), expresan que es la suma de procesos psíquicos que reajustan el sentido de una actividad, hacia la satisfacción de la necesidad y exigencia social ante la cual el sujeto se prepara para que posteriormente pueda laborar, aportar en la sociedad y convivir en ella. Desde esa mirada, la motivación por el estudio está compuesta de elementos como los motivos, el interés por estudiar, las necesidades personales, el deseo de lograr una situación económica próspera, entre otros. De ese modo el educando motivado por una actividad evidencia una actitud positiva e interés por aprender como respuesta a una necesidad consciente, independiente, autorregulada por él, hasta cumplir con su meta que es apoderarse de los procedimientos y 
las acciones de la actividad de aprendizaje que se manifiestan en las habilidades y los modos de actuación y las actitudes positivas en el qué y cómo hacer las actividades individuales y grupales que realiza.

\section{El interés como categoría psicológica}

Etimológicamente, la palabra interés proviene del latín interés se, que significa 'importar; en este orden de ideas, el interés es imprescindible motor de la personalidad y un factor importante en el aprendizaje, la palabra interés es conocida y empleada frecuentemente en la práctica social. Es común escuchar que un sujeto puede estar interesado en algo porque su significado es importante para él por tener algún sentimiento positivo hacia el objeto.

Según Harackiewicz, Smith, y Priniski (2016), el interés puede considerarse como una disposición que los individuos llevan consigo de un contexto a otro. Por el contrario, el interés situacional es más momentáneo y está vinculado a la situación; en otras palabras, puede ser una reacción específica a algo en una situación determinada. Un punto clave, es que la interacción entre la persona y el objeto que determina el grado de desarrollo del interés es fundamental, por lo tanto, las características personales y los contextos sociales contribuyen a la experiencia de interés cuando se participa en una actividad.

Asimismo, Walkington y Bernacki (2014), afirman que el interés es, por lo tanto, un estado psicológico caracterizado por una mayor atención, esfuerzo y afecto, experimentado en un momento particular, así como una predisposición duradera para volver a comprometerse con un objeto o tema particular a lo largo del tiempo. Mientras que para Daskalovska, Koleva e Ivanovska (2012), el interés es un impulso interior, una emoción o un deseo que mueve a una persona a una acción particular. Al respecto, Naranjo (2009), expresa que el interés está formado por una serie de motivos por los que los individuos se portan de la manera en que lo hacen. Asimismo, indica que cuando el 
comportamiento es motivado por una actividad es poderoso, dirigido y permanente en el sujeto.

El análisis realizado posibilita comprender que el interés es una manifestación de la personalidad que se orienta por determinados motivos externos e internos que experimenta el sujeto en su relación con el medio sociocultural. Ello depende de la influencia que reciba de la actividad que observa que debe reunir determinados requisitos para lograr la internalización, procesamiento y comprensión lo que potenciará cada vez más el interés por el aprendizaje.

Por su parte, para Rubinstein (1977),contribuye con una definición integral sobre la categoría el interés por el aprendizaje, al enfatizar que es la formación psicológica particular que orienta las actividades del ser humano hacia el conocimiento de determinados fenómenos, objetos o hechos, que se presentan en la correspondencia entre lo afectivo y lo cognitivo; prevalece la orientación afectiva, por lo que compone una formación motivacional; como una manifestación de la orientación de la personalidad que interviene por su trascendencia consciente y por su fuerza de atracción emocional.

En esa postura teórica se nota la prioridad que el especialista le otorga a la orientación de la actividad para actuar y aprender para que el sujeto pueda accionar en el qué, cómo, para qué realizar la actividad y qué valor y sentido tiene. En ello la orientación clara y precisa es una condición necesaria para activar la comprensión y el interés en el educando. Otro requisito es que el docente guíe el aprendizaje desde un ambiente de comunicación asertiva, interacción social y colaboración en grupo, con el fin de lograr el conocimiento nuevo y aplicarlo en solucionar las tareas idiomáticas ya sean orales o por escrito con el fin de reconocer las fortalezas y las necesidades de su aprendizaje integral.

Por su parte, los teóricos del interés más contemporáneo como Froufe (2011), Castellanos et al; (2007), Ortiz (2012), Sáez (2014) y González (2008), sostienen que el 
concepto interés como categoría general está formada o se concreta en dos componentes esenciales: el interés individual y el interés situacional, el interés individual se considera más duradero, por lo que perdura en el tiempo y el interés situacional responde a una situación particular del contexto. En este orden de ideas, tres factores son importantes en el desarrollo del interés: el conocimiento, la emoción positiva y valor personal, es decir, que a medida que los individuos aprenden más sobre un tema, se vuelven más hábiles y con mayor conocimiento, a su vez, esto tiene un efecto positivo a nivel psicológico porque produce una sensación satisfactoria al sentirse más competente y capacitados y a medida que pasan más tiempo con la actividad en este caso de aprendizaje, se puede encontrar un significado personal y relevante de dicha la actividad (Harackiewicz y Hulleman, 2010).

Por otro lado, hay que considerar que mientras más orientado esté el estudiante y conozca los objetivos de la actividad más interesado estará y comprometido por el aprendizaje, por hacer, conocer y desarrollar habilidades y seguir explorando. Por ejemplo, si un alumno está estudiando inglés, y uno de sus objetivos es convertirse en un traductor de esa lengua, logrará el propósito por ser una fuerza interna, necesidad y motivo que lo anima a interesarse en aprender lo mejor posible el idioma y para tener mayores posibilidades laborales y profesionales. Desde esta perspectiva, el interés tiene un rol esencial en el aprendizaje, en el rendimiento académico, y en su formación integral (Harackiewicz, Smith, y Priniski, 2016).

En ese sentido, plantea Castellanos et al; (2007), Addine (2013) y Ortiz (2012), que es una responsabilidad del docente y está en los principios didácticos estimular y animar a los estudiantes a descubrir sus potencialidades, necesidades e intereses, para poder vislumbrar un curso de vida fundamentado en el crecimiento humano como personalidad integral. De esta manera, se pone metas y vence los obstáculos y se adapta a las exigencias y alcanza los fines que le dan felicidad a lo largo de la vida. En este sentido, se asevera que 
promover los intereses en los educandos por el estudio van de la mano con la felicidad y la satisfacción que se alcanzan; son componentes importantes del bienestar, por lo tanto, la ejecución de actividades que sean interesantes, retadoras y les provoquen extrañeza a los estudiantes inciden en los procesos de asimilación consciente que les proporciona un nivel de satisfacción que lo impulsa a seguir estudiando (Harackiewicz y Hulleman, 2010).

El interés es un poderoso proceso de motivación que estimula el aprendizaje, guía las trayectorias académicas y profesionales, y es esencial para el éxito académico, el interés es tanto un estado psicológico de atención y afecto hacia un objeto o tema en particular, como una predisposición duradera a volver a comprometerse con el tiempo. Por lo tanto, el interés es un resultado importante, y un componente crucial del éxito en el ámbito académico, deportes, u otras áreas. Así que el interés por una actividad o un tema puede tener una gran influencia en la vida de las personas y puede influir en la manera en que deciden pasar su tiempo libre, y al influir en la selección de los cursos, las especialidades de la universidad, así como en la trayectoria de las carreras después de la universidad.

Cultivar el interés no debe ser una ocurrencia tardía de la situación típica de aprendizaje: el interés es esencial para el éxito académico. El docente debe velar por lograr intervenciones atrayentes que estimulen la observación, la atención y el interés de los estudiantes son importantes en cualquier contexto educativo, pero pueden ser más necesarias en dominios académicos que muchos estudiantes no encuentran inicialmente interesantes o aquellos dominios en los que el interés generalmente disminuye con el tiempo. Para finalizar, es importante destacar que el interés tiene un papel mediador, como parte del proceso de motivación que es significativo en todas las dimensiones de la vida de un individuo. 


\section{Interés por el aprendizaje de Inglés}

El aprendizaje de los distintos idiomas tiene muchas particularidades, y el interés es uno de los factores más importantes que influyen en el éxito del aprendizaje de un idioma, la investigación ha demostrado que el éxito en el aprendizaje de idiomas está relacionado con las actitudes positivas, el interés y la motivación, es fundamental la actitud de aprender y comunicarse en un idioma diferente, en este caso en inglés, entendiendo que, parte de un conocimiento muy general, que se estructura redefiniendo un nuevo conocimiento, que implica adquirir un vocabulario para cambiar esquemas internos, este proceso puede darse de forma natural o por medio de la asimilación progresiva; sin embargo, dependerá de la práctica, la repetición y la retroalimentación de la información que reciba (Toapanta, 2017).

En este mismo contexto, se planeta la expresión oral como una habilidad necesaria para aprender inglés, lo que envuelve la comprensión de diversos signos para darle significado, también la fluidez, es preciso acotar que la expresión oral efectiva parte de un conocimiento implícito, la persona debe estar claro del mensaje que desea comunicar. De igual forma, la destreza receptiva debe estar presente en cada interacción comunicativa, para comprender la nueva información en otro idioma es necesario que la persona tenga destrezas auditivas para captar el mensaje y procesarlo. En un sentido más amplio, se infiere que, los estudiantes necesitan identificar el idioma a través de los sonidos distintivos, para poder comprenderlos y desarrollar la habilidad de reproducirlos, de allí pues, que para aprender un nuevo idioma debe contar el estudiante con un campo de experiencia de interacción con otros que le permita en forma constante comprender el mensaje para interpretarlo, familiarizándose con la pronunciación (Toapanta, 2017).

Desde la postura de los estudiantes como protagonistas activos, participativos, dialógicos y comunicativos en la clase, para que comprenda, asimile y aplique la estructura 
del idioma al construir palabras, frases, oraciones u otros textos orales y por escrito. Para lograrlo deben observar, concentrarse, comprender las expresiones idiomáticas, tener seguridad en los que dicen y cómo lo dicen en un clima se seguridad al preguntar o expresar sus ideas e interactuar con sus iguales en el trabajo en grupo y luego exponiendo ante la clase. Ello los prepara para comunicarse en el salón, con las personas de su alrededor, en el contexto, la televisión, teatros u otras necesidades que estimulen su destreza auditiva durante la comprensión e interacción del mensaje. Es necesario entender la realidad desde la visión de la persona que, por necesidad trata de entender el mensaje, agudizando el sentido del oído (Benavides, 2013).

De acuerdo con Benavides (2013), el rol del docente es esencial porque con su comunicación clara, precisa y asertiva debe orientar, guiar y controlar el proceso de enseñanza - aprendizaje. Debe comprobar el tiempo y los recursos didácticos utilizados durante el tratamiento al contenido en la clase a fin de observar cómo los educandos se concentran, asimilan, se interesan, procesan la información y producen los conocimientos y se comunican a través de diálogos sencillos que el docente evaluará con la participación de todos. Congruente con ello, Castellanos, et al, (2007), Díaz (2010) y Addine (2013), sostienen que el educador es un profesional competente que debe demostrar maestría pedagógica para concentrar el interés por el aprendizaje de los estudiantes. El uso de los recursos didácticos como los medios audiovisuales, relacionar el tema con las situaciones reales y concretas del contenido del idioma provoca la motivación e interesar al estudiante para que se concentre en la actividad.

Otro aspecto que interviene en el aprendizaje del idioma y que es una habilidad comunicativa esencial es la escucha. Según Roméu (2007) y Cassany (2009), el docente debe ser un ejemplo lingüístico en general y en su accionar en la clase, debe velar por la escucha activa del estudiante por formar parte del proceso de comprensión, del pensar, el 
lenguaje y para lograr la comunicación. La habilidad de escuchar permite a la persona decodificar la palabra, la oración, el mensaje, entender el lenguaje verbal y no verbal lo cual le permite aumentar su capacidad de comprensión e interacción comunicativa. En fin, para lograr esas exigencias en la clase, se requiere de una metodología o conjunto de métodos que influyan en el interés por el aprendizaje del inglés en los educandos. De ahí que el contenido objeto de estudio deberá atenderse según las subcategorías establecidas: base conceptual, procedimental y actitudinal:

En la base conceptual, el docente debe propiciar una orientación clara y precisa de la actividad objeto de estudio, a fin de estimular la observación, atención, seguridad, comprensión, confianza del educando para que pregunte, opine, critique con la intención de que asimile, procese la información y construya el saber.

En la base procedimental los educandos deberán demostrar las habilidades en el saber hacer en las actividades que debe ser variadas, suficientes y diferenciadas y realizarlas en un clima de trabajo colaborativo, de análisis, de aplicación y de autoevaluación de qué y cómo han realizado la tarea y cumplido el logro esperado previstos.

En lo actitudinal se evidenciará la disposición, responsabilidad, las relaciones interpersonales positivas, el respeto, la tolerancia, la ayuda mutua, el esfuerzo, la perseverancia por aprender el idioma y autorregular su comportamiento que redundará en el fortalecimiento del interés permanente continuar aprendiendo porque es consciente que cada vez amplía sus capacidades idiomáticas que le permiten producir textos ajustados a la normativa del Inglés. Como se aprecia la enseñanza-aprendizaje del idioma inglés ha ido evolucionando progresivamente por los avances en la ciencia y la tecnología que exigen cada vez más de las personas y de los profesionales en particular su conocimiento y el perfeccionamiento de las destrezas comunicativas orales y escritas para poder acceder a la 
información actualizada y desenvolverse en el mercado profesional y laboral como parte del nivel cultural adquirido.

\section{Métodos que estimulan el interés por el aprendizaje del Inglés}

Como es reconocido el método es un componente didáctico que con sentido lógico y unitario estructura la enseñanza- aprendizaje desde la presentación y tratamiento del contenido, con el fin de motivar e interesar al educando durante el proceso de edificación del conocimiento y el perfeccionamiento de las destrezas al realizar la actividad de aprendizaje, evaluarla y aplicar lo aprendido en la solución de problemas (Álvarez de Zayas, 1997).En este sentido, Sáez (2014), afirma que, el cerebro es un órgano que se acostumbra a procesar patrones habituales, a lo rutinario, a entender cosas cotidianas de la misma forma como vía para enfrentarse a la realidad. Por ello, requiere de la novedad por lo que todo acto diferente a esos patrones, se guarda y pasa a la memoria a largo plazo.

Esa postura teórica requiere que la institución educativa introduzca los avances de la Neurociencia, porque la enseñanza de las diversas asignaturas continúa siendo tradicionalista, por lo que se hace preciso que los docentes concienticen que sin emociones no hay búsqueda del conocimiento y desarrollo de las habilidades, que existe relación entre estos factores. Se amerita de la aplicación de métodos y procedimientos que provoquen la curiosidad, el descubrimiento, la satisfacción, la alegría y la motivación en el educando por el aprendizaje (Sáez, 2014). Igualmente lo confirma, Bueno (2016), al enfatizar que se requiere emplear métodos de enseñanza- activos, reflexivos, comunicativos, lúdicos, creativos que potencien el interés y el ímpetu en el aprendizaje, porque es necesario estimular los códigos del cerebro a fin de que los educandos se motiven y desarrollen emociones positivas en la clase. Insiste que los docentes continúan en las aulas enseñando 
de la misma manera que hace 200 años y que no es posible que los estudiantes aprendan de esta forma.

De esa manera se comprende que los métodos y procedimientos que deben utilizarse en la enseñanza de una segunda lengua como es el Inglés deben orientarse a estimular el pensamiento, el lenguaje, la comunicación oral y escrita a fin de lograr la asimilación de los conocimientos y desarrollen las habilidades comunicativas generales. Entre estos se pueden mencionar: el diálogo, la conversación, la elaboración de resúmenes, las dramatizaciones, los cuadros sinópticos, la utilización de software educativo, la consulta de fuentes diversas, los esquemas lógicos, entre otros.

Al revisar los referentes didácticos, se aprecia que existen variadas clasificaciones de los métodos para el proceso educativo que se fundan en criterios diferentes. Labarrere (1998) y Addine (2015), afirman que se deben tener en cuenta los criterios que determinan el origen de la adquisición de los conocimientos por la relación del educador con la actividad y los educandos.

Según los criterios expuestos la enseñanza de la asignatura Inglés requiere de métodos comunicativos, dialógicos y los prácticos son principales para el perfeccionamiento y la formación de habilidades y hábitos que incluyen la realización de las actividades prácticas, la ejercitación, los trabajos en laboratorios y en equipos. Entre ellos se presentan los siguientes.

\section{Método de proyecto}

El método de proyecto se orienta a partir de una situación o actividades de aprendizaje que debe organizarse desde el objetivo previsto. La situación planteada debe responder a una problemática habitual del grupo estudiantil, de la profesión o del contexto. Mediante los requerimientos del trabajo en grupo los educandos anticipadamente orientados se indica una actividad que entre todos deben resolver (Pimienta, 2012 y Tobón, 2013). 
Para conseguir el propósito debe partir de una problematización sobre la realidad a fin de explorar los previos saberes relacionados con el fin de estudio. Una vez lograda esa parte es necesario profundizar en los fundamentos teóricos a fin de aplicar el nuevo conocimiento en la solución de la tarea. La metodología de trabajo en proyectos educativos simboliza una opción para la integración de conocimientos, potenciar el pensamiento crítico, la investigación, las relaciones interpersonales por el trabajo en equipo y aprenden a conjugar la teoría con la práctica. (Moreno y Velázquez, 2017).

\section{El método de conversación heurística}

Sobre el método heurístico, Romèu (2007), plantea que cuando se aplica de manera eficiente por el docente, se caracteriza porque el estudiante desde su base gnoseológica y las habilidades logradas descubre un nuevo concepto o algo nuevo en la clase. Al aplicarse en la clase se parte de los conocimientos empíricos de los alumnos y a partir de un grupo de preguntas con el método de la mayéutica precisar un concepto. Requiere el proceder metodológico, la interacción y el diálogo entre los actores educativos al analizar el objeto de investigación. Es así, que se estimula pasar de los saberes que se conocen a los desconocidos, así como también de lo simple a lo complejo, para ejercitar el razonamiento lógico. Al emplear este método el educador debe mostrar situaciones pedagógicas que establezcan las refutaciones cognitivas, problematizar mediante la plática y encontrar soluciones de manera colaborativa, aplicando lo aprendido (Lomas y Tusón, 2012 y Domínguez, 2010).

\section{Métodos de aprendizaje socializado o colaborativo.}

Se caracteriza porque crea una estructura de interacción cognitiva con cada miembro del grupo (Manrique, 2014). Por tanto, se aviva la interacción en un ambiente social y comunicativo para conseguir un objetivo en común. Este método facilita al alumno la integración social, a través de actividades que acoplen sus capacidades e intereses para 
lograr propósitos complejos. La enseñanza socializadora fomenta el aprendizaje mediante las dinámicas de trabajo grupal (Álvarez 1997).

De esta forma, el aprendizaje colaborativo enaltece algunas característicos que se diferencian en el estudiante como la autodeterminación, logrando el triunfo de su aprendizaje adquiriendo una segunda lengua poseyendo implicaciones de una natural interacción resultante como practicante - contexto educativo - educador (Manrique, 2014). El proceso educativo se fundamenta en la generalizadora lógica para la consolidación y organización de la información, asimilación y la interiorización de lo aprendido. El objetivo de este método es transfigurar los conocimientos del alumno en un aprendizaje activo que despierte la motivación.

\section{El método lúdico}

Este método integra procedimientos y estrategias trazadas para crear un ambiente de armonía, interacción y comunicación donde los alumnos que están inmersos en el proceso educativo, aprenden mediante el juego didáctico y actividades divertidas que les motiva el pensar; pueden incluirse contenidos, del currículo general (Lomas y Tusón, 2012). El método lúdico desarrolla el interés por el aprendizaje, la expresión oral, la creatividad, también en la comunicación donde el alumno aprende en un ambiente de alegría y satisfacción mediante la interacción con sus compañeros. A su vez estimula el aprendizaje cognitivo, el vocabulario, el desarrollo del pensamiento, la imaginación y las habilidades para la enseñanza- aprendizaje de cualquier disciplina curricular (Manrique, 2014).

Por lo tanto, el juego como actividad didáctica puede utilizarse en la clase para la motivación, y para que el educando construya el conocimiento con sus propias especificidades que inciden en el desarrollo del interés y la motivación por la actividad de aprendizaje. 
En resumen, la sistematización teórica llevada a cabo sobre la categoría interés por el aprendizaje, posibilitó asumir como autor de base a Rubinstein (1977), por ajustarse a los objetivos y fines de la presente investigación, así como también se consideraron otros especialistas como: González et al. (2004), Ortiz (2008), Sáez (2014; Bueno (2017), Parks, Gilad y Bardi (2003), Abulizi (2017), Harackiewicz, Smithy Priniski (2016), Toapanta (2017), Robbins y Judge (2017) y Benavides (2013), que amplían la mirada del autor. Desde esta postura teórica se identifican las subcategorías apriorísticas y los indicadores propiciando como conclusión elaborar la matriz de categorización (Anexo $\mathrm{N}^{\circ} 2$ ).

\section{Subcategorías apriorísticas}

Base conceptual: Se refiere a los principios, conceptos y explicaciones que construyen el conocimiento conceptual y que no se aprenden de forma literal, sino abstrayendo su significado esencial e identificando las características definitorias y las reglas que las componen. Incluye los principios y los conceptos. El conocimiento conceptual se va construyendo partiendo de concepciones, explicaciones y principios que no se conciben de manera literal, sino abstrayendo su significado fundamental e identificando las particularidades definitorias y las reglas que los componen. Por lo tanto, el conocimiento conceptual demanda para su aprendizaje la existencia de un mínimo de comprensión del contenido por aprender, considerando el proceso de comprensión de la nueva información. La comprensión, se plantea en este nivel como la capacitación especializada supone no solo poseer los conocimientos, sino las habilidades de saber hacer, producir o generar otras cosas con ese conocimiento, a fin de estimular la observación, atención, seguridad, comprensión, confianza del educando para que pregunte, opine, critique con la intención de que asimile, procese la información y construya el saber. De acuerdo con Perkins (2003), comprender significa la habilidad de pensar y actuar con flexibilidad partiendo del 
conocimiento, superando la memorización potenciando el pensamiento crítico y valorativo. Al comprender el sujeto es capaz de desempeñarse flexiblemente en cualquier campo teórico donde interactúa como aseveran: Rubinstein (1977), Díaz y Hernández (2010), Tobòn (2015) y Addine (2015).

Indicadores: Conoce los principios y conceptos del interés por el aprendizaje. Domina los enfoques teóricos de la enseñanza y el aprendizaje.

Base procedimental: Hace referencia a la ejecución de procedimientos, estrategias, técnicas, habilidades, destrezas, métodos, etcétera. El saber procedimental es práctico, porque está basado en la realización de varias acciones u operaciones. El contenido procedimental está fundamentado en la realización de acciones u operaciones, ya sea de manera práctica o cognitivo, supone el empleo de operaciones mentales de mayor complejidad que las requeridas para el aprendizaje que es básicamente de reproducción de tipo teórica, entendiendo los procedimientos como operaciones intelectuales que se aplican de manera ordenada y sistemática sobre la realidad. Otro aspecto importante es que el contenido está referido al aprendizaje de procedimientos o habilidades como un conjunto de acciones que usa el sujeto dirigidas hacia la consecución de un objetivo determinado. Se consideran procedimientos, estrategias, los métodos y las técnicas, pero en común integran el desarrollo de capacidades del nivel de habilidad, hasta el de destreza. Algunos autores que sustentan esta subcategoría son: (Rubinstein, 1977; Díaz y Hernández 2010, Tobòn, 2015 y Addine, 2015).

Indicadores: Motiva a sus alumnos a producir textos sencillos. Aplica los procedimientos a tener en cuenta en la construcción de textos.

Base actitudinal: Son las competencias interpersonales con las que se relaciona satisfactoriamente el alumno con sus semejantes y el contexto, es decir, la nueva información la aplica ante las diversas situaciones que puede afrontar en la vida. Los 
contenidos actitudinales están configurados por componentes de tipo cognitivos, afectivos y habilidades como las preferencias, sentimientos y las conductas que son declaraciones de intención y acciones. El componente evaluativo en las actitudes, porque estas implican una disposición o carga de naturaleza afectiva positiva o negativa hacia objetos, instituciones sociales, personas, o situaciones donde evidencian la disposición, responsabilidad, la tolerancia, la ayuda mutua, el esfuerzo, la perseverancia y relaciones interpersonales positivas, y disposición por aprender el idioma y autorregular su comportamiento que redundará en el fortalecimiento del interés permanente por aprender porque es consciente que amplía sus conocimientos y habilidades idiomáticas y cumple sus objetivos trazados (Rubinstein 1977; Díaz y Hernández 2010; Tabón, 2015 y Addine, 2015).

Indicadores: Participa y realiza la tarea con responsabilidad. Reconoce sus logros y limitaciones. Colabora y socializa con sus compañeros en las distintas actividades.

\section{Fundamentos teóricos y reflexión sobre la estrategia metodológica}

El término estrategia deriva del latín, strateğ̌a que a su vez proviene de la voz griega estratos (ejército) y agein (conductor, guía). Por consiguiente, el concepto primario es el arte de dirigir las operaciones militares. Por su parte, la Real Academia de la Lengua Española (RAE, 2017) determina que el término estrategia tiene tres acepciones: como el arte de dirigir los combates militares, por otra parte, el arte para dirigir un asunto, y grupo de los reglamentos que aseveran una decisión adecuada en cada momento.

Al respecto, Sierra (2004), sostiene que la estrategia es un procedimiento que permite la formación y desarrollo de una postura resistente y posiblemente adaptable a determinadas áreas que le permita a una institución lograr sus objetivos, a pesar de que el comportamiento sea complejo y no siempre sea previsible. Partiendo de esta posición semántica, se comprende que una estrategia es una pauta para la ejecución de la meta trazada, en cuanto guíe el accionar de la persona a un área determinada y especifique las 
actividades a realizar para obtener determinados objetivos. Desde esta postura, se puede decir que la estrategia debería ser planeada, organizada y debería determinar las actividades que deberán ejecutarse para el logro de los objetivos definidos.

Otro análisis amerita la categoría método de enseñanza, que según Castellano et al; (2007), Díaz (2010) y Addine (2013), posee características de un sistema y muestra la manera de organizar las actividades del docente y de los educandos para lograr las metas. El método guía la mecánica educativa con relación al objeto y el contenido a abordar. Tanto la elección, organización y utilización del método, se convierten en interrelaciones cruciales entre el educando, el profesor y el grupo que garantizan el aprovechamiento consciente de un determinado contenido. En relación a la metodología, Sánchez y Reyes (2015), indican que estudia al método o al grupo de métodos a partir de la perspectiva sistémica en la que desarrollan los diversos aspectos del saber. Ante lo cual, Addine (2013), especifica que el método se entiende como el camino que asumen los alumnos y el profesor para lograr, ordenada y secuencialmente, una meta de manera que se respete las normas establecidas.

Por su parte Gordillo (2007), manifiesta que la metodología se refiere al estudio del método (o métodos) a partir de un procedimiento sistemático mediante el cual se obtienen modos de conocimiento. Así pues, el método viene a ser más limitado, siendo las pautas comunicativas que se aplican a un acontecimiento para lograr las metas de forma planificada y controlada. En este sentido se comprende que una estrategia metodológica está compuesta por distintos métodos y procedimientos que tienen como finalidad dinamizar la actuación del docente para optimizar el pensamiento, la reflexión, motivar el pensamiento crítico, e interés en los alumnos como lo postulan Tobón, (2009) y Castellanos et al. (2007). 
Congruente con ello, Díaz y Hernández (2010), aseveran que la estrategia metodológica está conformada por operaciones que emplea el profesor y que poseen como fin el logro de aprendizajes en el estudiante. Se les considera como ayudas pedagógicas; y deben iniciar desde principios motivacionales y del trabajo cooperativo. Por su parte, Pimienta (2012) conceptualiza la estrategia metodológica como un instrumento o modelo pedagógico que el docente utiliza en su desempeño para contribuir al desarrollo de los conocimientos, las habilidades y las competencias de los alumnos durante el proceso de enseñanza- aprendizaje.

En esa línea de ideas el Ministerio de Educación de Perú (Minedu, 2009), sentencia que la estrategia metodológica es un conjunto de procedimientos y recursos empleados por el educador para que los alumnos desarrollen capacidades que les permita la adquisición, interpretación y procesamiento de información y hacer uso de sus capacidades para producir nuevos conocimientos, y emplearlos en situaciones reales que tienen que afrontar en sus día a día. En estos fundamentos se comprende que, la estrategia metodológica tiene como reto dinamizar la clase de idiomas siempre que se empleen variados métodos, procedimientos y medios materiales que concentren la atención y el interés de los estudiantes, su participación y cuestionamiento y lo motiven porque ha comprendido. Se logra esa actitud si es que se usa un sistema de tareas de aprendizaje que sean variadas, diferenciadas y suficientes que respondan a las necesidades de los educandos a fin de propiciar la motivación y el interés por solucionarlas y el desarrollo de las habilidades comunicativas del idioma.

Por su parte, Ibarguen (2013), añade que la estrategia metodológica es la pauta de las acciones a ejecutar de manera consciente e intencional por el docente conducidas a un objetivo referido al aprendizaje. Asimismo, sostiene que para elaborar una estrategia será fundamental considerar una serie de instrucciones pertinentes dirigidas por el profesor para 
que los procedimientos que ejecuten fomenten la motivación y el aprendizaje en los estudiantes. Una concepción integral presenta, Velázquez (2014), al afirmar que la estrategia metodológica se orienta al proceso de enseñanza- aprendizaje a partir del profesionalismo del docente para conducir el aprendizaje desde un sistema de métodos con la intención de problematizar, dialogar, reflexionar y valorar el contenido de la enseñanza donde los estudiantes son protagonistas conscientes de las transformaciones que alcanzan en las formas de pensar, sentir y hacer.

Las reflexiones teóricas realizadas permiten aseverar que la estrategia metodológica es un producto teórico - práctico que como resultado de la investigación se fundamenta desde posiciones científicas, didácticas, psicológicas, lingüísticas y pedagógica en la que el rol del docente es de mediador, comunicador asertivo y los estudiantes son protagonistas en función de lograr las transformaciones necesarias en el proceso de enseñanza - aprendizaje. De esa manera se comprende que la categoría estrategia metodológica tratada desde la perspectiva pedagógica, posibilita ampliar los sustentos conceptuales alrededor de la enseñanza del idioma en la práctica pedagógica. La reflexión permite comprender que es un modelo metodológico caracterizado por integrar un conjunto de métodos activos, comunicativos, investigativos, colaborativos, medios didácticos audiovisuales y la actividad de estudio que propicien el protagonismo, concentración, seguridad, confianza e interés en los estudiantes por aprender la estructura fonológica, lexical, semántica y gramatical en la construcción de textos del idioma Inglés.

Lo anterior reafirma que es un modelo teórico- práctico para ser aplicado en cualquier disciplina curricular compuesto por un conjunto de métodos, procedimientos, medios materiales, formas de evaluación que el educador emplea al orientar y guiar el proceso educativo, en este caso de la asignatura Inglés con el propósito de dinamizar la clase y provocar en los estudiantes la motivación y el interés por el aprendizaje del idioma 
y desarrollen los conocimientos y las habilidades comunicativas tanto oral como por escrito. Cabe destacar que es de gran relevancia emplear en la clase un sistema de actividades de aprendizaje de diferentes niveles de complejidad que el profesor debe planificar con anterioridad y deben caracterizarse por ser diferenciados y que en todo momento den respuestas a las necesidades de los alumnos, con el fin favorecer la motivación y el interés por solucionarlas, asimismo, el desarrollo de las habilidades comunicativas del idioma.

Al concluir el análisis de la categoría apriorística estrategia metodológica se toma como autora de base a Velázquez (2014), por ajustarse al objetivo de la investigación, así como se han revisado los aportes de otros autores como: Tobón, (2009), Díaz y Hernández (2010), Pimienta (2012) y Sánchez y Reyes (2015). Desde esa concepción se determinaron las subcategorías apriorísticas y los indicadores que facilitaron concluir la matriz de categorización (Anexo N. 2).

\section{Subcategorías apriorísticas.}

Exigencias del proceso de enseñanza y aprendizaje: Se concretan en un conjunto de principios didácticos y estudios actualizados de la didáctica y de las ciencias pedagógicas en particular, que posee como finalidad de estudio el proceso educativo.

En este sentido estas deben incurrir en las maneras de sentir, pensar, y actuar de los educandos en la clase de Inglés de manera que piense y se comunique de forma oral y por escrito y se eduque de forma integral (Silvestre y Zilberstein 2011, y Addine 2015).

Indicadores: Utiliza las categorías didácticas y los principios en la enseñanzaaprendizaje. Aplica el diagnóstico como proceso para transformar al educando.

Los sistemas de métodos: Conjunto de métodos que favorecen el desarrollo cognitivo y las habilidades de comunicación a través de la problematización, el diálogo la 
investigación al priorizarse las actividades que exijan el descubrimiento y el planteamiento de soluciones al producir textos en inglés de distintas complejidades en situaciones comunicativas de su contexto (Romèu, 2007 y Cassany, 2013). Existen métodos variados como la heurística, la problematización, la inclusión de la música, las actividades lúdicas, las excursiones y las investigaciones donde el alumno explora y descubre lo que está en los libros por sí mismos convirtiéndose en un acicate para aprender. Ese accionar le induce altas motivaciones y ayuda que florezcan las emociones positivas, un interés creciente por la actividad de estudio y, por tanto, adquieren un aprendizaje independiente y creativo (Sáez, 2014).

Indicadores: Aplica los métodos problémicos, comunicativos, heurísticos y creativos en la clase. Orienta la actividad de aprendizaje según las necesidades desde la autorregulación de lo que aprenden y cómo lo aprenden.

Rol docente: Para Díaz y Hernández (2010) y Velázquez (2014), el docente posee una gran responsabilidad en la tarea educativa por lo que debe, emplear métodos que motiven al alumno al desarrollo de un pensamiento lógico y reflexivo, asimismo, a realizar la edificación de conocimiento y aplicación para resolver una problemática. Esto se debe irradiar en la sistematización metodológica al desplegar la clase, relacionando la didáctica y dialéctica de modo holístico, para desarrollar en el alumno las habilidades, conocimientos y destrezas. Asimismo, el rol del docente definido como la responsabilidad del educador de fungir como mediador, y comunicador, para impartir conocimientos y dialogar con los estudiantes y demás integrantes de la comunidad educativa.

Indicadores: Demuestra ser un mediador competente, comunicativo y facilitador del aprendizaje. Crea un ambiente comunicativo rico empleando métodos que estimulan el protagonismo de los educandos. Emplea en la clase estrategias de aprendizaje colaborativo que promueven el diálogo y las relaciones interpersonales. 
Rol del estudiante: Los estudiantes son sujetos sociales y psicológicos, que poseen una determinada personalidad, sobre la cual se basan para llevar a cabo las funciones reguladoras y autorreguladoras de sus patrones de actuación en diversos contextos de su vida. El alumno es el personaje principal, activo, problematizador, dialógico, cooperativo y participativo en el conocimiento, desarrollando habilidades que le posibilitan transfigurar sus maneras de sentír, pensar, y hacer en su proceder. De esta manera se convierte en un alumno motivado e interesado por la tarea de estudio a partir de la investigación, la observación crítica, la autonomía, la reflexión, y aprende, demostrando en su forma de actuar positivas actitudes y capacidades de autoconocimiento, evaluación, control y regulación en su realización Al respecto, Castellanos et al. (2007), caracterizan algunos atributos del rol del educando en el proceso educativo. En primer lugar, debe sentirse responsable, protagonista, y activo en el proceso de enseñanza-aprendizaje. También debe poseer un rol activo al ser consciente que es co-participe de la construcción de su propio aprendizaje. Otro rol es el de indagación, elaboración de tareas, ejecutando acciones y procedimientos en la búsqueda del saber.

Indicadores: Evidencia ser consciente y responsable de su aprendizaje. Soluciona tareas de aprendizaje propio y en colaboración de modo significativo. Emplea estrategias de aprendizaje comunicativo y metacognitivas. 


\section{Capítulo II}

\section{Diagnóstico o trabajo de campo}

Se realizó en una universidad privada de Lima, tuvo como propósito conocer la preparación teórica y didáctica que poseen los docentes para desarrollar el interés por el aprendizaje del idioma inglés en los estudiantes de I ciclo de la Carrera de Administración. El proceso de sistematización teórica de las categorías apriorísticas permitió aplicar las técnicas y diseñar los instrumentos para la recolección, procesamiento y triangulación de los datos. Dichos instrumentos y técnicas fueron aplicados y validados a una muestra intencionalmente seleccionada por tener las condiciones propicias para cumplir con el objetivo del proceso de diagnóstico (Anexo N. 1),

Los métodos empíricos utilizados en el recojo de la información se ubican: una entrevista semiestructurada, observación a clases, prueba pedagógica y encuesta, como instrumentos de investigación: guía de entrevista a docentes, cuestionario a estudiantes, prueba pedagógica a alumnos y guía de observación a clases (Anexo N. 3). Los datos obtenidos a través del proceso investigativo son cualitativo y cuantitativo: los primeros se procesaron mediante tablas de reducción de datos, codificación y categorización, mientras que los segundos se procesaron mediante el uso de SPSS, cuyos resultados se muestran en tablas de frecuencias y gráficos. La triangulación permitió identificar las categorías emergentes, y las tablas de frecuencia consintieron establecer algunas regularidades y tendencias. 


\section{Análisis, interpretación y discusión de los resultados obtenidos con la aplicación de los instrumentos}

\section{Resultados de la entrevista semiestructurada los docentes.}

Se realizó una entrevista semiestructurada a tres docentes de la especialidad de inglés que se codificó y categorizó, siendo su interpretación cualitativa la siguiente:

Sobre la categoría interés por el aprendizaje, se observa en las docentes aproximaciones empíricas sin dominio conceptual a profundidad. Un docente afirma que un alumno se interesa por el aprendizaje, cuando presta atención, cuando realiza todas las actividades, cuando se interesa porque el profesor revise su trabajo y cuando hace sus tareas; el otro refiere que el interés se basa en las relaciones, vivencias, experiencias y es justamente el hecho de encontrar en la clase contenidos relacionados con sus vivencias, sus experiencias donde logra esa conexión y, el tercero, opina que es un estado anímico relacionado con el aprendizaje. Se aprecia falta de fundamentos teóricos sobre el aprendizaje, tomando en consideración que el interés es una condición psicológica del ser humano orientado por la necesidad y el deseo de construir conocimientos.

En cuanto al enfoque comunicativo, los entrevistados señalan que el objetivo del curso es lograr que los estudiantes se comuniquen, desarrollen competencias lingüísticas y comunicativas, y que ello se logra a través del diálogo constante entre el docente y los estudiantes; enfatizan que al explicar un tema y hacer preguntas sobre el mismo, todos van a estar a la expectativa. Si lo haces constantemente, el alumno estará pendiente porque es posible que en cualquier momento el profesor te pregunte algo. Pese a sus apreciaciones, no demuestran dominio teórico del mismo, sino referencias conceptuales básicas sobre la comunicación como estrategia de enseñanza y la relación de esta con el idioma.

También los docentes se refirieron al enfoque socio-constructivista, como expresión de interacción social, autonomía, protagonismo del estudiante, la valoración de sus saberes 
previos para lograr un aprendizaje significativo. En ese sentido un docente señala que primero se activan sus saberes previos estableciendo una conexión entre los temas tratados y los nuevos. Aunque los elementos mencionados son aspectos asociados al enfoque socioconstructivista, el aprendizaje significativo va más allá del encadenamiento de los temas que se van desarrollando en el curso, y la implementación de un enfoque socioconstructivista implica además la superación de prácticas conductistas que se evidenciaron a lo largo del discurso de los docentes entrevistados. En las entrevistas se evidenció la referencia a un método o enfoque ecléctico, haciendo alusión a la forma en que el docente combina diversas estrategias y métodos que permitan hacer más atractiva la clase a los estudiantes, al respecto el docente 1 explica que utiliza un enfoque ecléctico porque integra varias estrategias, hablar, escribir, traducir, música y otras prácticas comunicativas.

Respecto a la categoría métodos y técnicas para fomentar interés por el aprendizaje, señalan la necesidad de hacer atractiva la clase y las actividades para el alumno, señalan que es preciso incentivar su interés, con la aplicación de recursos, como videos, canciones, juegos, dinámicas, con miras a que los estudiantes disfruten en la clase. Se trata de implementar estrategias lúdicas para motivar; relacionar lo que se hace en clases con la realidad, con las vivencias y experiencias histórico-sociales.

Los docentes exponen las diversas técnicas que utiliza para el logro de los objetivos y para mantener el interés del estudiante en las actividades de la clase en general. Un docente utiliza la técnica del resumen al final de la clase, como medio para fijar los conocimientos y verificar el nivel de atención que los alumnos y los dos restantes señalan que utilizan el subrayado como técnica de apoyo, para especificarle cual es la idea principal, el Main topic, los supporting details y todos esos temas, como fundamento de la competencia escritura; el otro profesor utiliza el ensayo y error asociada a una técnica 
creada por él en la que el alumno una vez redactado el texto, se somete a la revisión por el docente, quien, al observar el primer error pronuncia la palabra "mistake".

También utilizan la ejemplificación, el repaso al iniciar cada clase, la técnica de la carpeta del estudiante o lo que el docente llama "técnica del impacto", que consiste, según el entrevistado, en hablar en tono de voz grave para llamar la atención, hacer énfasis con la voz en palabras o ideas que se quieren destacar, lo que se integra con la repetición, para que el estudiante pueda identificar lo que es importante. En ello destaca el predominio de técnicas tradicionales, aun cuando demuestran el propósito y las acciones didácticas para lograr el interés por el aprendizaje. El docente debe propiciar que el estudiante se implique en la actividad a partir del significado que tiene para él, que reconozcan su significación y valore la importancia de lo que aprende y para su propio desarrollo. Sin embargo, el uso de estos métodos tradicionales limita la apropiación y el desarrollo de las habilidades por la falta de preparación para guiar el aprendizaje desde posiciones reflexivas, dialógicas, y problematizadoras, para concientizarse de los cambios en la forma de sentimiento, pensamiento y el actuar.

Sobre el interés por el aprendizaje los docentes entrevistados hicieron referencia a variables personales como la actitud de los estudiantes, los entrevistados destacan que estos deben mostrar un estado emocional, disposición y voluntad para la atención, participación y compromiso activo con el conocimiento, con la clase y todas las actividades que se desarrollan en ella, así como las que el estudiante debe cumplir como tareas fuera del espacio educativo. En correspondencia con lo anterior, la motivación comprende un conjunto de procesos psíquicos dirigidos a satisfacer las necesidades del individuo reveladas en su comportamiento en pro de un fin. Al respecto, los docentes consideran que el estudiante debe estar motivado y que ellos contribuyen a hacerlo de diversas maneras, uno señala que motiva a los estudiantes al recalcarle las razones por las 
que están estudiando y que deben estar interesados; el otro docente refiere que es necesario motivar sus intereses, sus preferencias, sus grupos de pertenencia, actividades comunes a fin de lograr su identificación con lo aprendido. La motivación, desde sus apreciaciones es base para que muestren interés por aprender, presten atención, realicen las actividades y participen.

Uno de los aspectos que inciden en el aprendizaje son los hábitos de estudio; cuando un estudiante no controla las condiciones y métodos para estudiar se compromete el aprendizaje. Un docente afirma que no basta asistir a clases, prestar atención y participar, sino que es necesario que el estudiante se comprometa a reforzar la experiencia por sí mismo, investigar y leer; mientras otro docente expresa que entre los hábitos de estudio debe resaltar que trabajen con limpieza, orden y responsabilidad. En fin, los entrevistados, aseveran que el interés por al aprendizaje es una condición que el estudiante debe desarrollar mediante la práctica sistemática del estudio. Lo anterior se relaciona a su vez con la subcategoría referida al perfil de cada estudiante, pues, conforme a la opinión de un docente se debe valorar qué alumnos tienen más dificultad que otros, diferenciarlos según sus necesidades y potencialidades, para personalizar el tratamiento. En este sentido, destaca que un aspecto común es el desinterés por la teoría, resistencia y desapego. Los docentes mencionan que existen una serie de condiciones personales que intervienen en el aprendizaje de manera favorable o desfavorable por un estado físico de cansancio (debido a diferentes razones), o la nutrición.

Los docentes tienden a atribuir a condiciones personales de los estudiantes la falta de interés por el aprendizaje, pero es fundamental que se comprenda que la función del docente es contribuir a potenciar en ellos ese estado psicológico a través del uso de métodos de enseñanza que contribuyan al desarrollo del pensamiento demostrándoles los 
pasos a perseguir en la resolución del ejercicio partiendo de postulados problémicos, dialógicos y lúdicos para conseguir la participación en la clase de los educandos.

En lo que respecta a lo actitudinal y valorativo para desarrollar el interés por el aprendizaje, los docentes indican que en su labor implementan estrategias para promover el trabajo en equipo, la participación, el pensamiento crítico, la creatividad, el reconocimiento, así como la confianza y seguridad del estudiante. En torno a la participación siempre está pendiente de todos; el otro docente explica que formula preguntas para fomentar la participación; y un tercer docente precisa que emplea la estrategia de no indicar qué integrante de cada grupo es el responsable de exponer con el propósito de que todos se preparen para ello. En lo que respecta al trabajo en equipo, los docentes fomentan la participación colaborativa y la responsabilidad con la conformación de grupo para realizar actividades o trabajos, asignándoles roles y monitoreando su dinámica. De este modo los docentes evidencian conocer que la interacción entre los estudiantes es una vía idónea para la adquisición activa del conocimiento, así como los efectos positivos que el trabajo colaborativo tiene en el rendimiento académico de los participantes, así como en las relaciones socio-afectivas que se establecen entre ellos.

Sobre la evaluación formativa, la metacognición y los factores que intervienen en el aprendizaje, afirman que la evaluación en los sistemas educativos es la sumativa, que se centra en los productos, los resultados del conocimiento obtenido; la evaluación formativa es una estrategia esencial en la construcción de un ambiente y una experiencia educativa más constructivista, dialógica y participativa. Ningún entrevistado emplea la evaluación formativa y centrada en los procesos; aunque sí la observación y el monitoreo de la actividad que realizan. La evaluación formativa implica que no solo se evalúen los resultados, sino que se considere por el estudiante la evolución, la vivencia en los logros 
progresivos del aprendizaje, y no es una práctica común en la clase y que podría tener una incidencia significativa en el interés por el aprendizaje.

En cuanto a las prácticas metacognitivas, los docentes entrevistados apenas esbozan algunas actividades orientadas a la metacognición y autorregulación del aprendizaje, cuando señalan que frecuentemente indagan sobre lo que aprendieron al final de la clase, y creen que es importante preguntar qué no aprendieron y por qué no. Desde estos planteamientos, es importante reflexionar acerca de que la metacognición es un camino para lograr un desarrollo más pleno de la autonomía de los estudiantes, lo cual se refleja en un aprendizaje que trasciende el ámbito académico proyectándose en la vida de los estudiantes, en un "aprender a aprender". Respecto al nivel de dificultad de las actividades, la presencia y atención a clases y los objetivos de aprendizaje, como elementos asociados a las prácticas metacognitivas, los entrevistados consideran que un factor importante para que el alumno se interese en aprender es conocer desde el principio cuál es el objetivo del curso, sabiendo que el conocimiento del objetivo de aprendizaje es un aspecto importante dado que permite tener claridad acerca de lo que hace y por qué lo hace.

Otro de los entrevistados, señala que las actividades deben ir incrementando en cuanto al grado de dificultad o de complejidad, incluso cuando trabajan en grupo. La implementación de esta técnica implica que debe conocerse a los estudiantes, sus potencialidades y limitaciones, no obstante, comúnmente los docentes no profundizan en este conocimiento, como se evidencia en la experiencia de los entrevistados, sino que evalúan superficialmente si los estudiantes están comprendiendo o no a partir de sus reacciones en clase. Al respecto, uno de los entrevistados señala que el tiempo es un aspecto determinante, pues en ocasiones los estudiantes llegan tarde y les cuesta seguir el hilo de la clase, pero evidentemente no implementa estrategias para un monitoreo efectivo de esta variable. 
Sobre los factores situacionales que intervienen en el aprendizaje, señalan el tiempo de clases, limitación del horario y otras como ambiente de clases, situación económica, entorno familiar, problemas sociales, entre otros. Las limitaciones de tiempo son una característica de los sistemas educativos por esquemas poco flexibles y estrictos, que limitan la creatividad y dinamismo del aprendizaje. En las entrevistas se denota que la clase ya se encuentra estructurada y que el tiempo con el que cuentan es limitado, de modo que incentivan la búsqueda activa del conocimiento. El docente debe estimular el interés por el aprendizaje a partir de las actividades de retroalimentación, monitoreo, facilitación, acompañamiento, exposición y supervisión. La retroalimentación, entendida como proceso mediante el cual el docente comunica de forma efectiva y permanente a sus estudiantes los objetivos, contenidos, métodos, orienta las actividades, las fallas en las que incurren y aspectos en los que muestran competencia para que sean conscientes y protagonistas de su aprendizaje, y que comuniquen al docente sus inquietudes, observaciones, avances e interpretaciones sobre la experiencia educativa.

En este orden, los docentes entrevistados afirman que implementan estrategias de retroalimentación al corregir los trabajos y actividades entregadas por los estudiantes y luego regresarlas para que ellos verifiquen cuáles fueron sus fallas, aunque también apuestan por lograr que el estudiante reflexione e identifique sus errores, proceso en el cual debe tener el acompañamiento del docente. De acuerdo a estas apreciaciones, los docentes entrevistados practican la retroalimentación como estrategia para desarrollar el interés de los estudiantes por el aprendizaje, no obstante, la implementación de esta técnica debe ser constante, bien dirigida, flexible, amigable y profunda, para que el alumno la valore como una experiencia positiva y enriquecedora, no como un control, señalamiento, cuestionamiento o reprobación de lo que hace, de su aprendizaje. 
Un tercer docente asevera que entre sus funciones está la de exponer, presentar las ideas a través de un discurso lógico y hace alusión que a veces el tiempo de exposición del profesor limita la participación de los estudiantes, por lo que debe atenderse a este aspecto; indica que debe ser el alumno el centro de atención en la clase incentivar su protagonismo tratando de tener un diálogo constante con el alumno.

En resumen, se evidencia que aunque los docentes muestran disposición a innovar en el uso de las estrategias de enseñanza - aprendizaje, se constatan limitaciones teóricas y didácticas sobre el tratamiento a la categoría interés y la motivación por el aprendizaje por la falta de métodos variados que inciden en el proceso de aprendizaje de los estudiantes.

\section{Análisis de la observación a clase a los docentes.}

Se realizó la observación a tres clases de los docentes del curso de Nivelación Inglés, lo cual se codificó y su interpretación es la siguiente:

La introducción a la clase presenta características similares en los tres docentes, pues se presenta el objetivo de la clase y comienza la implementación de las estrategias, métodos, técnicas y herramientas que los docentes han desarrollado para el cumplimiento de dicho objetivo. En cuanto a los enfoques del aprendizaje que se evidencian en la acción didáctica del profesor, se pudo evidenciar que, de los tres casos, solo en una de ellas el docente aplica de manera somera, una estrategia orientada a indagar sobre los saberes previos sin un diagnóstico aceptable sobre el nivel del estudiante. Se constata que los docentes no realizan un diagnóstico psicopedagógico de los educandos sobre sus habilidades, conocimientos, situación social o intereses con el objetivo de dar un tratamiento a la diversidad del aprendizaje.

En esa medida, puede afirmarse que esta condición propia del enfoque socio constructivista y del aprendizaje significativo no se cumple en el desarrollo de las clases 
observadas; prevalece un protagonismo del docente, puesto que es él que tiene una participación significativamente mayor que la del estudiante en la experiencia educativa, lo que fortalece el análisis precedente sobre el predominio de prácticas tradicionales, no alineadas con los enfoques constructivistas de la educación. En las estrategias metodológicas aplicadas por el docente en la clase se observó el predominio del uso de métodos tradicionales en la elaboración de textos; no obstante, en una clase se aplicaron algunas dinámicas retadoras, mediante juegos de roles; y en las tres clases se capta la atención por medio de una introducción amena, uso de canciones, actividades novedosas con ayuda de las TIC y la retroalimentación permanente con los estudiantes sobre los ejercicios realizados. En general, no se apreció en ninguna clase aplicación de estrategias o prácticas metacognitivas ni acciones orientadas a promover el protagonismo estudiantil y sí se comprobó en las tres clases la relación de los conocimientos con la realidad con el entorno real de los estudiantes.

Los docentes se conciertan al contenido del sílabo rígidamente, no se realizan ajustes tomando en cuenta las necesidades de los educandos; en cuanto a los métodos de enseñanza reproductivos y las actividades son predecibles y el contenido es abordado con ejemplos reales pero que muchas veces no responden a ejemplos que los estudiantes puedan usar en su vida profesional. Se observa que los docentes de dos clases principalmente, siguen las actividades del libro al pie de la letra, generando monotonía en la clase. Respecto a los factores asociados al interés por el aprendizaje, y la atención que prestan en la clase, en una clase algunos alumnos conversan sobre otros temas y no muestran interés en aportar con sus saberes o intervenir en sus grupos, otros se muestran aburridos y se distraen con facilidad; mientras que dos docentes no logran captar la atención de todos (distraídos con el teléfono móvil); mientras en la otra clase el docente estimula la atención y se mantiene durante toda la clase. Se constató el impacto de diversas 
estrategias metodológicas empleadas que activó la participación, interés y compromiso de los estudiantes durante el desarrollo de la clase.

En cuanto a la actitud y la motivación se observa el mismo comportamiento anterior, en las dos primeras clases se observa dispersión, indiferencia y baja motivación en los alumnos, mientras que en la tercera clase los estudiantes se muestran más motivados, interesados y concentrados en las actividades didácticas. Se analizó la formación actitudinal, valorativa y el interés por el aprendizaje en cuanto a la orientación y la comunicación, los tres docentes demostraron un buen manejo del contenido, seguridad y diálogo con los educandos; sin embargo, en una clase es mucho más evidente el uso de un enfoque comunicativo, pues el docente se comunica asertivamente con sus alumnos, se muestra respetuoso, les permite expresarse con libertad y los escucha activamente.

En la promoción del trabajo en equipo se evidencia que, en las tres clases, los docentes propician espacios de colaboración e interacción social en sus estudiantes para compartir saberes y experiencias, favoreciendo el aprendizaje significativo, las relaciones comunicativas y el intercambio de conocimientos y experiencias. No se logra una participación generalizada en dos clases, pues no todos los estudiantes intervienen de forma activa ni en las actividades realizadas en grupo. Se demostró la falta de compromiso para realizar los trabajos colaborativos o individual, se distraen en vez de recurrir a sus habilidades para absolver sus dudas. Tampoco se observan estrategias direccionadas a estimular el pensamiento crítico y creativo en el estudiante.

Referente a la evaluación formativa, metacognición y factores situacionales al iniciar sus clases, los tres docentes explican con claridad y precisión el objetivo de aprendizaje, lo que se constituye la base para el tratamiento de las prácticas metacognitivas. En ninguna de las clases se aplican estrategias este sentido; se limitan a 
sugerir a los estudiantes reflexionar sobre lo aprendido, a preguntar si se logró el objetivo expuesto o identificar sus limitaciones, pero el ejercicio metacognitivo no se realizó.

El rol del docente, se observó dominio conceptual y teórico del contenido por los profesores, un buen nivel de planificación y estructuración de la clase. Se denota que han organizado su sesión de clases y el material a presentar es conocido por el estudiante y tiene acceso. La retroalimentación se realiza de forma limitada, pues escuchan a los estudiantes y corrigen las actividades, tanto a nivel individual como en equipo, pero no se profundiza en las prácticas dialógicas y el acompañamiento al estudiante en el descubrimiento de sus necesidades, potencialidades y expectativas en torno al aprendizaje, que le permite conocerse y fortalecer su desempeño.

Los docentes llevan a cabo actividades de monitoreo, asignan las actividades, ofrecen asesoría y están atentos a las inquietudes a fin de brindarles ayuda, verifican el cumplimiento y en general controlan el desarrollo de la clase. No obstante a que sus funciones se ejecutan de forma exitosa no solo por lo conceptual y procedimental, sino que si tienen una actitud favorable; aunque en una clase se evidenció que el docente se mostró cansado, mientras que en la otra se proyectó con alegría y energía positiva. En general se evidencia dominio de la asignatura por los docentes, no obstante, se aprecian limitaciones didácticas reflejadas en la falta de aplicación de métodos y estrategias dialógicas, interactivas y lúdicas al dirigir la enseñanza- aprendizaje, lo que influyen negativamente en la observación, la concentración e interés en el desarrollo de las habilidades y los conocimientos comunicativos en los alumnos. 


\section{Resultados de la encuesta aplicada a los estudiantes.}

La encuesta se aplicó a 40 estudiantes con la finalidad de conocer el nivel de satisfacción e interés por el aprendizaje del idioma inglés. Los resultados del procesamiento estadístico figuran en el Anexo $N^{\circ} 5$, y su valoración analítica es la siguiente:

En cuanto al interés que despiertan los docentes por el aprendizaje, solo 14 educandos $(35 \%)$ expresan que casi siempre los docentes cumplen esta función, mientras que $21(52,5 \%)$ consideran que sólo a veces ocurre y $5(12,5 \%)$ señalaron que casi nunca los profesores logran su interés por el aprendizaje. Las estrategias, métodos y técnicas empleadas por los docentes no logran su propósito, se requiere implementar prácticas educativas más dialógicas, participativas, lúdicas, atractivas y motivadoras. En lo que respecta a si la clase de inglés intenta relacionar la lengua aprendida con actividades del contexto social y real, el 16 (40\%) expresa que esto se logra casi siempre, mientras que 20 (50\%) consideran que a veces y $4(10 \%)$ casi nunca. Tales respuestas indican que los docentes no logran contextualizar el contenido de la asignatura, limitando la posibilidad de un aprendizaje significativo de la lengua.

En cuanto a si el docente orienta y les motiva a producir textos sencillos, 11 (27,5\%), afirman que siempre o casi siempre se cumple esta función docente, mientras que $22(55 \%)$ responden que a veces y $7(17,5 \%)$ casi nunca. En el perfil de la carrera de Administración se precisa que los estudiantes reciben una formación bilingüe intensiva con la finalidad de que estén preparados para competir profesionalmente. Si no existe la debida orientación y motivación por parte del profesor como se evidencia en las respuestas aportadas, no se logra de forma efectiva y oportuna este objetivo.

Al indagar acerca de la importancia del contenido de la asignatura de Nivelación Inglés $4(10 \%)$ responden siempre, $11(27,5 \%)$ casi siempre, mientras que 19 (47,5\%) afirman que $a$ veces y $6(15 \%)$ casi nunca. Con respecto a si el alumno asigna importancia 
al estudio del idioma y responsabilidad académicas, sus respuestas dan cuentan de que es baja la valoración, interés y el sentido de responsabilidad lo muestra en relación a aprendizaje del idioma, lo que repercute a su vez en el logro de los objetivos planteados. En cuanto a su participación responsable en las actividades propuestas sean de manera grupal o individual, $4(10 \%)$ manifiestan que siempre y $10(25 \%)$ casi siempre, en contraste con los estudiantes que respondieron a veces $20(50 \%)$, casi nunca $5(12,5 \%)$ o nunca $1(2.5 \%)$. Al analizar estos resultados se evidencia que no todos asumen el compromiso de participar con responsabilidad en el desarrollo de las actividades de aprendizaje.

Respecto a si reconocen sus limitaciones y si tienen el propósito de superarlas a través de sus motivación y recomendaciones del docente, 5 (12\%) indican que siempre y $12(30 \%)$ casi siempre; $22(55 \%)$ refirieron que a veces y 1 (2,5\%) indicó que casi nunca. Esto revela que no es común la práctica de autoevaluación en los estudiantes; se evidencia que la labor docente debe enfocarse en las prácticas metacognitivas, que permitan a los estudiantes precisar sus necesidades, limitaciones y potencialidades. Al indagar si los alumnos reflexionan sobre lo aprendido al finalizar las clases, $6(15 \%)$ indica que siempre lo hacen, $7(17,5 \%)$ expresa que casi siempre, 20 (50\%) refieren que a veces, mientras que $7(17,5 \%)$ expresan que casi nunca reflexionan sobre lo aprendido en la clase. Estos resultados refuerzan la conclusión sobre una baja tendencia en los estudiantes a reflexionar y autoevaluar el proceso de aprendizaje, lo cual les conlleva a la desmotivación, desinterés y resultados poco satisfactorios en la experiencia educativa.

En referencia a si el docente presenta su clase de manera didáctica a fin de estimular el interés por el aprendizaje, el 19 (47,5\%) los encuestados consideran que $a$ veces y $4(10 \%)$ casi nunca, mientras que $17(42,5 \%)$ se distribuye entre siempre $2(5 \%)$ y casi siempre 15 (37,5\%). Ello refleja que los docentes deben enfocarse en fortalecer su 
preparación psicopedagógica, potenciando el uso de las estrategias didácticas más adecuadas para la generación del interés por aprender.

En lo relativo a si el docente se interesa por conocer a los estudiantes y sus dificultades para orientarlos en su desempeño, 6 (15\%) indican que esto ocurre siempre, 16 (40\%) expresaron que casi siempre y $12(30 \%)$ revelaron que a veces y $5(12,5 \%)$ opinaron que casi nunca y $1(2,5 \%)$ nunca. Si el docente no establece una relación de confianza y comunicación con el estudiante se aprecian limitaciones. Los resultados arrojan que, aunque algunos docentes cumplen esta función, existen deficiencias desde la apreciación de los estudiantes que no cumplen cabalmente con su rol en cuanto al tratamiento a las dificultades del estudiantado y la alternativa para mejorar.

Respecto a si se sienten motivados cuando el profesor presenta situaciones retadoras, al orientar qué aprender y cómo lo aprender, 8 (20\%) indican que siempre, 25 $(62,5 \%)$ casi siempre y $4(10 \%)$ a veces y $3(7,5 \%)$ manifiestan que casi nunca. Contrario a la tendencia observada, se aprecia una valoración positiva por los estudiantes, en cuanto a su motivación para aprender actividades retadoras desarrolladas por el docente.

Sobre la forma en que el docente presenta el nuevo conocimiento y si facilita el aprendizaje, $6(15 \%)$ manifiesta que siempre, $12(30 \%)$ casi siempre y $21(52,5 \%)$ a veces, y el $1(2,5 \%)$ respondió casi nunca. Se demuestran desde el sentir estudiantil que el docente debe reforzar el empleo de estrategias que potencien su rol como mediador en la actividad, y les motive a resolver problemas, pensar y recrear el conocimiento.

Sobre su protagonismo en la enseñanza- aprendizaje, solo 13 (32,5\%) expresa que siempre $4(10 \%)$, casi siempre $9(22,5 \%)$, a veces $23(57,5 \%)$ y casi nunca $4(10 \%)$. El hallazgo refleja que, la mayoría, consideran que asumen un rol pasivo en el que reciben información. Ello limita el desarrollo constructivo del conocimiento y el logro de un aprendizaje significativo. 
El análisis realizado concluye que existen limitaciones en el nivel de interés de los alumnos por el aprendizaje como consecuencia de las dificultades docentes en la preparación teórica y la falta de empleo de la didáctica dialógicas, retadoras y motivadoras que despierten el interés y la valoración por la asignatura.

\section{Resultados de la prueba pedagógica aplicada a los estudiantes.}

La prueba pedagógica se aplicó a los 40 alumnos del curso de Nivelación Inglés, cuyo análisis cuantitativo está en el Anexo $\mathrm{N}^{\circ} 5$ y su interpretación es la siguiente:

En cuanto a la habilidad lectora, 6 alumnos $(15 \%)$ respondieron correctamente a la actividad requerida, $20(50 \%)$ respondieron 3 o 4 preguntas de manera correcta mientras que $14(35 \%)$ solo respondieron 1 o 2 preguntas de forma correcta, lo que demuestra un bajo nivel de compresión lectora, cuyas causas mayormente se deben a la pobreza de vocabulario, escasos conocimientos previos, desconocimiento o falta de dominio de las estrategias de compresión o escaso interés en la tarea.

En la segunda parte que busca evaluar el vocabulario, gramática y la expresión oral de la lengua, 6 (15\%) lo ejecutaron con un mínimo de error al presentar uno o dos desaciertos, $19(47,5 \%)$ presentaron de 3 a 5 imprecisiones y 15 (37,5\%), respondieron de forma deficiente; evidenciando un nivel bajo al identificar de manera incorrecta las formas gramaticales, al identificar el antónimo de los adjetivos presentados, o al identificar el orden lógico de una conversación. Demostrando falta de conocimientos, habilidades y actitudes en el desarrollo de las habilidades lingüísticas y comunicativas en general.

La mayor dificultad se observó en la escritura al solicitarle formar oraciones con los vocablos propuestos, 6 (15\%) lograron el máximo puntaje, 17 (42,5\%), estructuraron bien tres o cuatro oraciones, mientras que 17, solo redactan una o dos oraciones bien. Ello refleja un bajo nivel de habilidades de redacción, por lo que el docente debe aplicar 
estrategias que contribuyan al desarrollo de las habilidades de redacción.

Al cierre del análisis se aprecia que de los 40 estudiantes, solo 6 (15\%), demostraron un nivel alto de asimilación y solución de los ejercicios; 20 (50\%) alcanzaron un nivel medio al responder acertadamente algunos ejercicios; y 14 (35\%), evidencian un resultado deficiente. Ello refleja un bajo nivel de los conocimientos y las habilidades idiomáticas por la falta de interés por el aprendizaje, lo que exige del docente transformar el proceso de enseñanza- aprendizaje del idioma.

\section{Análisis e interpretación de las categorías emergentes.}

Acerca del método de triangulación, Bisquerra (2004), indica que es un proceso adecuado que posibilita analizar sobre datos obtenidos de modo integral, compararla con los supuestos teóricos y metodológicos, ordenados en el marco teórico a fin de percibir la repercusión en el problema de estudio las categorías emergentes. En ese sentido, se identifican y analizan las categorías emergentes sustantivas con la finalidad de interpretarlas, valorarlas y reconocer las fortalezas y otros factores o causas que afectan el logro de los objetivos y la calidad del aprendizaje de los estudiantes del curso de Nivelación Inglés, en la carrera de Administración de una universidad privada de Lima. A continuación, en la figura N. 2, se presenta las categorías emergentes sustantivas, resultante del proceso de diagnóstico de campo: 


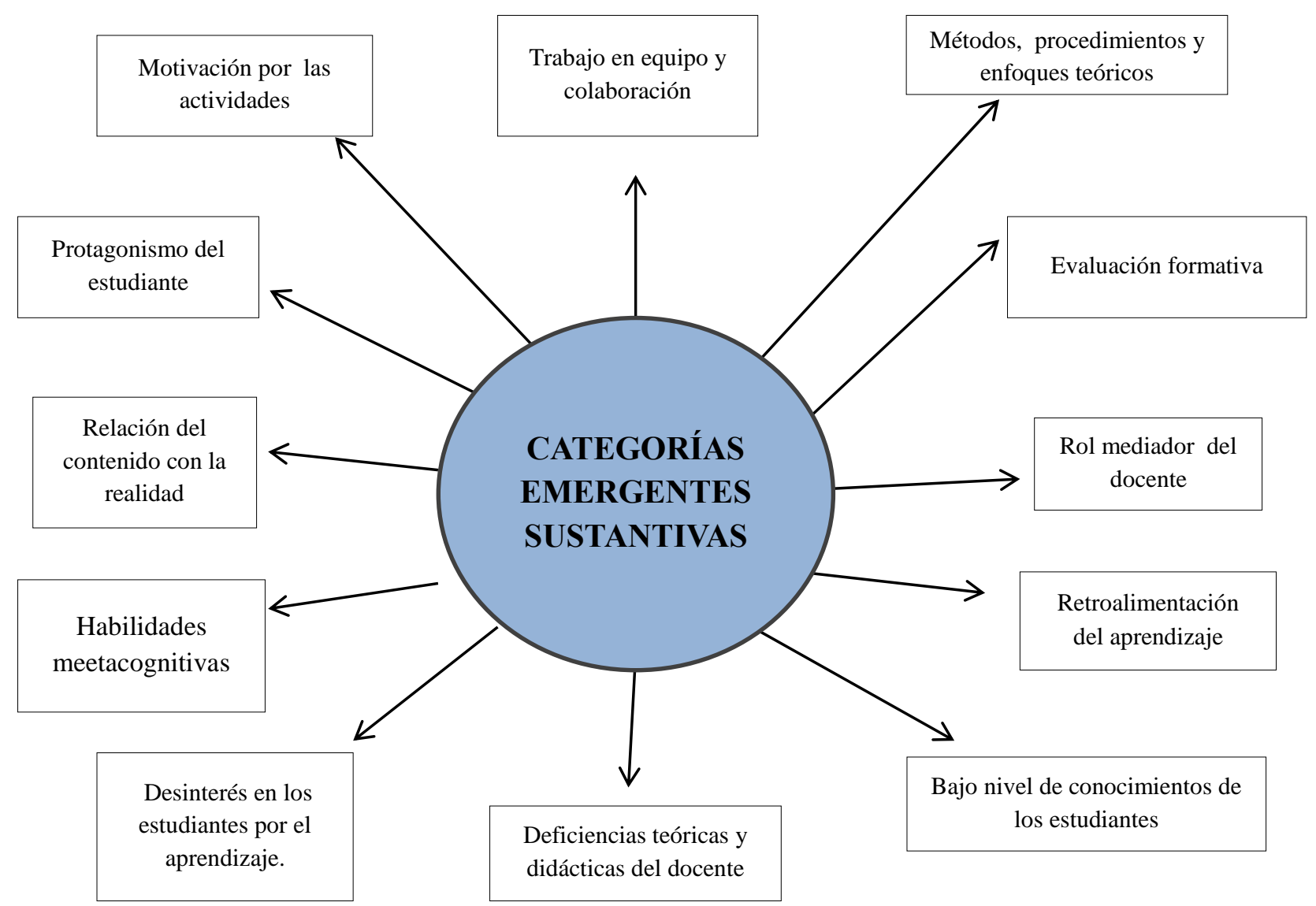

Figura 2. Categorías emergentes sustantivas. Fuente. Elaboración propia (2020).

A partir de la triangulación e interpretación de la información derivada de las entrevistas a los docentes; las observaciones a clases de a los profesores, las encuestas realizadas y las pruebas pedagógicas aplicadas a los estudiantes, se han identificado tres categorías emergentes que influyen negativamente en el problema investigado en los educandos, a saber: Desinterés y baja valoración en los estudiantes por el aprendizaje del contenido de la asignatura Inglés; Deficiencias teóricas y didácticas del docente al dirigir el proceso enseñanza-aprendizaje; El nivel de conocimiento y habilidades de los estudiantes es inferior a las exigencias curriculares de la asignatura que cursan. A continuación, en la figura 3 , se presentan las categorías emergentes que influyen negativamente en el problema objeto de esta investigación: 


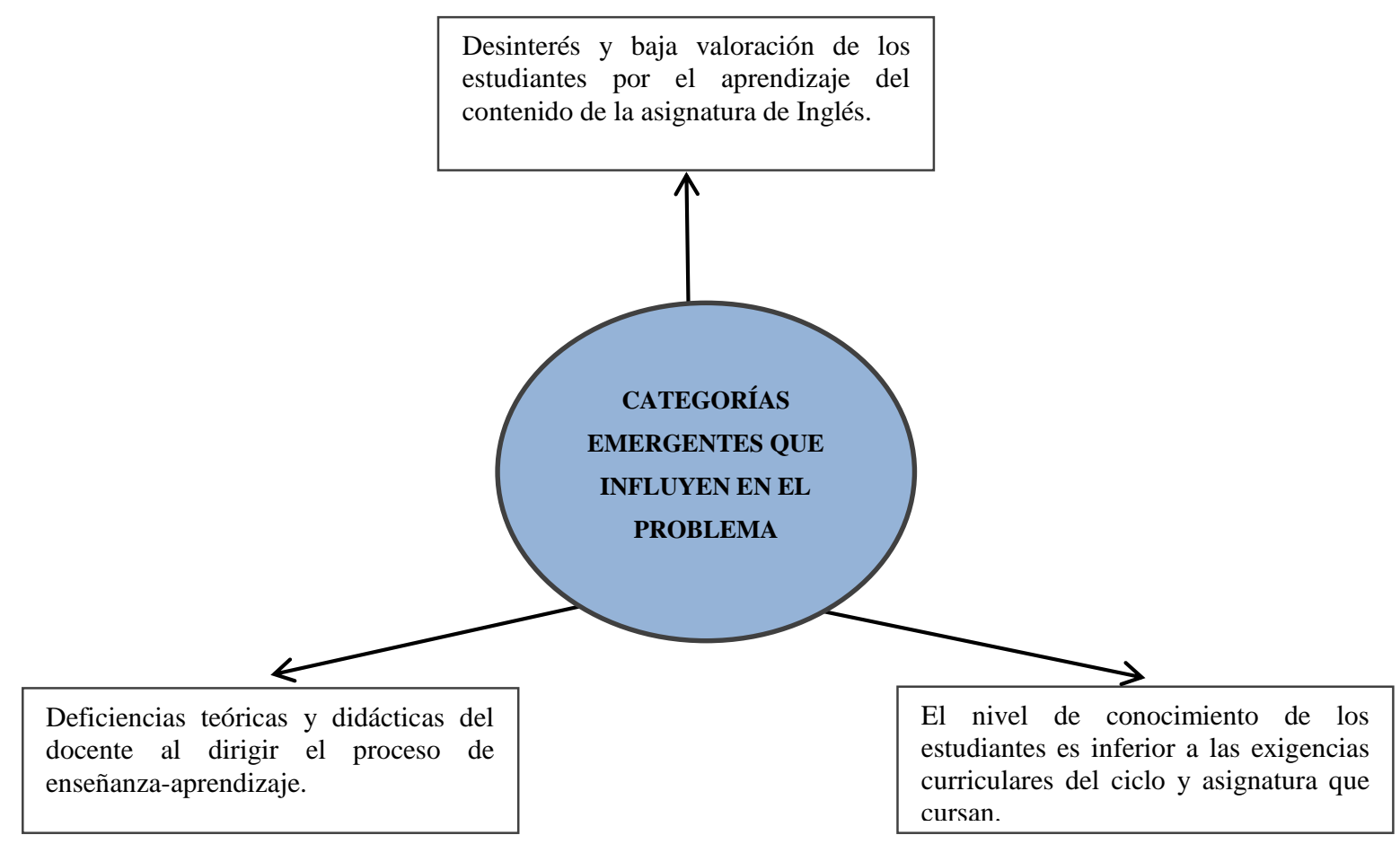

Figura 3. Categorías emergentes que influyen en el problema. Fuente. Elaboración propia (2020).

\section{Relaciones analíticas e interpretativas entre datos y categorías emergentes}

Se procede a continuación, a contrastar teóricamente las categorías emergentes que inciden en el problema de la presente investigación.

Desinterés y baja valoración de los estudiantes por el aprendizaje del contenido de la asignatura de Inglés.

Según los referentes teóricos de especialistas como: Rubinstein (1977), Ausubel (1983), Díaz y Hernández (2010), Castellanos et al. (2012) y Ortiz (2012), indican que la motivación y el interés por el estudio son primordiales para conseguir un significativo aprendizaje, autorregulado y consciente, al relacionar elementos de aprendizaje cognitivos, sociales y afectivos. Del mismo modo, afirman que cuando se potencia la motivación extrínseca e intrínseca en el educando, se estimula y genera la disposición para desarrollar actividades que involucran la constancia, perseverancia en un ámbito de alegría cuando se alcanza una meta establecida.

El profesor debe estar preparado para conducir la enseñanza-aprendizaje 
promoviendo un ambiente de trabajo colaborativo donde los estudiantes investiguen y sean conscientes cómo aprenden y de lo que aprenden. En la observación a clases y en la entrevista aplicadas a los docentes se corrobora la presencia de actitudes en los estudiantes que demuestran desinterés y baja valoración por el aprendizaje del idioma, se evidencian expresiones de cansancio, conducta dispersa, indiferencia por el trabajo en equipo en cumplimiento de las tareas, entre otros aspectos; y en la prueba pedagógica se revela un bajo nivel de conocimientos y habilidades como consecuencia de una didáctica que no estimula el pensamiento crítico, la creatividad ni el protagonismo estudiantil que conduce al desinterés por el aprendizaje.

\section{Deficiencias teóricas y didácticas del docente para dirigir el proceso}

\section{enseñanza-aprendizaje.}

De acuerdo a Addine et al. (2015), Tobón (2013), Pimienta (2012), Díaz y Hernández (2010), Martínez (2004), y Álvarez (1997), la didáctica capacita al profesor en la planificación, las funciones, norma, y principios que tienen que tener en cuenta al orientar la clase. Tiene como objetivo integrar los componentes utilizando métodos que posibiliten cuestionar, problematizar, analizar, e investigar el contenido, estimular los saberes previos y que los educandos perciban la importancia de lo aprendido y cómo aplicarlo. Así serán protagónicos al ser conscientes de qué hacen, cómo lo hacen y qué utilidad tiene en la práctica profesional. El docente en la clase debe poseer dominio teórico y habilidades pedagógicas, emplear estrategias, procedimientos, técnicas e instrumentos para fomentar el interés estudiantil por el aprendizaje.

En las entrevistas y observaciones de clases se identificaron limitaciones conceptuales y procedimentales para el ejercicio de la didáctica en los docentes, que se expresan en el predominio de una enseñanza tradicionalista, donde el protagonismo lo asume el docente como expositor, mientras que los estudiantes, como receptores, asumen un rol pasivo, que 
afecta su interés por el aprendizaje, desincentivando las actividades analíticas y reflexivas, pues no se emplean recursos didácticos que promuevan la participación activa y esto limita el aprendizaje significativo del proceso educativo. Es necesario, por tanto, fortalecer el dominio docente de conceptos, teorías y enfoque teóricos, así como en relación a las estrategias, métodos y técnicas que puede implementar para motivar e interesar al estudiante.

El nivel de conocimiento de los estudiantes es inferior a las exigencias curriculares del ciclo y asignatura que cursan.

En el perfil de los egresados y en los fundamentos de la asignatura Nivelación en Inglés de una universidad privada de Lima (2019), se indica que los estudiantes se deben comunicar a través de las cuatro habilidades lingüísticas: comprensión auditiva, comprensión lectora, producción oral y producción escrita con destreza y fluidez para el desempeño personal, académico y profesional: realizar trabajos de investigación, elaborar casos y dominar un vocabulario asociado a su carrera. En la prueba pedagógica y la observación de clases se reflejó que la mayoría de los estudiantes revelan un limitado desarrollo de sus conocimientos y habilidades que no les permite alcanzar las metas establecidas; el nivel de conocimientos y saberes previos no son suficientes para responder efectivamente a las demandas curriculares del curso que cursan los educandos.

\section{Conclusiones aproximativas de la investigación}

El proceso investigativo permitió constatar que los docentes presentan dominio de nivel básico sobre los conocimientos conceptuales y metodológicos inherentes a la didáctica universitaria, lo cual se evidenció a través de actividades que no lograban atraer la atención de los estudiantes, estimular su participación activa e incentivar su interés por aprender, tomando en cuenta que prevalece una visión tradicional, unidireccional y monótona del 
proceso educativo.

En las observaciones a clases se constató desinterés y baja valoración de los estudiantes hacia las clases del idioma y a las actividades de aprendizaje. Ello obedece a la limitada preparación didáctica del docente sobre los métodos para promover entornos de aprendizaje dinámicos donde el estudiantado sea consciente de lo que aprenden y cómo aprenden; en consecuencia, los educandos revelan bajo un nivel de habilidades y de valoración de sus experiencias y vivencias de aprendizaje, de ahí lo necesario de emplear metodologías activas que contribuyan a potenciar la esfera cognitiva, afectiva y volitiva.

A partir del análisis del proceso de triangulación se dedujo que el nivel de conocimientos y habilidades de los estudiantes no son suficientes para que respondan con éxito a las exigencias que se enuncian en el diseño curricular de la asignatura; esta falta de correspondencia podría ser atendida por un docente que maneje los fundamentos teórico conceptuales, así como los principios metodológicos.

Los resultados se lograron a través del proceso del diagnóstico del estado actual, así como de la triangulación, haciendo posible establecer la dimensión del problema científico, examinándolo y comenzar la modelación de la propuesta que posee como fin contribuir a desarrollar el interés por el aprendizaje. 


\section{Capítulo III}

\section{Modelación, validación y aplicación de la propuesta}

Partiendo de los datos obtenidos en el diagnóstico de campo se identificaron las categorías emergentes incidentes en el problema de la investigación se procedió a la modelación de la estrategia metodológica para contribuir al interés por el aprendizaje del idioma Inglés en los estudiantes de una universidad privada de Lima.

\section{Propósito de la investigación}

El propósito de la estrategia metodológica es contribuir al desarrollo del interés por el aprendizaje del idioma Inglés en los estudiantes de primer ciclo de la carrera de Administración de una universidad privada de Lima. La estrategia metodológica se sustenta en los fundamento socioeducativos, psicológicos, pedagógicos, lingüísticos y curriculares que sirven de punto de partida en su estructura y concreción.

\section{Fundamento socioeducativo.}

La propuesta de la estrategia metodológica está dirigida a los estudiantes de la disciplina Nivelación Inglés de la carrera de Administración de una Universidad de Lima, ubicada en el distrito de la Molina. La universidad es una empresa privada de prestigio que cuenta con más de 19 mil estudiantes distribuidos en sus programas de pregrado y posgrado. Esta casa de estudios cuenta con un modelo de formación profesional que garantiza el buen desarrollo académico de sus alumnos, así como una exigente formación bilingüe que se lleva a cabo, mediante un plan curricular que incluye cursos de inglés, así como la enseñanza de un programa intensivo de dicho idioma, con el objetivo de formar profesionales emprendedores bilingües que tengan la capacidad de leer y escribir en inglés, así como de realizar trabajos de investigación, diseñar casos y dominar el vocabulario asociado a su carrera. 
La población estudiantil del ciclo 2020-1 de la carrera de Administración que llevan el curso de Nivelación Inglés es de 346 alumnos, entre los que se encuentran los que están en estatus regular y los alumnos del programa beca 18, que tienen como particularidad, que no han estudiado la asignatura de inglés previamente. Cabe destacar, que los estudiantes se encuentran distribuidos en aulas con un máximo de 25 integrantes. Asimismo, cuenta con 14 especializados en dicha asignatura y un coordinador general de la asignatura.

Ante este contexto social, los estudiantes ponen en práctica sus experiencias, sus potencialidades y deficiencias en la enseñanza-aprendizaje en su quehacer que reflejan en los planos cognitivos y psicológicos, tales como desinterés por el aprendizaje y en el plano teórico-práctico al realizar las actividades por falta de una orientación precisa que los ayude a desarrollarse con éxito.

La propuesta se sustenta en la necesidad de optimizar el interés por el aprendizaje del Inglés en los educandos por lo necesario que es para su desarrollo social, cultural y profesional, al facilitarles mejores oportunidades, así como el acceso a información especializada y además porque es la lengua oficial en muchos eventos y organizaciones internacionales. De este modo, se busca generar un impacto no solo en el ámbito educativo, sino también en el desarrollo social. Esto precisa de una integradora didáctica de la lengua que incida en el análisis conceptual lingüístico como precisan González (2003), Vygotsky (1987), Roméu, (2007), Castellanos et al. (2007), Cassany (2013), y Domínguez (2010) entre otros especialistas.

\section{Fundamento psicológico.}

Las edades de los estudiantes se manifiesta entre los dieciocho años y veinticuatro años, quienes todavía son sujetos en formación, es decir, que algunos todavía no han logrado la estabilidad en sus procesos psicológicos, razón por la cual todo lo que pueda trabajarse en lo educativo va a contribuir a un mejor desarrollo de estos procesos. En este sentido, los 
docentes ameritan conocer las características de los estudiantes partiendo del diagnóstico integral del estudiante, contemplando no solo los aspectos cognoscitivos sino también lo referente al área afectiva motivacional con la finalidad de dar orientaciones adecuadas en el proceso formativo.

Las necesidades e intereses de los estudiantes, expresan Rubinstein (1977), González (2003) y Naranjo (2009), se revelan en la esfera psicológica a partir de los aspectos volitivos, afectivos y emocionales como parte del proceso biológico, psicológico y social que experimentan en esas etapas los jóvenes en sus vidas, a fin de estimular el desarrollo holístico. Por lo tanto, las formas de comunicación y de dirección que adopte el docente como parte del proceso instructivo - educativo, contribuirá al desarrollo integral del alumnado.

La propuesta metodológica se diseñó partiendo de los fundamentos psicopedagógicos con el objetivo de potenciarlas necesidades, motivación y actividades que estimulen las positivas emociones y el interés por aprender como precisa Rubinstein (1977), González (2003), Ortiz (2008), Mora (2017) y los argumentos de la didáctica desarrolladora desde los teóricos de Vygotsky (1987), y Castellanos et al. (2007).

\section{Fundamentos sociológicos.}

En la educación superior, sobresale las necesidades que presentan los estudiantes de fomentar su pensamiento, expresarlo y comunicarse de forma oral y por escrito con claridad, precisión, y coherencia, demostrando profesionalismo y dominio de los argumentos lingüísticos del idioma al comunicarse y socializar sus puntos de vistas y su manera de pensar y relacionarse con sus semejantes como un ser social interactivo y solidario. Al respecto, el artículo 9 de la Ley Universitaria 30220 (2014), orienta como uno de los objetivos de la educación superior, el dominio del idioma Inglés, así como la, identidad nacional sustentada en la diversidad cultural, lingüística, y étnica, impulsado 
mediante el desarrollo sostenible y el fomento de la integración con otras culturas.

\section{Fundamento pedagógico.}

La estrategia se fundamenta en las ciencias pedagógicas, que tiene como objetivo supremo la integral formación del ser humano para la vida. Ese propósito se alcanza gradualmente por la capacidad transformadora de la escuela con la orientación, planificación, conducción y control de la enseñanza-aprendizaje, al tener un diagnóstico de la diversidad que lo proyecta desde posiciones valorativas, dialógicas y desarrolladoras. En tal sentido, Álvarez de Zayas (1999), Ortiz (2013) y Addine (2015), explican que la pedagogía suscita cambios en la formación y desarrollo de la personalidad, e indican que unido a las familias, los grupos, los medios de comunicación y las instituciones culturales y la escuela son los responsables de la educación. Desde este enfoque, Ortiz (2013), Addine et al. (2015) y Álvarez de zayas (2016), definen la práctica pedagógica como un proceso mediante el cual, el docente cumple un rol de mediador esencial cuya tarea se centra en crear condiciones para que sus alumnos logren desarrollar su potencial cognitivo- afectivo a través de la práctica analítica y cuestionadora de modo que el estudiante es consciente de su forma de pensar, actuar y expresarse.

Según las consideraciones de esta perspectiva pedagógica, la estrategia asume los fundamentos teóricos - metodológicos que facilitan la realización de una clase renovada desde una didáctica desarrolladora que estimula el pensar y el hacer, como precisa, Castellanos et al. (2007), y ejercitada por Rico et al (2013) y Zilberstein y Silvestre (2011), quienes consideran el aprendizaje como un acto de adquisición de la cultura, bajo condiciones de orientación e interacción social, lo que requiere de un proceso activo, reflexivo y regulado, a través del cual el alumno aprende de manera consciente y gradual los contenidos, procedimientos, formas de actuar, y de pensar en el que se desarrolla. 


\section{Fundamentos didácticos}

Se toma el enfoque socioformativo como fundamento didáctico en la dirección de la clase, aportado por Tobón (2013), que se basa en los argumentos de la escuela histórico cultural de Vygotsky (1987), el pensamiento complejo de Morín (1999), el interés por el aprendizaje de Rubinstein (1977) y aprendizaje significativo de Ausubel (1983) y la didáctica desarrolladora de Castellanos et al. (2007), que resaltan la formación integral de lo cognitivo, afectivo y emocional del estudiante preparándolo para afrontar retos, proyectos, resolver problemas a nivel personal y social. Es una concepción que articula en el aprendizaje, el contenido, los saberes previos, el contexto social donde se desarrolla el alumno, trascendiendo la esfera exclusivamente gnoseológica a fin de integrar el saber hacer, el ser y el convivir (Delors, 1996).

Desde esta visión, el aprendizaje es concebido como un proceso individual, social, dialéctico y complejo que incita cambios en las maneras de pensar, sentir y hacer como expresión de la concepción curricular por competencias que pondera una formación general en el tratamiento del saber, comprometiendo lo conceptual, actitudinal y procedimental en el proceso de enseñanza- aprendizaje. Ello exige del docente la atención individual y colectiva del nivel de desarrollo real, y motiva su tránsito al potencial estimulando las destrezas para la solución de problemas partiendo de las experiencias desde el entorno sociocultural (Vygotsky, 1987; Hernández, Guerrero y Tobón, 2015).

En la estrategia modelada, el educador es un profesional mediador que guía y modela la praxis al logro del objetivo general que tiene como fin incidir en la formación integral de los educandos al adquirir las habilidades y los conocimientos al relacionarse con la tarea, controlar el proceso seguido y el resultado, empleando la evaluación formativa para potenciar la esfera motivacional, cognitiva, afectiva y las relaciones interpersonales en el proceso de enseñanza - aprendizaje. Tomando en cuenta este enfoque 
didáctico, se asume la dirección y organización de la enseñanza- aprendizaje como un espacio de interacción comunicativa, que es objeto de estudio de la didáctica, con un cuerpo de leyes, principios y categorías didácticas que caracteriza y connota desde un amplio fundamento teórico (Castellanos, et al. 2007; Pimienta, 2012; Addine, 2013; Tobón, 2013 y Álvarez de Zayas, 2016).

\section{Fundamento curricular.}

En la estructura de la estrategia metodológica se tiene en cuenta las indicaciones de la Ley Universitaria N. 30220 (2014), en la que se indica que los centros de Educación Superior, deben determinar el diseño curricular de cada especialidad según las necesidades nacionales y regionales que aporte al desarrollo del país. Con el objetivo de formar profesionales que egresen con eficiencia, y promover el desarrollo de las competencias profesionales que faciliten al egresado su incorporación al mercado profesional.

Desde esas perspectivas, en el diseño curricular de la carrera de Administración, objeto de estudio, figura en el plan de estudio la asignatura de Inglés, que tiene como propósito contribuir a la formación de emprendedores bilingües, que se apropien de las habilidades comunicativas y conocimientos necesarias para desempeñarse como en el mundo globalizado. En este sentido, el docente debe dosificar y planificar las sesiones de clases contemplando los diferentes componentes que demanda cada unidad didáctica del curso de modo que antes de iniciar las sesiones de clases, el docente tenga planificado el contenido que desarrollará, así como los métodos que aplicará y como los evaluará. Esto le permitirá determinar los objetivos que lograrán sus alumnos a corto, mediano y largo plazo.

\section{Fundamento lingüístico del idioma Inglés.}

El aprendizaje del inglés permite el acceso y comunicación en variados contextos sociales, posibilita afianzar las habilidades comunicativas e interesar a los estudiantes por su 
aprendizaje de manera significativa, desarrollando las habilidades lingüísticas esenciales, como: escucha, comprensión auditiva, comprensión lectora, producción oral y producción escrita, con destreza y fluidez para el desempeño personal, académico y profesional (Rubinstein, 1977; Roméu, 2007 y Cassany, 2013). En este sentido, la propuesta favorecerá la interacción comunicativa con la intención de que el estudiante interactúe con el docente y con sus pares en la clase de forma empática y asertivamente, a fin de estimular la expresión del pensamiento, el lenguaje, los sentimientos, intereses, necesidades e ideas que lo oriente a asumir actitudes analíticas que le posibiliten mantener relaciones sociales en permanente diálogo, convivencia democrática, respeto y tolerancia.

Por ser una propuesta basada en una dinámica integradora que busca la formación integral del alumnado, es esencial aplicar métodos que inciten la motivación intrínseca ayudando a razonar, comprender y lograr los objetivos. Se proyectan las acciones para favorecerla eficiencia del aprendizaje y enseñanza del idioma, enfatizando en el valor del lenguaje como medio de comunicación y socializador conectado a la psicología y al desarrollo cultural de misma sociedad. Es así, como resalta la importancia de percibir que el aprendizaje del inglés no se limita al conocer, usar los verbos y las reglas de gramática, sino que es ineludible calar en la cultura que representa, para conocer el país, y sobre todo, acercarse a los requisitos fónicos, sintáctico y lexicales que le facultan para conectarse con la transculturización y comunicarse de forma oral y por escrito.

\section{Dosificación de la unidad didáctica de la asignatura Nivelación Inglés.}

Para conocer la forma en que se integran los fundamentos del currículo de la carrera de Administración de una universidad de Lima, se muestra la dosificación de la unidad didáctica número II de la asignatura de Inglés, tomada en cuenta para la propuesta diseñada como se muestra en la tabla N.2. 
Tabla 2.

Dosificación de la unidad didáctica 2 de la asignatura inglés.

\begin{tabular}{|c|c|c|c|c|c|c|}
\hline Sesión de aprendizaje & Métodos & Competencias & Capacidades & Conceptual & $\begin{array}{l}\text { Valores a } \\
\text { formar }\end{array}$ & Indicadores \\
\hline $\begin{array}{l}\text { Sesión 1: } \\
\text { Live, work and study } \\
\text { Phrases with like, } \\
\text { Have }\end{array}$ & $\begin{array}{l}\text { Método } \\
\text { creativo y lúdico. }\end{array}$ & $\begin{array}{l}\text { Emplea el tiempo presente } \\
\text { para narrar aspectos de su } \\
\text { vida personal. }\end{array}$ & $\begin{array}{l}\text { Usa distintos verbos de forma } \\
\text { positiva y negativa en el Presente }\end{array}$ & $\begin{array}{lrr}\text { Reconoce frases } & \text { con los } \\
\text { verbos: tener, } & \text { vivir, } \\
\text { trabajar, estudiar. }\end{array}$ & $\begin{array}{l}\text { Responsabilid } \\
\text { ad, Respeto, } \\
\text { tolerancia. }\end{array}$ & $\begin{array}{l}\text { Demuestra interés, para escribir } \\
\text { oraciones positivas y negativas } \\
\text { sobre él usando los verbos like, } \\
\text { work, study, entre otros. }\end{array}$ \\
\hline $\begin{array}{l}\text { Sesión 2: } \\
\text { My free time } \\
\text { Free time activities } \\
\text { An online interview }\end{array}$ & $\begin{array}{l}\text { Método } \\
\text { heurístico, } \\
\text { investigativo, y } \\
\text { comunicativo. }\end{array}$ & $\begin{array}{l}\text { Demuestra dominio de } \\
\text { vocabulario y de estructuras } \\
\text { gramaticales básicas para } \\
\text { desenvolverse en situaciones } \\
\text { diarias y familiares. }\end{array}$ & $\begin{array}{l}\text { Formula preguntas y utiliza } \\
\text { respuestas cortas en el Presente } \\
\text { Simple para hablar de actividades } \\
\text { de tiempo libre. }\end{array}$ & $\begin{array}{l}\text { Lee e infiere información } \\
\text { de un texto. Deduce el } \\
\text { significado de palabras o } \\
\text { expresiones usando datos } \\
\text { del texto. }\end{array}$ & $\begin{array}{l}\text { Cooperación, } \\
\text { laboriosidad, } \\
\text { responsabilida } \\
\text { d. }\end{array}$ & $\begin{array}{l}\text { Identifica el vocabulario del } \\
\text { tiempo libre. Escucha atentamente } \\
\text { la pronunciación del nuevo } \\
\text { vocabulario. }\end{array}$ \\
\hline $\begin{array}{l}\text { Sesión 3: } \\
\text { Buying things }\end{array}$ & $\begin{array}{l}\text { Método } \\
\text { Comunicativo y } \\
\text { socializado. }\end{array}$ & $\begin{array}{l}\text { Dialoga utilizando } \\
\text { estructuras gramaticales } \\
\text { básicas y pretende ser un } \\
\text { cliente o un vendedor en una } \\
\text { tienda. }\end{array}$ & $\begin{array}{l}\text { Realiza una dramatización en el } \\
\text { contexto de una tienda. Utiliza los } \\
\text { pronombres demostrativos this, } \\
\text { thes, that, those apropiadamente. }\end{array}$ & $\begin{array}{l}\text { Escucha el audio de } \\
\text { diálogos que se da en una } \\
\text { tienda. } \\
\text { información que escucha } \\
\text { en el audio. }\end{array}$ & $\begin{array}{l}\text { Liderazgo, } \\
\text { compromiso, } \\
\text { flexibilidad. }\end{array}$ & $\begin{array}{l}\text { Escucha un diálogo } \\
\text { contextualizado en una tienda, } \\
\text { reconociendo las preguntas clave } \\
\text { del diálogo. }\end{array}$ \\
\hline $\begin{array}{l}\text { Sesión 4: } \\
\text { What tim } \\
\text { e is it? }\end{array}$ & $\begin{array}{l}\text { Método } \\
\text { problémico } \\
\text { comunicativo, y } \\
\text { socializado. }\end{array}$ & $\begin{array}{l}\text { Desarrolla una conversación } \\
\text { usando expresiones de } \\
\text { tiempo y la hora. }\end{array}$ & $\begin{array}{l}\text { Obtiene información sobre el } \\
\text { tiempo de manera oral. }\end{array}$ & $\begin{array}{l}\text { Identifica los días de la } \\
\text { semana y palabras de } \\
\text { tiempo, diciendo la hora; y } \\
\text { hablando de la hora. }\end{array}$ & $\begin{array}{l}\text { Compañerism } \\
\text { o, paciencia, } \\
\text { responsabilida } \\
\text { d. }\end{array}$ & $\begin{array}{l}\text { Habla sobre su rutina los días } \\
\text { domingos y sus compañeros } \\
\text { adivinan si sus afirmaciones son } \\
\text { verdaderas o falsas. }\end{array}$ \\
\hline Sesión 5: & $\begin{array}{l}\text { Método creativo, } \\
\text { comunicativo, y }\end{array}$ & $\begin{array}{l}\text { Escribe oraciones y párrafos } \\
\text { de corta extensión utilizando }\end{array}$ & $\begin{array}{l}\text { Descubre sus rutinas usando } \\
\text { oraciones negativas y positivas en }\end{array}$ & $\begin{array}{l}\text { Identifica oraciones sobre } \\
\text { rutinas diarias, en Presente }\end{array}$ & Responsabilid & $\begin{array}{l}\text { Escribe oraciones básicas } \\
\text { teniendo en cuenta la estructura }\end{array}$ \\
\hline A typical day & heurístico & \begin{tabular}{llll} 
estructuras & \multicolumn{2}{c}{ gramaticales } \\
básicas sobre & su rutina \\
diaria. & & &
\end{tabular} & $\begin{array}{l}\text { el presente Simple de forma } \\
\text { escrita. }\end{array}$ & $\begin{array}{l}\text { Simple en positivo } \mathrm{y} \\
\text { negativo. }\end{array}$ & $\begin{array}{l}\text { laboriosidad, } \\
\text { compañerismo }\end{array}$ & \\
\hline $\begin{array}{l}\text { Sesión 6: } \\
\text { Where does she work? }\end{array}$ & $\begin{array}{l}\text { Método } \\
\text { problémico, } \\
\text { investigativo, y } \\
\text { comunicativo. }\end{array}$ & $\begin{array}{l}\text { Identifica y comprende } \\
\text { frases y expresiones de uso } \\
\text { frecuente en un texto } \\
\text { auditivo corto y sencillo en } \\
\text { inglés relacionadas con su } \\
\text { entorno inmediato. }\end{array}$ & $\begin{array}{l}\text { Brinda información sobre el } \\
\text { trabaio de otras personas en } \\
\text { Presente Simple de manera oral. }\end{array}$ & $\begin{array}{l}\text { Elabora frases con las } \\
\text { preposiciones on, in, at, } \\
\text { presentando preguntas y } \\
\text { respuestas cortas en el } \\
\text { presente simple. }\end{array}$ & $\begin{array}{l}\text { Laboriosidad, } \\
\text { responsabilida } \\
\text { d, honestidad. }\end{array}$ & $\begin{array}{l}\text { Formula preguntas utilizando las } \\
\text { formas gramaticales correctas } \\
\text { para indagar sobre las actividades } \\
\text { que un familiar suyo realiza } \\
\text { durante la semana. }\end{array}$ \\
\hline $\begin{array}{l}\text { Sesión 7: } \\
\text { An evening out }\end{array}$ & $\begin{array}{l}\text { Método creativo, } \\
\text { comunicativo, } \\
\text { socializado. }\end{array}$ & $\begin{array}{lr}\text { Dialoga } & \text { utilizando } \\
\text { estructuras } & \text { gramaticales } \\
\text { básicas } & \text { sobre temas } \\
\text { conocidos y habituales. }\end{array}$ & $\begin{array}{l}\text { Crea conversaciones simples para } \\
\text { organizar salidas. }\end{array}$ & $\begin{array}{l}\text { Expresa frases } \text { sobre } \\
\text { comida y bebida en un } \\
\text { restaurante. }\end{array}$ & $\begin{array}{l}\text { Cordialidad, } \\
\text { cooperativism } \\
\text { o, } \\
\text { laboriosidad, }\end{array}$ & $\begin{array}{l}\text { Utiliza adecuadamente frases para } \\
\text { pedir bebidas y comidas en un } \\
\text { restaurante. }\end{array}$ \\
\hline $\begin{array}{l}\text { Sesión 8: } \\
\text { A day off }\end{array}$ & $\begin{array}{l}\text { Método creativo, } \\
\text { investigativo, y } \\
\text { comunicativo. }\end{array}$ & $\begin{array}{l}\text { Contesta preguntas } \\
\text { personales con coherencia y } \\
\text { fluidez. }\end{array}$ & $\begin{array}{l}\text { Describe la frecuencia con la que } \\
\text { realiza sus actividades favoritas. }\end{array}$ & $\begin{array}{l}\text { Emplea adverbios } \text { de } \\
\text { frecuencia } y \text { frases con } \\
\text { every. }\end{array}$ & $\begin{array}{l}\text { Responsabilid } \\
\text { ad, } \\
\text { laboriosidad. }\end{array}$ & $\begin{array}{l}\text { Dialoga utilizando estructuras } \\
\text { gramaticales básicas sobre temas } \\
\text { conocidos y habituales. }\end{array}$ \\
\hline
\end{tabular}




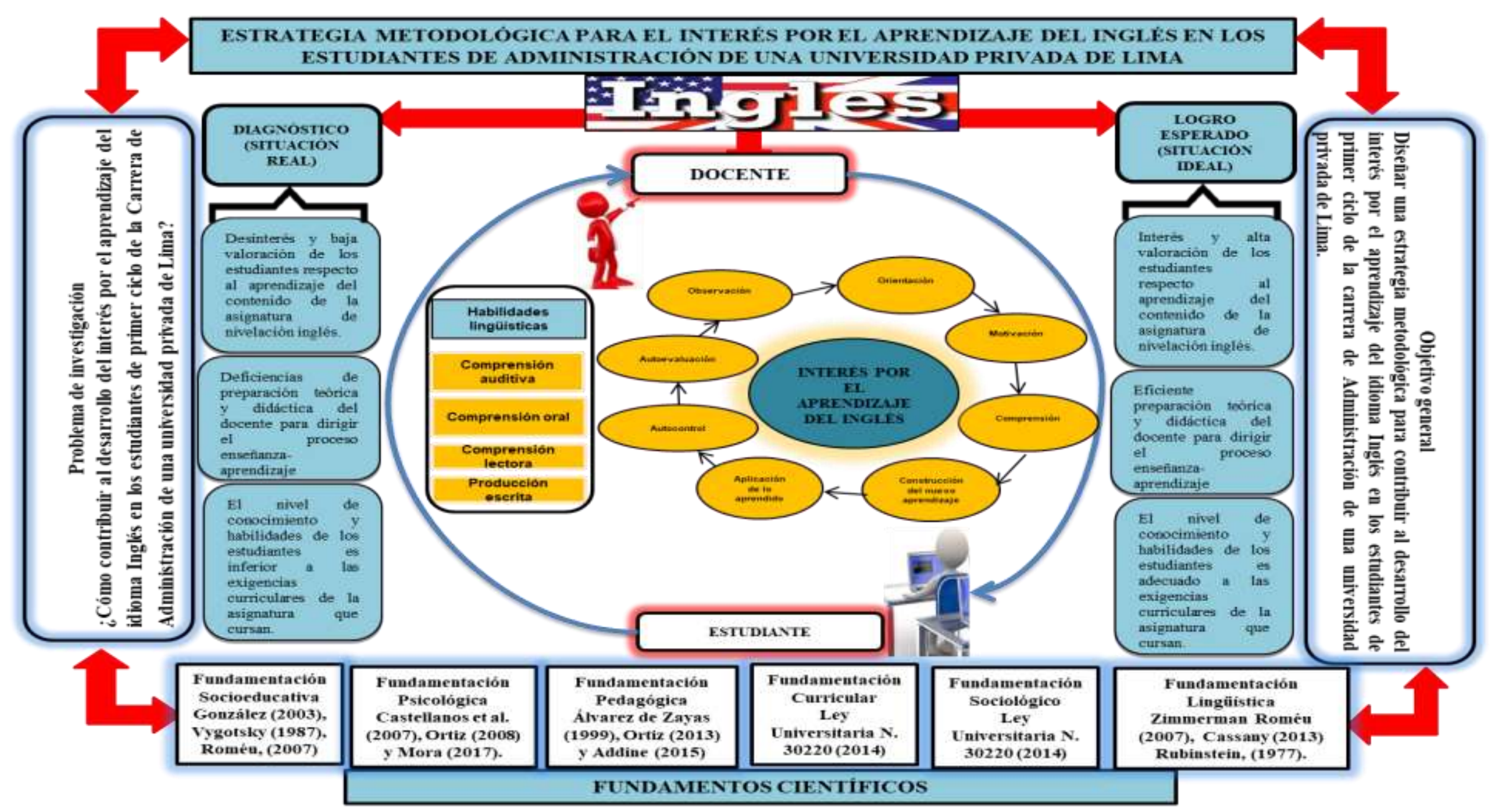

Figura 4.Esquema teórico-funcional que representa la estrategia metodológica. Fuente. Elaboración propia (2020). 


\section{Esquema teórico-funcional de la estrategia metodológica propuesta}

El esquema teórico-funcional refleja la lógica interna, las relaciones que se suscitan entre los componentes y estructura de la propuesta que se concretan en la estrategia metodológica modelada con el propósito de contribuir a la solución de la problemática investigada. En este orden de ideas, el diagnóstico de campo permitió comprobar de manera objetiva el actual estado del problema investigado, correspondido con la desmotivación por aprender la asignatura de Inglés por los alumnos en el proceso educativo y las categorías emergentes que tienen incidencia en ello.

La estrategia metodológica modelada fundamenta la enseñanza y aprendizaje de la asignatura Inglés partiendo del enfoque comunicativo, sociocultural, y cognitivo, postulado por Roméu (2007), e integrado dialécticamente a la didáctica desarrolladora de Castellanos et al (2007). Estos argumentos teóricos postulan que la enseñanza de la lengua tiene como base la lingüística y los argumentos teóricos de Vygotsky (1987), en lo referido a la relación entre el lenguaje, el pensamiento y el contexto.

Esta postura manifiesta que el lenguaje es el medio fundamental para la apropiación del conocimiento, la socialización y el vehículo esencial de la comunicación humana. Desde esta perspectiva se prioriza la interacción del hablante con el objeto y la socialización del aprendizaje, el conocimiento de las estructuras lingüísticas formales del idioma, a fin de lograr el objetivo sobre el desarrollo de las habilidades comunicativas integrales al producir textos orales y escritos según la situación comunicativa y el contexto del hablante. (Cassany, 2009; Domínguez, 2010 y Rodríguez y Pérez (2017). 


\section{Estructura de la estrategia metodológica modelada}

Partiendo de las categorías emergentes que inciden en el problema investigado se modeló la estrategia metodológica con una estructura específica como parte de un modelo pedagógico teórico- práctico resultante de una investigación como precisan, Cruzata (2007) y De Armas y Valle (2013), la que se caracteriza principalmente por su:

\section{Carácter integrador.}

La propuesta se considera integradora debido a que está fundamentada en postulados teóricos para que, mediante la práctica, transformar una concreta realidad educativa. Es así, como se seleccionaron las teorías pertinentes específicas de las ciencias sociales (pedagogía, psicología) para establecer las respuestas, así como el plan de acción más adecuado para resolver la problemática del interés por el aprendizaje de la asignatura inglés en los estudiantes de la institución de estudio.

\section{Carácter sistémico.}

Para modelar la estrategia se escudriñó sobre la problemática, mediante el diagnóstico estudiantil y el contexto socioeducativo, donde se sondean aspectos normativos de la institución, las características psicológicas de los estudiantes, el entorno social, siendo estos los subsistemas del objeto de estudio, que se especifica en el sistema de clases.

\section{Carácter investigativo.}

La estrategia metodológica es substancialmente el resultado de un estudio que implicó los fundamentos de la investigación científica en el campo de las ciencias sociales. Se utilizaron métodos teóricos y prácticos para el desarrollo de la investigación académica. 
De esta manera, en la propuesta se presentan los métodos de enseñanza que incrementan la curiosidad por el saber, la investigación y el descubrimiento, que favorece a la formación de un alumno con habilidades independientes, pensamiento creativo, crítico y reflexivo.

\section{Carácter comunicativo.}

Además de fomentar el interés de los alumnos por la asignatura, la estrategia al plantear distintos métodos de enseñanza de la lengua desde escenarios de aprendizaje reales de la práctica social, ejercita el desarrollo de las habilidades comunicativas escritas y orales de la lengua inglesa. Mediante los métodos investigativos, socializadores, comunicativos, problematizadores, lúdicos, entre otros, los alumnos experimentan un nivel de motivación e interés superior en las clases.

\section{Misión}

La estrategia metodológica tiene la misión de mejorar el interés por el aprendizaje del Inglés por parte de alumnos de primer ciclo de la carrera de Administración de una universidad privada de Lima. Para esto, se busca que los docentes orienten el proceso de enseñanza-aprendizaje de manera efectiva, situando a los estudiantes como protagonistas de la actividad pedagógica y a la vez, consintiendo que desarrollen sus habilidades comunicativas en inglés de manera cooperativa y autónoma.

\section{Visión}

Se orienta la estrategia metodológica a favorecer el desarrollo del bilingüismo estudiantil en un ambiente de interés creciente por aprender más sobre el código de este idioma, así como de la cultura de los países de habla inglesa. Asimismo, se pretende ayudar con el desarrollo de la praxis docente y la mejora de las habilidades de la profesión, todo esto en beneficio de la población de estudiantes y de la mejora de la calidad educativa. 


\section{Objetivo general}

El objetivo general de la estrategia metodológica modelada es contribuir al desarrollo del interés por el aprendizaje de la asignatura de Inglés en los estudiantes de primer ciclo de la carrera de Administración. Para tal propósito, se requiere del compromiso del educador porque de su praxis pedagógica depende que el educando se interese por aprender y se cumplan este objetivo.

\section{Principios didácticos en los que se sustenta la estrategia metodológica}

En la propuesta modelada se incluyen con fluidez los principios didácticos argumentados por Vargas y Hernández (2006) y Álvarez de Zayas (1997), adaptados al objetivo de la investigación con la finalidad de orientar al educador en su desempeño a fin de lograr el aprendizaje esperado, como por ejemplo: el principio de sistematización de los contenidos, principio del carácter científico, principio de la relación entre la teoría y la práctica, principio de relación entre lo concreto y lo abstracto, principio de activación de conocimientos previos, principio de asequibilidad, principio del carácter consciente, principio de la solidez del conocimiento, y de la actividad independiente estudiantil, principio de vinculación entre lo individual y lo colectivo.

La aplicación de dichos principios en la clase le permite al docente guiar y orientar la enseñanza- aprendizaje de manera que integra y le da lógica interna, a las acciones que realizan el docente y los estudiantes, a la didáctica del contenido de forma integral que hace más accesible el proceso de asimilación, así como la producción de un nuevo conocimiento de manera significativa y consciente al alumno por el rol protagónico que toma en la aplicación y evaluación de su aprendizaje. 


\section{Categorías didácticas de la estrategia metodológica modelada}

En la estrategia modelada se toma la dirección del proceso educativo a partir de los postulados del enfoque sociocultural, cognitivo, y comunicativo propuesto por Roméu (2007), que integra los planteamientos aportados por otros especialistas como: y Addine (2015) y Álvarez de Zayas (2016), al destacar los componentes de la clase como célula esencial de la enseñanza- aprendizaje:

La categoría de entrada de la clase, es el problema que origina la contradicción entre lo conocido y lo nuevo por conocer en los estudiantes que debe ser estimulado a través del diálogo por el profesor.

El objetivo se identifica desde el problema y el logro esperado en los estudiantes. Ello requiere activar el interés por el aprendizaje de los conocimientos de la materia Inglés y el propósito es conseguir que en el proceso de enseñanza - aprendizaje los estudiantes estén motivados y puedan asimilar procesar y aplicar el contenido. El contenido abarca el sistema de conocimientos lingüísticos del idioma, las habilidades procedimentales y las actitudinales que son sistematizados a través del sistema de clases direccionadas a estimular un aprendizaje consciente y significativo en función de los intereses y necesidades del estudiantado.

La categoría método de enseñanza posee carácter sistémico, indicando el camino, para regular la praxis del profesor y de los alumnos por lograr las metas y fines. Se proponen los métodos investigativos, problémicos, y heurísticos que direccionan la interacción del proceso educativo en su correspondencia con la finalidad y el contenido a tratar. Su elección, ordenación y ejecución establece un espacio de interacción vital entre el alumno, el educador y el grupo, garantizando, la asimilación y comprensión de los contenidos de cada clase. 
Los medios o recursos didácticos se asumen como vía para lograr la objetividad del aprendizaje a fin de lograr que los alumnos asimilen y se interesen de manera consciente por el contenido idiomático. Desde los criterios de Castellanos et al. (2007), los medios ofrecen información audiovisual necesaria para potenciar la asimilación, el pensamiento abstracto, asumir posiciones, comprender la información y transformarla en el nuevo conocimiento, ejercitar las habilidades y apliquen lo aprendido en la tarea de aprendizaje.

La categoría evaluación se concibe como parte del proceso de aprendizaje, tiene la finalidad de controlar el grado de desarrollo de los alumnos, con el fin de intervenir tomando en cuenta las necesidades individuales. Se recomienda la aplicación de la evaluación diagnóstica, sumativa y la formativa, debido a que cada una exige del alumnado un conocimiento holístico y estimular las habilidades comunicativas y su comportamiento que lo orienta en el qué, cómo, para qué hacer y la toma de decisiones. Se pondera la evaluación formativa abordada desde el trabajo grupal e individual como parte de un mismo sistema, donde cada uno tiene su lugar conveniente en proceso educativo en el que se destaca el rol del docente, el de los alumnos y del grupo.

\section{El rol del docente.}

Constituye un profesional competente que guía y facilita mediante el diálogo el aprendizaje entre los educandos en un ambiente de asertividad con el fin de contribuir al interés y el desarrollo integral del estudiante, promoviendo la colaboración y el respeto (Tobón, 2013; Díaz y Hernández, 2010 y Castellanos et al, 2002). El educador en la clase debe cumplir las siguientes funciones: Función docente- metodológica: Se corresponde con la praxis del educador donde busca diseñar, ejecutar y evaluar el proceso educativo desarrollador para un aprendizaje significativo. Función orientadora: Circunscribe actividades que propicien que los estudiantes se auto-conozcan, a los otros y a su contexto; que desarrollen destrezas para lo aprendido, eficientemente lo ejerzan en sus proyectos de 
vida, entorno laboral, y afrontarlos plenamente; A manera general, el docente guía a los alumnos en el aprendizaje y en su etapa de evolución.

En este orden de ideas, el educador es un guía y mediador, del proceso educativo, creando adecuadas condiciones ante los contextos de aprendizajes, incentivando a que los alumnos valoren, opinen, razonen, socialicen ideas, y tomen posturas críticas, contribuyendo así, a desarrollar la personalidad en un contexto colaborativo y optimista, para alcanzar los fines de aprendizaje. Cabe destacar, que el educador como mediador, debe manejar la comunicación dialógica y pedagógica asertiva, para conseguir una asimilación consciente y activa del contenido y llevar a cabo las actividades de aprendizaje, partiendo de lo más simple a lo de mayor complejidad, dando prioridad al desarrollo desde lo menos complejo a lo más complejo, a fin de ejercitar las habilidades comunicativas. En su desempeño debe promover un ambiente adecuado para incidir en la adquisición de los conocimientos, y el desarrollo de habilidades, contribuyendo a la formación integral del alumno.

El rol del estudiante. El estudiante en el proceso educativo debe tener un rol activo, protagónico, y responsable, en la construcción de su propio aprendizaje, para construir el conocimiento, desde la asimilación de la información. Esto lo orienta y guía en el pensar antes de proceder a realizar la tarea de forma autorregulada, metacognitiva, y autoevaluando la congruencia de sus acciones en interacción con sus compañeros de manera respetuosa y solidaria.

En este sentido, debe ejercitar acciones que lo lleven a pensar, indagar, predecir y crear tareas renovadoras en cada momento y etapas del proceso, estableciendo los procedimientos y las acciones a realizar en la búsqueda del qué se debe aprender, qué utilidad tiene a través de la problematización del saber de manera dialéctica, lo cual lo orienta a conseguir aprendizajes significativos. Deben ser educandos interesados, 
motivados y responsablemente desarrollen su autoaprendizaje, partiendo de la valoración y reflexión. El educando debe tener conocimiento de sus deficiencias, capacidades, y fortalezas como aprendiz, y partiendo de allí poder autoevaluar la eficacia de sus avances.

Debe indagar, investigar y tener una actitud positiva frente sus desatinos, analizar sus éxitos y sus fallas; debe entender que el esfuerzo es esencial para alcanzar los resultados, y expectativas sobre su aprendizaje. De forma activa, participa en los procesos comunicativos y de cooperación que surgen en el grupo; siendo consciente de que él también aprende de ellos y comprende que los otros aprenden también de él. Igualmente, el alumno valora el aprendizaje, como parte intrínseca de su esencia y como vía para crecer intelectual, personal, moral social, y afectivo.

El rol del grupo. Constituye un grupo de estudiantes heterogéneos, con una propia identidad, constituida a raíz de las relaciones comunicativas que asumen metas, normas, códigos y fines comunes que son participados como parte del bien común en una dinámica grupal (Castellanos et al., 2002). En el grupo se desarrollan tareas que favorecen los interaprendizajes, que es la eficacia instrumental del proceso como tal, en la construcción de valores personales y de cualidades. Bajo estos criterios, el grupo tiene un rol decisivo en lo valorativo y axiológico por el aprender, se impulsa el trabajo individual y grupal como partes de un mismo sistema donde cada uno tiene su espacio y lugar, conveniente en el proceso de enseñanza- aprendizaje.

En el trabajo cooperativo y colaborativo pone en práctica acciones que se realizan como un medio de aprendizaje en el grupo donde aprenden el qué y cómo en interacción dialógica y la socialización a partir de la ayuda que se producen entre todos. En la clase debe propiciarse un ambiente de la interacción dialógica y con la participación mutua y respeto a fin de conseguir confianza y seguridad al producir los conocimientos y 
las habilidades comunicativas como se refleja en el siguiente esquema que representa el proceso de enseñanza - aprendizaje.

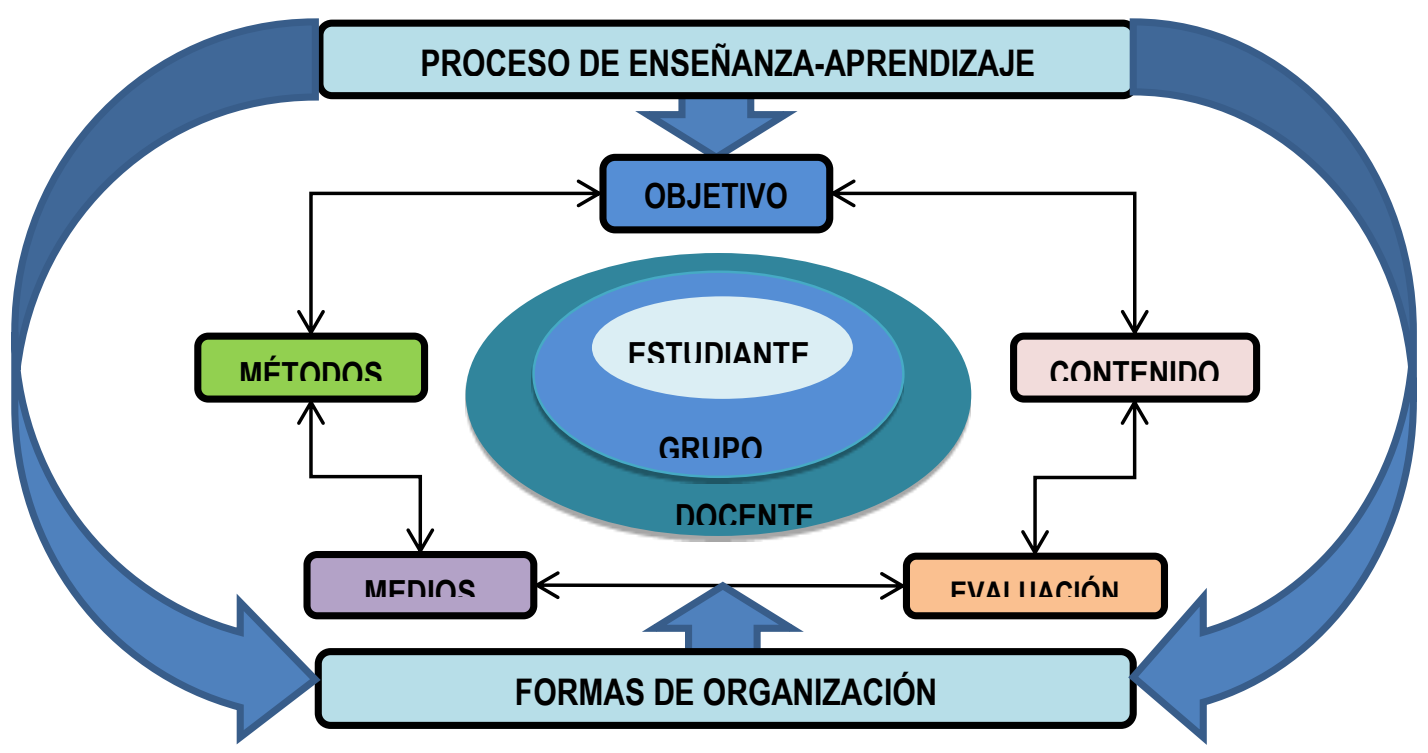

Figura 5.Componentes del proceso de enseñanza - aprendizaje. Fuente. Elaboración propia (2020).

\section{Exigencias de la actividad de aprendizaje.}

La actividad de aprendizaje es una categoría de gran valía en el desarrollo de la personalidad. Es así, que Brito (1987), señala que la actividad del aprendizaje es un proceso donde la persona satisface sus escaseces, se vincula con la realidad y adopta determinado comportamiento hacia la misma según sean sus motivaciones, intereses, y necesidades. Asimismo, González (2003), sostiene que la actividad del aprendizaje es un proceso donde la persona interactúa con el contexto incidiendo en él, también transforman a la propia persona.

Estos referentes teóricos, aseveran que es preciso comprender que entre el alumno y el objeto, media la actividad que se produce en interacción y comunicación, y los instrumentos como potenciadores de las capacidades y habilidades procedimentales. Según afirma Silvestre y Zilberstein (2011), la actividad de estudio que se realiza en la clase, 
entendida como un espacio cultural con exigencias específicas tiene como fin de conquistar el interés y la motivación de los educandos en la búsqueda activa del conocimiento y el desarrollo de las habilidades.

En la estrategia metodológica se propone que la actividad de estudio, para estimular el interés por el aprendizaje del idioma, se debe proceder metodológicamente atendiendo a los siguientes pasos: observación, motivación, comprensión, construcción, aplicación de lo aprendido, el autocontrol y la autoevaluación como se representa en la figura N. 6.

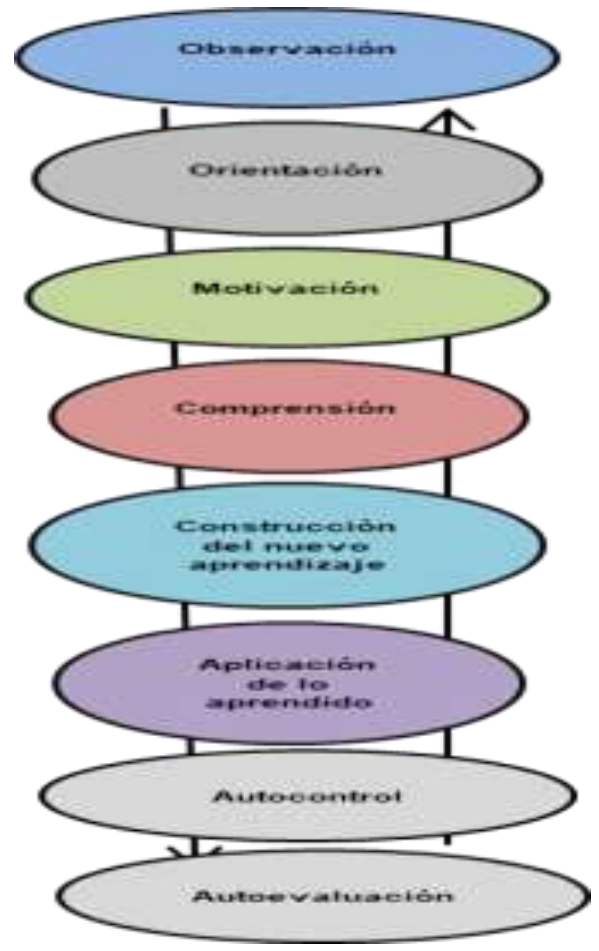

Figura 6. Pasos metodológicos de la actividad de aprendizaje. Fuente. Adaptado de Silvestre y Zilberstein (2011).

La estrategia propuesta sugiere atender en la clase los siguientes momentos metodológicos en la actividad de estudio para estimular el interés en los educandos por el aprendizaje del Inglés:

\section{Observación.}

Constituye un proceso intelectual consistente en examinar con atención el objeto para asimilar la información, procesarla, comprender y asumir postura. El docente debe 
aplicarla en su desempeño constantemente como procedimiento pedagógico para conocer cómo aprende cada uno para diagnosticar el estado real en el nivel de conocimientos y habilidades lingüísticas, constatar las fortalezas y las debilidades en la diversidad y tomar medidas oportunas.

\section{Orientación.}

La orientación es una función del docente en el proceso formativo, ya sea a nivel grupal de la clase o individual. La orientación en la enseñanza y aprendizaje debe proyectarse a través de una comunicación asertiva, debe ser clara, precisa hacia los objetivos y el contenido a tratar, cómo realizar la actividad y sobre todo el logro esperado por cada estudiante y su evaluación.

\section{Motivación}

La motivación es un estado psicológico que el docente debe conquistar a partir de las fortalezas y necesidades del alumnado para lograr los objetivos de la clase. La actividad comunicativa del profesor, el nivel de competencia y ejemplaridad se convierten en elementos motivacionales. El aprendizaje desarrollador requiere de una tarea retadora y atractiva que estimule la curiosidad, la indagación, la exploración y la investigación por conocer. Exige de variados procedimientos como la socialización, el diálogo, lo lúdico, y la colaboración en el trabajo grupal con el propósito de alcanzar aprendizajes significativos que puedan vincular lo aprendido en el idioma con su cotidianidad.

\section{Comprensión.}

Es un proceso que comprende la estimulación y creación mental por el que, partiendo de ciertos datos aportados por el docente, los estudiantes crean una imagen del mensaje que se explica, requiere de la conexión entre los conocimientos ya adquiridos con los nuevos a través de la concatenación de las ideas, acciones y operaciones que potencian el interés para realizar la actividad con éxito. Para lograrlo el docente debe demostrar con variados 
ejemplos el qué, cómo, para qué realizar la tarea y cómo se llevará a cabo la evaluación atendiendo a la diversidad del grupo y sus particularidades.

\section{Construcción del nuevo aprendizaje.}

Implica el proceso donde el estudiante desde su rol protagónico asimila, procesa, interpreta, comprende la información y produce el conocimiento individual y colectivo con sus iguales y aplica lo aprendido en la solución de los problemas idiomáticos orales y por escrito. Esta construcción se puede hacer de muchas formas, una de ellas es aprender haciendo, por ejemplo, si el objetivo es conocer nuevos vocablos con el fin de emplearlas en frases, oraciones o párrafos; si el objetivo es profundizar en un tema sobre las vacaciones, después de estudiado pueden dialogar o dramatizarlo contextualizándolo como que están en alguna playa eso los motiva e interesa y será una actividad significativa que seguramente siempre recordaran.

\section{Aplicación de lo aprendido.}

Hace referencia a que los educandos reconozcan el valor y la utilidad de los conocimientos adquiridos, su relación con el contexto y la vida y lo apliquen. El docente debe fomentar la ejercitación de lo aprendido complejizando la tarea de aprendizaje de lo fácil a lo difícil y en la medida que van avanzando, incorporar otros contenidos más complejos con la intención de favorecer su crecimiento integral. Al aplicar lo aprendido en las tareas en grupo se potencian los saberes, las habilidades comunicativas en la construcción de textos orales y por escrito según el contenido idiomático estudiado.

\section{Autocontrol}

Implica que el estudiante es consciente y posee la orientación para realizar la actividad de manera metacognitiva, sabe qué, cómo realizarla y qué acciones poner en marcha para resolver la tarea, por ello ejecuta el autocontrol de sí y controla el producto de sus compañeros. 


\section{Autoevaluación.}

La coevaluación y la autoevaluación son habilidades que facultan al estudiantado a valorar sus avances y fallas de forma individual y colectiva no solo en lo conceptual, sino en lo procedimental y actitudinal de forma consciente con nuevos retos.

\section{Característica de la secuencia metodológica de la clase}

Las actividades que realizan en la clase deben poseer una secuencia que transite de lo simple a lo complejo, y que de forma dinámica, sistemática, coherente y fluida facilite el desarrollo del conocimiento accediendo en los alumnos la asimilación y construcción de la información de manera actitudinal, conceptual, y procedimental. De tal forma, las actividades de aprendizaje y también las de evaluación propuesta quedarán engranadas con el interés por el aprendizaje en los varios momentos del proceso educativo, para promover el interés por el aprendizaje, mediante la secuencia de: observación, orientación, motivación, comprensión, construcción, aplicación, autocontrol y autoevaluación. (Tobón y Pimienta, 2010; Díaz y Hernández, 2010y Addine et. al; 2015).

La célula primordial del proceso pedagógico es la sesión de clase, donde el profesor guía, comunica, y muestra las actividades para conseguir el aprendizaje establecido en los distintos momentos didácticos, tomando en cuenta el grado de complejidad y donde los alumnos constaten, sus avances y logros, pudiendo ser en el inicio, desarrollo o cierre de la clase; activando el pensamiento y las habilidades investigativas en la resolución de problemas de la asignatura de inglés. Durante el inicio de la clase, el propósito es lograr obtener la atención del educando a partir de lo que conoce y conseguir fundar una relación inquebrantable entre el propósito de la sesión y los conocimientos previos. Para esto, se traza una situación problemática donde el docente y los alumnos puedan crear un diálogo fomentando expectativa por el nuevo conocimiento, usando la mayéutica. Durante el 
desarrollo de la clase, el profesor provoca la necesidad de la búsqueda de la información para resolver el problema de aprendizaje. Ello exige plantearles diferentes actividades a realizar de manera grupal o individual donde deben observar, analizar, hacer comparaciones y adquirir distintos roles, usa materiales y recursos previamente preparados para lograr la asimilación y comprensión del contenido por los educandos como protagonistas en este proceso. El rol del docente es de acompañamiento, comprobar constantemente los logros y las fallas presentadas mediante la observación y el diálogo a fin de reorientarlos. A continuación, se presentan algunas actividades de aprendizaje que muestran el accionar del docente desde la enseñanza colaborativa y desarrolladora que incide en el aprendizaje de las habilidades comunicativas:

\section{Ejemplos de tareas de aprendizaje.}

\section{Ejemplo 1: Live, work and study}

El objetivo de la actividad es que el alumno sea capaz de crear oraciones de forma positiva y negativa en el Presente Simple utilizando los verbos like, study, work y live. Para ello se propone la aplicación del método creativo y lúdico. El docente inicia saludando a sus estudiantes de manera entusiasta, muestra interés en saber cómo se encuentran sus alumnos, generando así un ambiente en donde el alumno se sienta apreciado y en confianza. El docente indica a los alumnos que van a realizar un juego. Divide el aula en dos grupos, y les pide que escojan un nombre divertido para su grupo. 

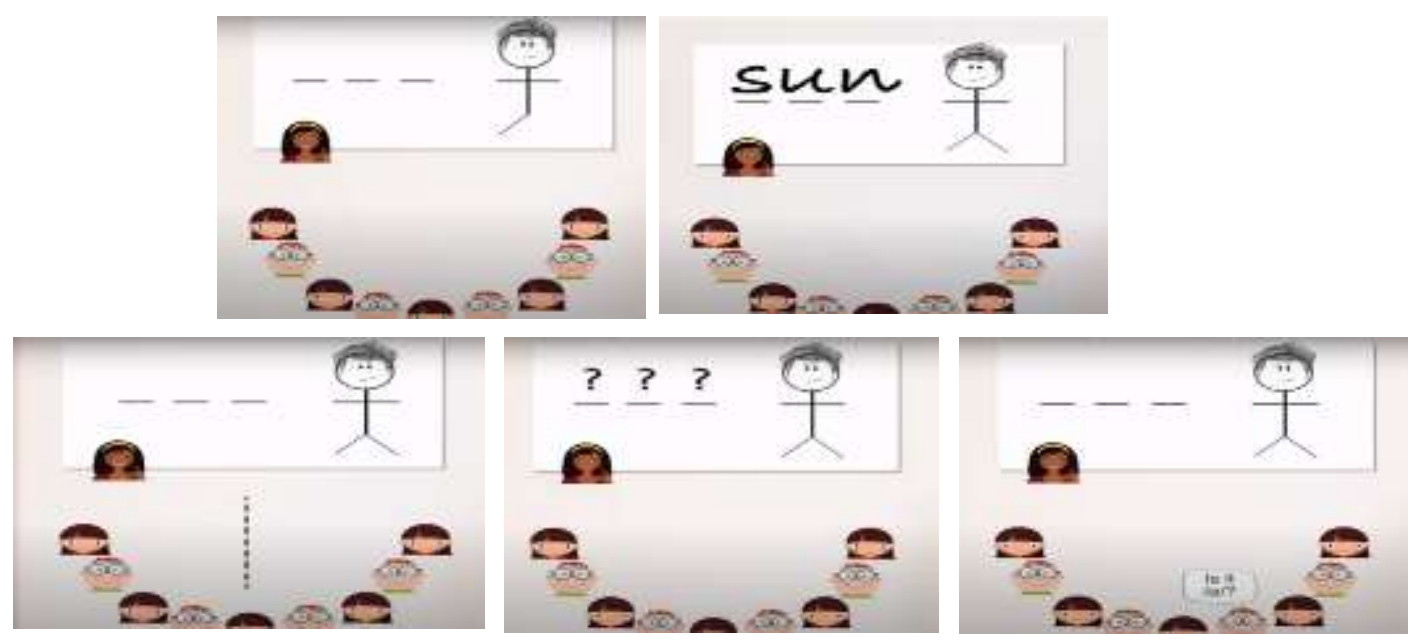

Figura 7. Adaptación del juego Hangman. Fuente. Elaboración propia (2020).

El docente proyecta imágenes y va explicando el juego. Les indica que tendrán que adivinar las letras de una oración de marea ordenada (adaptación del juego hangman) y que cada equipo tendrá una oportunidad de decir una letra antes de que se adivine la respuesta correcta. Dibuja un hombre con palitos a cada extremo de la pizarra, y les coloca el nombre que cada grupo eligió, y les indica que cada vez que un participante diga una letra incorrecta, el docente irá borrando partes del cuerpo del hombre de palitos que dibujó. El grupo que adivine la oración será el ganador. Luego, coloca las líneas en la pizarra de modo que los alumnos adivinen las letras de la oración. Para hacer la actividad un poco más amena y divertida, el docente podría crear un poco de suspenso, por ejemplo, cuando le digan una letra, pretender que sí es, pero antes de escribirla voltearse y decir que no, y de este modo la actividad se hace divertida. Una vez que se descubra la oración, el docente escribe en la pizarra: I LIKE ROCK MUSIC

Partiendo de esa oración, el docente les pregunta si ellos creen que esa oración es verdadera con respecto a él: What do you think? Is this sentence true for me? Los estudiantes posiblemente respondan: Yes, it is/No, It isn't. Después que los alumnos den su respuesta final, el docente escribe en la pizarra: I don't like rock music (no me gusta la 
música rock). Y les pregunta: Is this sentence positive or negative? (¿Esta oración es positiva o negativa?). Buscando de esta manera que los alumnos indiquen que es una oración negativa. Seguidamente, el docente muestra flashcards que contienen verbos (like, have, live, work y study) seguidos de una imagen. El profesor toma un flashcard que contiene el verbo have y la imagen de un carro, lo observa, lee el verbo y señala el auto provocando que los estudiantes identifiquen la imagen y digan: a car. Teniendo de esa manera la frase have a car. Seguidamente muestra un flashcard que contiene el verbo like y la imagen de una pelota de football, sigue el mismo procedimiento, provoca que sus alumnos indiquen que dicha frase sería: like football.

Y así sucesivamente, conforme va mostrando los flashcards, provoca que los educandos activen los conocimientos previos y vayan identificando las frases. Una vez identificadas, el docente modela la pronunciación hasta que ellos no solo identifiquen todas las frases, sino que se sientan seguros de pronunciarlas bien.

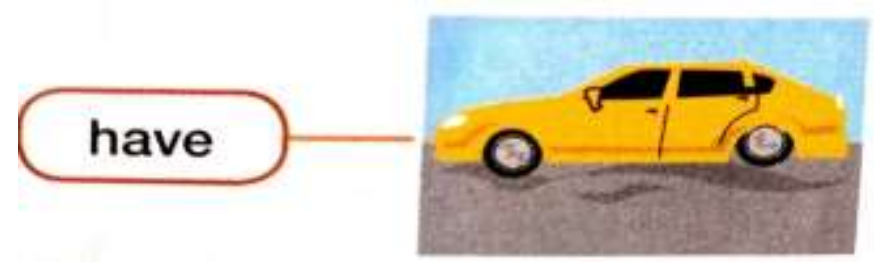

Figura 8.Flashcards.Fuente. Elaboración propia (2020).

A continuación, solicita a cinco educandos que elijan un flashcard y expresen oralmente una oración con sentido negativo. En la medida que cada estudiante expresa la oración, se escribe en la pizarra y entre paréntesis, el nombre del estudiante que participó.

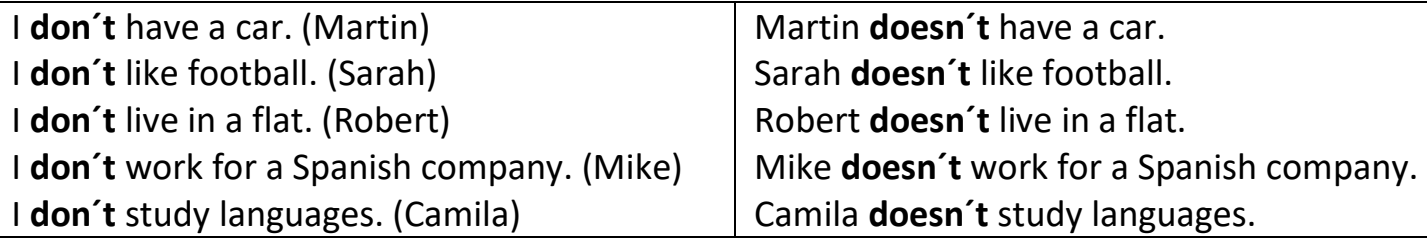

Martin doesn't have a car. Sarah doesn't like football. Robert doesn't live in a flat. Mike doesn't work for a Spanish company. Camila doesn't study languages.

Figura 9.Ejemplo de anotación en la pizarra. Fuente. Elaboración propia (2020). 
Seguidamente, al costado de cada oración, el docente inicia una nueva oración con el nombre del alumno que participó; y para escribir las siguientes oraciones pide la participación del alumnado. Y de esta manera provoca que ellos generen sus propios conceptos respetando las reglas gramaticales para formular oraciones con sentido negativo según la primera y la tercera persona del singular o plural. Este concepto se reforzará a través de un ejercicio y una actividad:

Ejercicio 1: Ejercicio del libro, donde los alumnos tienen una lista de oraciones, y se les pide que le pongan un visto bueno a aquellas que son ciertas para ellos y formulen oraciones con sentido negativo con aquellas que no son ciertas. Por ejemplo: 1.- I like Italian food $\sqrt{ } 2$.- I have a sister. I don't have a sister.3.- I study English $\sqrt{ } 5$.- I work in an office. I don't work in an office.

\section{Actividad:}

El docente reparte una hoja en blanco a todos los alumnos y proyecta una tabla, la cual les pide copien en su papel. Una vez listo, el docente indica a los alumnos que completen la ficha en la columna en donde dice "Me", con un visto si la respuesta es positiva o con una " $\mathrm{x}$ " si la respuesta es negativa. Pasado el tiempo indicado les indica que deben intercambiar sus hojas para que su compañero complete la columna "my classmate". Una vez listo, los estudiantes devuelven la hoja a sus compañeros para empezar con la actividad.

\begin{tabular}{|l|l|l|}
\hline \multicolumn{1}{|c|}{ Activity } & \multicolumn{1}{|c|}{ My classmate } & \\
\hline Like volleyball & $\checkmark$ & Xe \\
\hline Like romanticmusic & $\checkmark$ & $\checkmark$ \\
\hline Live in a big house & $\checkmark$ & $\mathrm{x}$ \\
\hline Live in the centre of the city & $\mathrm{x}$ & $\checkmark$ \\
\hline Work for a small Company & $\mathrm{x}$ & $\mathrm{x}$ \\
\hline Work in an office & $\mathrm{x}$ & $\checkmark$ \\
\hline Study French & $\mathrm{x}$ & $\mathrm{x}$ \\
\hline
\end{tabular}

Figura 10.Tabla de actividad. Fuente. Elaboración propia (2020). 
El docente indica que los alumnos deberán escribir oraciones con la información que tienen en la tabla para lo cual brinda 2 ejemplos a partir de los cuales explica el uso de "and" y "but": 1.- She likes volleyball but I don't like volleyball. 2.- She likes romantic music and I like romantic music.

Mientras los estudiantes escriben sus oraciones, el docente pone música de fondo con el objetivo de favorecer el aprendizaje en un ambiente de aprendizaje positivo, donde el alumno disfruta del proceso de aprendizaje. Con respecto al docente, éste monitorea el trabajo de sus alumnos y apoya a los alumnos que presentan dificultad. Terminado el tiempo establecido, y con el objetivo de evitar la monotonía, el docente designa a cada alumno un número y pide que se levanten de su sitio y formen parejas con el alumno que le haya tocado el mismo número que a él. Una vez emparejados, les da unos minutos para que corrijan mutuamente sus oraciones.

A continuación, se le orienta algunos alumnos, que escriban sus oraciones en la pizarra. Les pide que en conjunto corrijan los posibles errores recurriendo a los conceptos tratados, con ello la actividad se centra en el estudiantado, quienes serán los que identifican los logros, los errores y deberán corregirlos; el docente actúa solo como un guía en el proceso. En este punto, los alumnos ya dominan el concepto de formular oraciones negativas para la primera y tercera persona y también lo han practicado. Se le solicita un educando que exprese una oración que sea verdadera para él, utilizando cualquiera de los verbos trabajados en la sesión (like, work, live and study). El docente pronuncia la oración expresada por el estudiante, agrega su propia oración y le pasa una pelotita a otro educando para que continúe con ejercicio. El usar la pelotita para indicar quién debe proseguir provoca curiosidad y expectativa haciendo el ejercicio más ameno, activa la atención por su turno y en general es un juego didáctico donde aprenden en un espacio de satisfacción y de ejercitación de lo aprendido. 
Estudiante 1: I don’t like chocolate.

Estudiante 2: He doesn’t like chocolate. I don't study French.

Estudiante 3: She doesn`t study French. I don`t live in a big house.

Para concluir la sesión el docente realiza la retroalimentación de la clase en donde resalta las fortalezas y debilidades. Asimismo, el docente proyecta un formato y los alumnos pondrán en una hoja dicho formato y pondrán un visto bueno al porcentaje que mejor describiría la oración que se les presenta. Pasado el tiempo, les pide que reflexionen sobre esta autoevaluación que acaban de realizar y los motiva a investigar un poco más sobre lo aprendido en la sesión con la finalidad de seguir aprendiendo y mejorando.

\begin{tabular}{|l|l|l|l|l|}
\hline & $\mathbf{( 2 5 \% )}$ & $\mathbf{( 5 0 \% )}$ & $\mathbf{( 7 5 \% )}$ & $\mathbf{( 1 0 0 \% )}$ \\
\hline $\begin{array}{l}\text { I know phrases with have, live, like and } \\
\text { study. }\end{array}$ & & & & \\
\hline I can write positive sentences. & & & & \\
\hline I can write negative sentences. & & & & \\
\hline I participate actively during the lesson & & & & \\
\hline I respect my classmates. & & & & \\
\hline
\end{tabular}

Figura 11.Tabla para cierre de actividad. Fuente. Elaboración propia (2020).

\section{Ejemplo 2: Buying things}

Se propone la utilización del método socializado recurriendo a la dramatización como herramienta didáctica en torno al tema "buying things" (Comprando cosas). En la sesión de clase, el objetivo consiste en que los alumnos creen el logo y nombre de su tienda, escojan los productos que deseen vender, le pongan un precio competitivo y a través de un diálogo pretendan ser un cliente o un vendedor de una tienda.

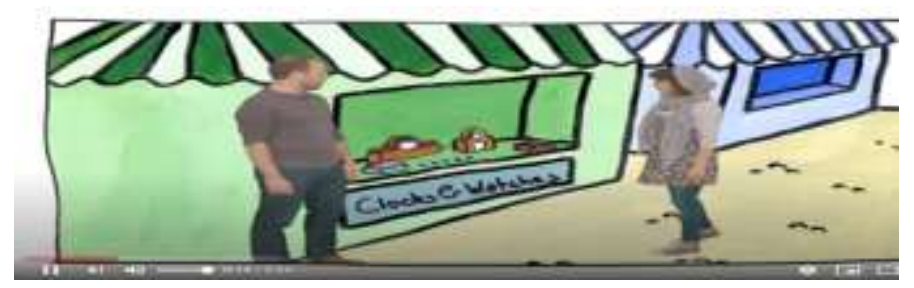

Figura 12.Video de motivación sobre lenguaje para usar al comprar. Fuente. Elaboración propia (2020). 
El docente inicia la sesión de clases con una comunicación asertiva, a fin de crear un clima psicológico adecuado en el aula para que sus alumnos se sientan en confianza. Una vez logrado esto, se les indica observar un video y les orienta el objetivo. El docente muestra solo los 36 primeros segundos del video (https://www.youtube.com/watch?v=9nVKK0O1MR4\&t=50s), donde se aprecia que un cliente realiza la compra de un producto. Al finalizar el video, el docente comienza con las siguientes pregunta: Whois he? (¿Quién es él?), Is he a waiter? (¿Es un mesero?), Is he a police officer? (¿Es un policía?). El docente continúa preguntando hasta lograr que uno de sus alumnos indique que el hombre es un vendedor (sales assistant/shop assistant/salesperson). Empieza preguntando por el hombre puesto que en la unidad anterior revisaron sales assistant. A continuación, el docente señala a la mujer y les pregunta. Who is she? (¿Quién es ella?). El docente escucha entusiastamente las respuestas de sus alumnos y en caso ninguno de ellos logre dar con la respuesta, los ayuda realizando otra pregunta que contiene la respuesta: Is she a customer? (¿Es una cliente?), buscando así que los alumnos identifiquen al vendedor y cliente.

Seguidamente, el docente les pregunta a los alumnos: Where are they? ¿Dónde se encuentran?), con la finalidad de que los alumnos respondan: In a market (en un mercado); continúa preguntando: What does the costumer buy? (¿Qué es lo que compra la cliente?), con la finalidad de que los alumnos respondan: A clock (un reloj); y por último pregunta: How much is the clock? (¿Cuánto cuesta el reloj?), la finalidad es que respondan: 10 pounds. Una vez que los alumnos han identificado la situación comunicativa, y a las personas que intervienen en esta interacción, el docente indica a los estudiantes que el objetivo de dicha clase será que ellos realicen una dramatización en donde actuarán como un cliente o un vendedor siendo capaces de utilizar el lenguaje adecuado. Captada la atención de los estudiantes, el docente presenta el vocabulario. Utiliza objetos reales con la 
finalidad de hacer que la experiencia de aprendizaje sea más memorable para el alumno. El docente muestra distintos objetos que trajo a la clase y les pide a los alumnos que la ayuden identificándolos:

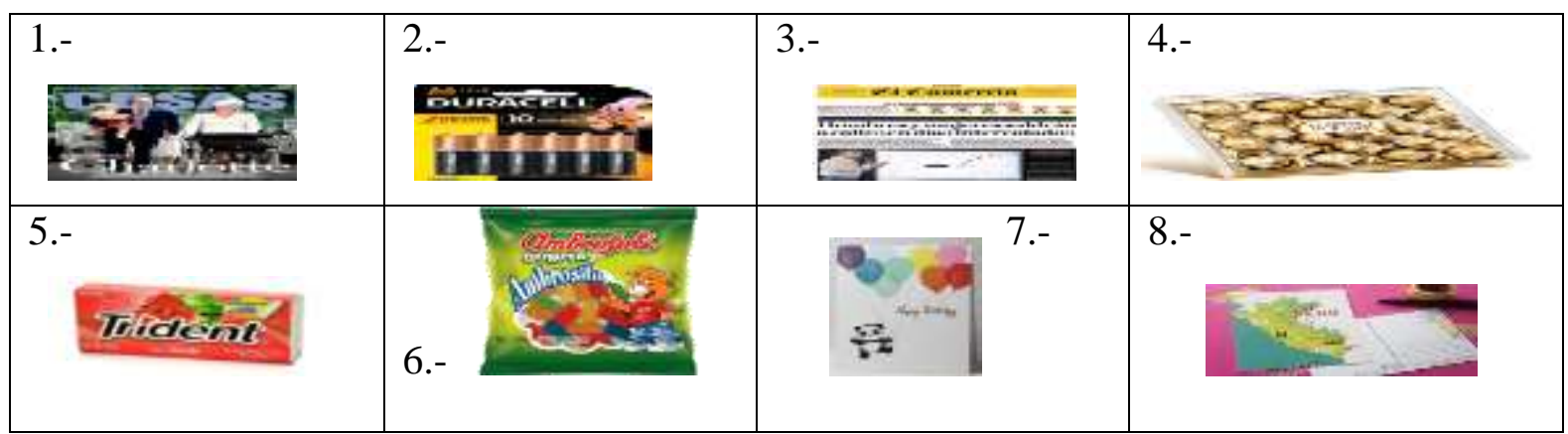

Figura 13.Identificación de objetos. Fuente. Elaboración propia (2020).

Con el fin de estimular los conocimientos previos, estos identifican primero aquellos objetos que reconocen y posteriormente, el docente apoya indicando el nombre de los restantes artículos. Luego se le modela la pronunciación articulatoria de cada objeto hasta que los alumnos no solo identifiquen el nombre de todos, sino que también tengan la confianza de haber comprendido y pronunciarlos correctamente. Una vez logrado el ejercicio, se les invita a realizar una actividad del libro que reforzará el aprendizaje del vocabulario presentado y que utilizarán en otros ejercicios de la clase. Seguidamente, el docente escoge dos objetos y les pregunta cuál es el costo aproximado del artículo, proyecta en la pantalla la pregunta que será respondida por los educandos y después de escucharlos, proyecta la respuesta:
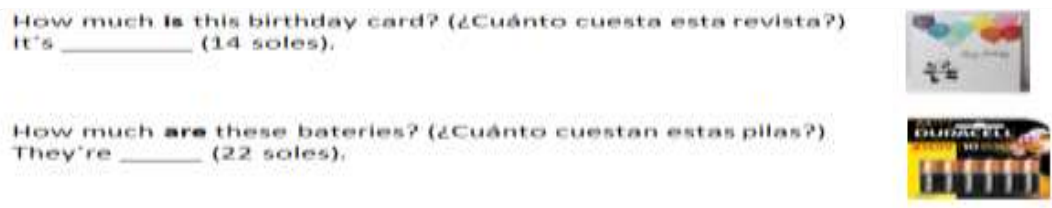

Figura 14. Valor de los objetos. Fuente. Elaboración propia (2020). 
A continuación, el docente selecciona una revista y con el fin de activar el conflicto cognitivo, les dice... si la pregunta es: How much is...? o How much are...? y al recibir la respuesta, le vuelve a preguntar: why? (¿Por qué?); provocando que los alumnos recurran a sus conocimientos previos, ejerciten los saberes que tienen en su mente. En todo momento se mantiene proyectando las primeras dos interrogantes, de modo que los alumnos las observen, las analicen y expresan sus argumentos. Luego les dice que indiquen cómo sería al preguntar por una sola cosa (singular), la pregunta sería How much is...? y para dos o más cosas (plural) la pregunta sería How much are...?.Al obtener la respuesta correcta, se proyecta en la pantalla: How much is this magazine?, e insiste en que los alumnos le den un precio aproximado de dicho objeto. El docente continúa y realiza la pregunta; cuál sería la interrogante correcta para dos objetos más. Reforzando de este modo la forma correcta de preguntar en el número singular y en el plural.

A continuación, se le solicita a los alumnos que se dirijan al libro y observen las cuatro fotos que se muestran en la unidad. Le solicita que se centren en el uso de las palabras que están en negrita (this, that, these, those) y lo ayuden a completar el cuadro que tiene proyectado en la pantalla. Provocando a través de las imágenes y las interrogantes del libro, que expresen sus propios conceptos y el profesor mediando en la tarea si es necesario.

\begin{tabular}{|l|l|l|}
\hline & \multicolumn{1}{|c|}{ Here $\downarrow$} & \multicolumn{1}{c|}{ There $\rightarrow$} \\
\hline Singular & (this) & (that) \\
\hline Plural & (these) & (those) \\
\hline
\end{tabular}

Figura15.Cuadro de this, that, these, those. Fuente. Elaboración propia (2020).

El docente, completará el cuadro de acuerdo a las respuestas de los alumnos, y formulando preguntas adicionales que refuercen el concepto del uso de This, that, these, those y fomentando el trabajo grupal en los educandos con el fin que desarrollen el diálogo, la socialización de ideas, tomen acuerdos y cumplan exitosamente el ejercicio. 
Una vez concluido la actividad grupal, el docente mostrará una imagen que reafirmará el concepto inferido por los alumnos.

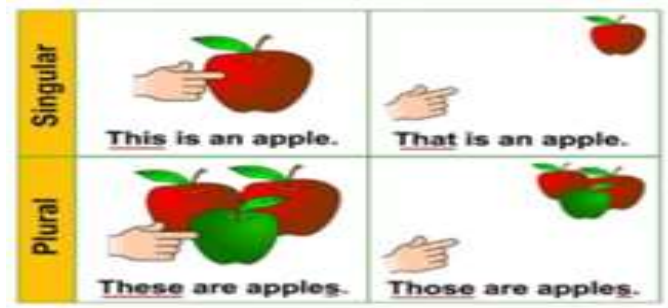

Figura16.Uso de This, that, these, those. Fuente. Elaboración propia (2020).

Posteriormente, pasarán a realizar una actividad del libro en donde los alumnos pondrán poner en práctica el uso de los pronombres demostrativos en mención. Los conceptos trabajados hasta este momento ayudarán para el momento en que los alumnos dialogan. El docente solicita al alumnado que cierren sus libros puesto que van a escuchar el audio de dos conversaciones que se realizan en una tienda, para lo cual les solicita recuerden cuáles son los objetos (el audio contiene vocabulario y pronombres demostrativos que se revisó al inicio de la sesión) que compran los clientes: You are going to listen to two conversations in a shop. What do the customers buy?

Una vez terminado el audio, se le asignan dos minutos para que comparen sus respuestas con sus compañeros. Pasado el tiempo, comparten sus respuestas con sus iguales, emiten sus criterios, opiniones y el profesor interviene si es necesario. Luego se les orienta abrir sus libros en la página donde se encuentra la conversación que escucharon y les indica que volverán a oír el audio, pero esta vez tendrán que completar los precios de los productos: Write the prices in these conversations. Al igual que en la primera vez antes de confirmar las respuestas con el docente, comparan y aplican la coevaluación con sus compañeros. Y luego con su pareja practican las conversaciones. 
Seguido el docente indica cerrar los libros y proyecta en la pantalla variadas interrogantes y frases (extraídas del audio que escucharon) que se pueden utilizar en el contexto de una tienda. A un lado coloca las preguntas o frases que pudiera utilizar un vendedor y al costado coloca aquellas que pudiera utilizar un comprador. Pero deja espacios en blanco los educandos deben lo completen. Una vez completada esta actividad, el docente modela la pronunciación y entonación de dichas preguntas y expresiones asegurándose de que sus alumnos se sientan seguros al expresarse y concluyen con una dramatización sobre la compra de un objeto.

En la que un alumno es un cliente y el otro es el comprador con ello enfatizan las habilidades orales. A estas alturas, los alumnos han ampliado el vocabulario y pueden formular preguntas para consultar el precio de objetos, y están familiarizados con las expresiones que se emplean en una tienda. Luego de la preparación, iniciarán la dramatización en la que tendrán que simular ser un cliente o un vendedor en una tienda. Se les precisa que serán evaluados por su desenvolvimiento, pronunciación, uso de la gramática, colaboración e interacción con sus compañeros. Durante la actividad, el docente supervisa, corrige, guía, orienta y motiva a los estudiantes.

\section{Dramatización:}

Paso 1: Formar parejas.

Paso 2: Docente reparte una hoja en blanco, plumones, y pide que de forma muy creativa plasmen el nombre o logo de su tienda.

Paso 3: Un alumno de cada tienda se acercará al escritorio del docente y seleccionará 5 objetos que deseen vender en su tienda (las opciones forman parte del vocabulario revisado en dicha sesión, o aprendidos en sesiones anteriores).

Paso 4: En la parte posterior de cada objeto, colocarle un precio acorde al mercado. 
Paso 5: El docente indica que la mitad de las tiendas estarán cerradas. A cada integrante de aquellas tiendas cerradas, le entrega una lista con el nombre de 3 objetos que tendrán que comprar en alguna de las tiendas. Y les pide que apunten el precio de los objetos que compran y al final sumen el total que gastaron. Mientras que, a los compradores, les pide que lleven la cuenta de los objetos que venden y al final sumen el total de sus ventas. El docente da inicio a la actividad, manteniendo la conversación proyectada en la pantalla como apoyo para aquellos que lo necesiten.

Paso 6: Pasado el tiempo establecido, las tiendas cerradas ahora estarán abiertas y los integrantes de las tiendas abiertas pasarán a ser clientes a quienes se les entrega una lista de 3 objetos que deberán comprar.

Paso 7: En la hoja donde plasmaron el nombre/logo de su tienda, los estudiantes colocaran el monto total que obtuvieron, por sus objetos vendidos, y lo pegarán en la pizarra (docente les brinda limpia tipo para ello). De este modo todos podrán ver qué tienda tuvo mayores ingresos, y será la que el docente nombre como ganadora; indicando que su éxito tal vez se debió a la calidad de sus productos, a sus buenos precios o tal vez a un buen servicio por parte de los vendedores. Conceptos claves para negocios exitosos. Para finalizar la sesión, el docente felicita a todos los alumnos por su creatividad en la creación del nombre/logo de sus tiendas y por la interacción grupal. E inmediatamente procede a realizar la retroalimentación, para consolidar las habilidades comunicativas aprendidas, destacando los aciertos y desaciertos. Pregunta de manera grupal: ¿Qué aprendimos a través de esta dramatización?

En resumen, con los ejemplos expuestos anteriormente se destaca la función mediadora del docente al planificar las actividades en función de conseguir el objetivo de la sesión que es fortalecer el pensamiento, el lenguaje y la comunicación del estudiantado. Con ello observa y diagnostica como asimilan, procesan y actúan los estudiantes en el 
trabajo en grupo, para darle el tratamiento persono lógico y así alcanzar el desarrollo de las destrezas y conocimientos. La secuencia metodológica propuesta ayuda a construir un ambiente reflexivo, crítico, proactivo, investigativo, y creativo, para responder a una problemática que activa la motivación y el interés por aprender. Durante el cierre de la sesión, el educador debe promoverla autorreflexión, autoevaluación, y la metacognición a nivel conceptual, actitudinal y procedimental, de lo aprendido y aplicado en las diferentes actividades de aprendizaje. La evaluación debe darse de manera integral, para que los alumnos valoren y reconozcan su avance logrado y el educador tome decisiones para el soporte de los que no lograron el objetivo propuesto como precisan Addine (2013), y Tobón (2017).

\section{La secuencia metodológica en la clase, debe promover:}

La motivación por el aprendizaje de los nuevos conocimientos como eje de partida para estimular la observación, la comprensión, la atención y el interés de los alumnos. Diagnóstico de los conocimientos previos de manera completa, tomando en cuenta lo conceptual, actitudinal y procedimental. Selección de diferentes estrategias de la enseñanza problémica y del enfoque por competencias, para generar curiosidad en los alumnos; así como, métodos que faciliten una participación activa como: investigativos, problémicos, heurísticos, lúdicos y creativos. Estimular actividades que causen en los alumnos: conflicto, cognitivo, al encontrarse situaciones problémicas donde se tiene limitada información y se amerita la solución. El alumno debe ser protagonista durante todo momento construyendo su propio aprendizaje. Debe emplear lo aprendido al enfrentar una nueva situación problémica, como resultado de un proceso metodológico eficiente de enseñanza y aprendizaje. El educador debe proponer actividades que demanden la aplicación de los nuevos conocimientos adquiridos. Además, debe considerar estrategias de 
evaluación, coevaluación y metacognición formativa del progreso de los alumnos, valorando su área cognitiva, actitudinal, y procedimental, de forma individual y grupal.

\section{Propuesta de talleres pedagógicos a los docentes}

Durante el diagnóstico de campo se evidenció deficiencias en los docentes al orientar la enseñanza-aprendizaje del idioma Inglés.

Ante a esta problemática y con el propósito de ayudar a su preparación teórica y didáctica se propone realizar talleres de capacitación pedagógica con la intención de ayudar a reforzar el dominio de los métodos, procedimientos, medios didácticos y las actividades de aprendizaje a partir de los fundamentos del aprendizaje desarrollador fin de debatir, discutir, y reflexionar sobre las exigencias teóricas y didácticas de la actividad de estudio tanto en lo cognitivo, afectivo emocional. Se proyectarán los talleres demostrando los contenidos a través de situaciones comunicativas a partir del nivel fonológico, lexical, morfológico y sintáctico del idioma Inglés en la clase a fin de que los educandos alcancen el nivel de conocimientos y el desarrollo de habilidades comunicativas integrales acorde a las exigencias de la universidad. A continuación, se presenta el diseño de los talleres de capacitación docente.

Tabla 3.

Propuesta de talleres de capacitación metodológica orientada a los docentes.

\begin{tabular}{|c|c|c|c|c|}
\hline Tema del taller & Objetivo & Campo temático & Actividades & Referencias \\
\hline $\begin{array}{ll}\text { Fundamentos } & \\
\text { teóricos } & \text { del } \\
\text { aprendizaje } & \text { del } \\
\text { idioma inglés } & \end{array}$ & $\begin{array}{l}\text { Analizar los sustentos } \\
\text { teóricos del aprendizaje del } \\
\text { idioma inglés y su influencia } \\
\text { en el proceso de formación } \\
\text { de los estudiantes. }\end{array}$ & El aprendizaje & $\begin{array}{l}\text { Dinámica, trabajo } \\
\text { grupal, lectura de } \\
\text { compendio, } \\
\text { plenaria. }\end{array}$ & $\begin{array}{l}\text { Rubinstein (1977), } \\
\text { Vygotsky (1979), } \\
\text { Piaget (1981), } \\
\text { Ausubel (1983), } \\
\text { Castellanos et al, } \\
\text { 2007; González, } \\
\text { 2008; Rico et al, } \\
\text { 2013, Mora, 2017. }\end{array}$ \\
\hline $\begin{array}{l}\text { Fundamentos de la } \\
\text { evaluación como } \\
\text { categoría didáctica } \\
\text { de la clase }\end{array}$ & $\begin{array}{l}\text { Profundizar en los referentes } \\
\text { teóricos de la evaluación } \\
\text { formativa, como categoría } \\
\text { didáctica, dentro del proceso } \\
\text { de enseñanza de la } \\
\text { asignatura inglés. }\end{array}$ & La evaluación & $\begin{array}{l}\text { Dinámica, trabajo } \\
\text { grupal, mapa } \\
\text { mental, exposición } \\
\text { de actividades } \\
\text { modelo y plenaria. }\end{array}$ & $\begin{array}{lr}\text { Tobón, } & 2013 ; \\
\text { Velázquez, } & 2014 ; \\
\text { Addine } & 2013 ; \\
\text { Álvarez de } & \text { Zayas, } \\
2016 . & \end{array}$ \\
\hline
\end{tabular}

Fuente: Elaboración propia (2020). 


\section{Taller $\mathbf{N}^{\circ} 1$.}

\section{Título: El aprendizaje del idioma Inglés}

Objetivo: Analizar los sustentos teóricos del aprendizaje del idioma inglés y su influencia en el proceso de formación de los estudiantes.

\section{Introducción.}

¿Qué importancia tiene el idioma inglés? ¿Qué perspectivas teóricas del aprendizaje del inglés se conocen? ¿Por qué es importante conocer los fundamentos teóricos del aprendizaje del inglés? ¿Cómo motivar el interés en los estudiantes por el aprendizaje del inglés?

\section{Desarrollo.}

Se comienza la capacitación con una dinámica donde todos con música de fondo vayan caminando y moviéndose alrededor del espacio haciendo contacto visual con sus colegas, a la indicación del facilitador deben tomar de la mano a la persona más cercana, entre los dos en una conversación responder las preguntas de la introducción y se repite esto, para que por lo menos cada uno comparta dos opiniones, la música se puede ir variando, para romper el hielo y motivar a los docentes a la participación activa.

Luego de la actividad, se realiza una plenaria, donde cada participante compartirá la respuesta a las preguntas que recibió de sus compañeros y la propia de forma concreta, y el facilitador retroalimenta precisando con profundidad y fundamentos teóricos las interrogantes. Posteriormente, se les entrega un material de apoyo, que contiene un compendio sobre los sustentos teóricos del aprendizaje del idioma inglés y su influencia en el proceso de formación de los estudiantes, que deben analizar y luego exponer por grupos. 


\section{Evaluación.}

Cada equipo de trabajo expondrá los fundamentos teóricos del aprendizaje del inglés, de forma sencilla, y luego cómo dichos sustentos se pueden aplicar concretamente en las clases. Para finalizar, se hace el cierre, compartiendo experiencias de la actividad.

\section{Duración.}

90 minutos

\section{Competencia.}

Conoce los fundamentos del aprendizaje del inglés

\section{Capacidad}

Emplea estrategias y procedimientos para fomentar el interés por el aprendizaje del inglés

\section{Conocimientos}

Emplea estrategias heurísticas e investigativas para mejorar el proceso de enseñanzaaprendizaje del inglés y el interés por este.

\section{Taller $\mathbf{N}^{\circ} 2$.}

\section{Título: Evaluación como categoría didáctica de la clase}

Objetivo: Profundizar en los referentes teóricos de la evaluación formativa como categoría didáctica, dentro del proceso de enseñanza de la asignatura inglés.

\section{Introducción.}

¿Qué rol cumple la evaluación en el aprendizaje del idioma inglés? ¿Cuáles son los tipos de evaluación de los aprendizajes? ¿Por qué es importante realizar la evaluación del aprendizaje del Inglés? ¿Cómo motivar el interés en los estudiantes por el aprendizaje del inglés mediante la evaluación? 


\section{Desarrollo.}

Se comienza la capacitación con una dinámica llamada responde con imágenes, consiste en que los docentes en grupos, van a realizar un mapa mental, utilizando diferentes materiales, imágenes y colores, donde simbolicen las respuestas a las preguntas formuladas en la introducción, para esto se dará un tiempo apropiado de aproximadamente 35 minutos, cada equipo tendrá un número que lo identifique. Al finalizar el tiempo, con un dado grande, se sorteará el equipo que le toca la participación, y así irán participando cada uno, explicando el significado de las imágenes en el mapa mental y el desarrollo de las interrogantes. Luego el facilitador, concretará las ideas y profundizará en referencia al tema de la evaluación en el aprendizaje del idioma, y estrategias para aplicarla en las clases, y que más que motivo de nervios para los docentes fomenten el interés por el aprendizaje y el logro de metas.

\section{Evaluación.}

Cada equipo de trabajo señalará en plenaria los elementos positivos, interesantes y por reforzar sobre la actividad. Para finalizar, se hace el cierre, compartiendo experiencias de la actividad.

\section{Duración.}

90 minutos

\section{Competencia.}

Conoce los fundamentos de la evaluación del aprendizaje del inglés

\section{Capacidad}

Emplea estrategias y procedimientos para fomentar el interés por el aprendizaje del inglés mediante la evaluación de los aprendizajes.

\section{Conocimientos}

Emplea estrategias heurísticas e investigativas para llevar a cabo el proceso de evaluación de los aprendizajes, en las clases. 


\section{Sugerencias para la aplicación de la propuesta modelada}

Con el fin de introducir en la práctica pedagógica la estrategia metodológica propuesta se sugiere cumplir con los siguientes momentos que garantizarán sensibilizar a los docentes sobre sus fundamentos teóricos y metodológicos a fin de transformar la clase:

Primero. Reunión con los directivos de la universidad para informarles sobre los argumentos teóricos y didácticos que sirve de base a la estrategia propuesta para la mejora del interés por el aprendizaje del idioma en estudiantes de primer ciclo de la carrera de Administración de una universidad privada de Lima.

Segundo. Reunión con el colectivo pedagógico del área disciplinar de Inglés para reflexionar sobre los fundamentos y como prioriza las normativas de la concepción curricular y las indicaciones de la Ley Universitaria N.30220 (2014).

Tercero. Argumentar la necesidad de la planificación, organización y dosificación de los contenidos de las unidades, así como de las sesiones pedagógicas con el propósito de que favorezcan los conceptos, valores, capacidades, y habilidades que se desarrollan en las actividades de aprendizaje y en las formas de evaluación.

Cuarto. Presentar los resultados que se obtuvieron en el diagnóstico, los problemas, las causas, y las estrategias para mejorar mediante la aplicación de la propuesta que potencia y contribuye al interés en los educandos por aprender.

Quinto. Explicar en qué consiste la fundamentación de los enfoques del aprendizaje contemporáneos, la pedagogía social, la enseñanza contextual, la socio formativa y evaluación formativa, que justifican la propuesta y contribuyen a propiciar el desarrollo de conocimientos, aptitudes y habilidades de forma integral en el educando, partiendo de la guía y orientación del profesor en la clase y la actitud participante del alumno. 
Sexto. Explicar la unidad didáctica dosificada como parte de la propuesta, que puede ser guía para la dosificación el resto de las unidades, inclusive de otras carreras; así como los modelos de sesiones de clase de la propuesta, diseñadas como respuesta al desinterés de los estudiantes por el aprendizaje y que permiten llevar a cabo una clase que estimule la observación, la motivación y el interés en los educandos en el qué y cómo realizar la tarea. Asimismo, se puntualizan los instrumentos de evaluación formativa y sus indicadores según las actividades a trabajar en clase.

Séptimo. Evaluar el impacto de la aplicación de la propuesta mediante la observación de clases a los educadores para constatar la transformación de la evaluación del aprendizaje de forma holística y el desarrollo en los alumnos. Para finalizar, se explica la importancia de planificar las unidades didácticas del programa de asignatura. Seguido se expone la unidad diseñada con dos sesiones de aprendizaje realizadas a modo de ejemplo. El objetivo trabajado se orienta a demostrar cómo estimular el interés por los conocimientos y las habilidades idiomáticas.

\section{Validación de la estrategia metodológica}

El producto científico resultante de la investigación se sometió al juicio de expertos con la finalidad de evaluar la validez y pertinencia tanto en el plano interno, como externo del diseño utilizado, su contribución en la solución de la problemática investigada y factibilidad de aplicación práctica. Para realizar dicha validación se emplearon dos rúbricas con variados indicadores y fungieron como expertos tres especialistas que ostentan el grado de maestro o doctor en las ciencias de la Educación y que se desempeñan actualmente de forma activa en la docencia universitaria. A continuación, se muestra la reseña de los expertos que validaron el producto científico de la investigación. 
Tabla 4.

Expertos que validaron la estrategia metodológica.

\begin{tabular}{ccccc}
\hline Nombres y Apellidos & $\begin{array}{c}\text { Grado } \\
\text { académico }\end{array}$ & Especialidad & $\begin{array}{c}\text { Ocupación } \\
\text { profesional }\end{array}$ & $\begin{array}{c}\text { Años de } \\
\text { experiencia }\end{array}$ \\
\hline Fernando Goñi Cruz & Doctor & Educación Matemático & Docente & 20 \\
Muñoz Salazar José Manuel & Doctor & Educación & Docente & 35 \\
Arbaiza Meza, Carlos Mariano & Maestro & Educación & Docente & 15 \\
\hline
\end{tabular}

Fuente: Elaboración propia (2020).

\section{Características de la valoración interna y externa de la estrategia metodológica}

Para evaluar la estrategia metodológica en cuanto a los aspectos internos y externos, se dispuso una rúbrica con indicadores cuantitativos y cualitativos. Se utilizaron dos fichas: la primera relativa al contenido de la propuesta y la segunda sobre su forma y posibilidad de aplicación en la práctica pedagógica. Cada una de las rúbricas cuenta con diez indicadores de carácter cuantitativo y cualitativo que le permiten la evaluación integral del producto. Los expertos presentaron sus puntos de vista evaluativos mediante un valor de sistema cuantitativo y su valor cualitativo: de deficiente (puntaje 1), bajo (puntaje 2), regular (puntaje 3), bueno (puntaje 4) у muy bueno (puntaje 5). En cada ficha el valor máximo a alcanzar es de cincuenta puntos, así al sumar las dos fichas se obtiene como máximo puntaje cien puntos en total.

Tabla 5 .

Valoración de las fichas de validación.

Tabla de valoración

\begin{tabular}{ll}
\hline $0-35 \%$ & Deficiente \\
$36 \%-51 \%$ & Baja \\
$52 \%-67 \%$ & Regular \\
$68 \%-83 \%$ & Buena \\
$84 \%-100 \%$ & Muy bien
\end{tabular}

Fuente: Elaboración propia (2020). 


\section{Evaluación interna y externa de la estrategia propuesta.}

La primera ficha de validación del valor interno de la estrategia metodológica propuesta, mediante ella se calificó la propuesta utilizando los indicadores: factibilidad de aplicación del resultado que se presenta; claridad de la propuesta para ser aplicado por otros; posibilidad de extensión a contextos similares; correspondencia con las necesidades sociales e individuales actuales; congruencia entre el resultado propuesto y el objetivo, novedad de conceptos y procedimientos; fundamentación curricular; pedagógica y educativa, contextualización a la realidad de estudio; objetivos claros y coherentes y existencia de un plan de acción de lo general a lo particular. El puntaje máximo considerado en esta ficha como ya se mencionó es cincuenta.

En la evaluación externa del producto presentado, se consideraron los indicadores siguientes: objetividad, organización, intencionalidad, coherencia, pertinencia, claridad, actualidad, suficiencia, consistencia y metodología. A continuación, presenta la evaluación otorgada por cada especialista a la rúbrica de validación interna y la externa de forma integral y la sumatoria total.

Tabla 6.

Sumatoria de valoración interna y externa otorgada por los especialistas.

\begin{tabular}{ccccc}
\hline Nombres y Apellidos & $\begin{array}{c}\text { Grado } \\
\text { académico }\end{array}$ & $\begin{array}{c}\text { Rúbrica de } \\
\text { validación interna }\end{array}$ & $\begin{array}{c}\text { Rúbrica de } \\
\text { validación externa }\end{array}$ & $\begin{array}{c}\text { Sumatoria de } \\
\text { valoración }\end{array}$ \\
\hline Fernando Goñi Cruz & Doctor & 45 & 45 & 90 \\
Muñoz Salazar José & Doctor & 47 & 47 & 94 \\
Arbaiza Meza, Carlos & Maestro & 46 & 45 & 91 \\
\multicolumn{2}{c}{ Total } & & & 275 \\
\hline
\end{tabular}

Fuente: Elaboración propia (2020).

En conclusión, luego de realizado el proceso de validación por expertos, la estrategia metodológica modelada obtuvo el puntaje de 92. 
Tabla 7.

Resultado total de la valoración interna y externa de la propuesta.

\begin{tabular}{ccc}
\hline Sumatoria de valoración total & Promedio de valoración & Valoración \\
\hline 275 & 92 & Muy bien \\
\hline
\end{tabular}

Fuente: Elaboración propia (2020).

Los resultados finales de la validación realizada por los expertos demuestran que la estrategia metodológica modelada es pertinente, relevante y orientadora para que los docentes perfección en los conocimientos teóricos y didácticos, a fin de incentivar el interés por el aprendizaje de la asignatura de Inglés en los estudiantes de la carrera de Administración de una universidad privada de Lima. Enfatizan que según los fundamentos científicos integrales de naturaleza científica, didáctica, curricular y la manera de concebir la actividad de aprendizaje, puede aplicarse en la práctica pedagógica en la carrera para la cual fue diseñada y también puede utilizarse en otras áreas curriculares de la facultad. 


\section{Conclusiones}

Como conclusión del proceso investigativo llevado a cabo, a través del marco teórico, el diagnóstico de campo y la modelación de la estrategia metodológica se arriba a las conclusiones generales.

\section{Primera}

Se cumplió el objetivo general de la investigación con la sistematización del marco teórico y la realización del diagnóstico de campo que permitió identificar las categorías emergentes influyentes en el problema y a partir de ello se modelo la estrategia metodológica para contribuir al desarrollo del interés por el aprendizaje en los estudiantes de la asignatura de Inglés de la carrera de Administración de una universidad privada de Lima.

\section{Segunda}

Se dio cumplimiento a la primera tarea científica de la investigación con el proceso de sistematización teórica y didáctica de las categorías y subcategorías apriorísticas e identificación de los indicadores, recurriendo a las fuentes científicas desde una visión integral que facilitó profundizar en el problema y proyectar las acciones para su transformación desde una perspectiva teórica completa que permitió la comprensión de los enfoques teóricos.

\section{Tercera}

Se cumplió con el proceso del diagnóstico o trabajo de campo a partir del diseño, validación y aplicación de las técnicas e instrumentos de recolección, procesamiento y triangulación de la información que permitió identificar las categorías emergentes 
generales y las que inciden en el problema objeto de investigación como la falta de preparación teórica y didáctica de los docentes al dirigir el aprendizaje, incidiendo negativamente en el interés de los estudiantes por el aprendizaje de la asignatura de Inglés de la carrera de Administración de una universidad privada de Lima.

\section{Cuarta}

La tercera tarea científica se cumplió con modelación de la estrategia metodológica sustentada en las bases teóricas, metodológicas y prácticas de forma integral, a fin de contribuir al desarrollo del interés por el aprendizaje en los estudiantes de la asignatura de Inglés, en la que el docentes se empodera didácticamente y aplica distintos métodos y actividades en la enseñanza- aprendizaje que estimula el protagonismo estudiantil a través de situaciones comunicativas que lo hace consciente de lo que aprende, cómo aprende y su aplicación práctica al producir textos orales y escritos en colaboración con sus iguales.

\section{Quinta}

Por medio del método de juicio de expertos se validó de positivo las potencialidades curriculares de la estrategia metodológica modelada en la que el docente alcanza un desempeño profesional eficiente al orientar la enseñanza- aprendizaje, a fin de lograr el interés por el aprendizaje de los contenidos de la asignatura de Inglés en los estudiantes de la carrera de Administración de una universidad privada de Lima. De esta manera se cumplió la cuarta tarea científica. 


\section{Recomendaciones}

\section{Primera}

Se sugiere valorar la estrategia modelada como resultado científico con los docentes de la carrera en los distintos ciclos académicos, a fin de destacar cómo los guía y orienta en la dirección del proceso pedagógico mediante métodos problematizadores, comunicativos, dialógicos, y reflexivos que incidan de forma significativa en el interés de los estudiantes por el aprendizaje del Inglés.

\section{Segunda}

Validar los resultados de la investigación en la práctica pedagógica con el objetivo de corroborar su efectividad en la estimulación del interés, el nivel de conocimientos y habilidades idiomáticas que hayan desarrollado los estudiantes en la actividad de aprendizaje de forma integral.

\section{Tercera}

Asistir a los eventos científicos y académicos programados con el fin de presentar los resultados de la investigación y demostrar las transformaciones y aportes a la solución la problemática sobre cómo incide la falta de interés por el aprendizaje en los estudiantes en el desarrollo de los conocimientos y habilidades comunicativas del idioma Inglés. 


\section{Referencias}

Addine, F. et. al. (2015). Didáctica de la pedagogía y la Psicología: Pueblo y Educación La Habana.

Agra, et.al. (2019). Análisis del concepto de aprendizaje significativo a la luz de la teoría de Ausubel. Revista Brasileira de Enfermagem, 72 (1), 248-255. doi: 10.1590 / 0034-71672017-0691

Álvarez de Zayas, R. (1997). Hacia un currículum integral y contextualizado. Academia.

Alzubaidi, E., Aldridge, J., y Khine, M. (2016). Aprendiendo inglés como segundo idioma a nivel universitario en Jordania: motivación, autorregulación y percepciones del entorno de aprendizaje. Learning Environ 19(1), 133-152. https://doi.org/10.1007/s10984-014-9169-7I

Anguita, Labrador y Campos (2003). La encuesta como técnica de investigación. Elaboración de cuestionarios y tratamiento estadístico de los datos (I). | Aten Primaria 31(8):527-38.

Babakr, H., Mohamedamin, P., y Kakamad, K. (2019). Piaget's Cognitive Developmental Theory: Critical Review. EducationQuarterlyReviews 2 (3) 517-524.

Benavides, Y. (2013). La destreza auditiva en el desarrollo de la competencia comunicativa oral en los estudiantes de los novenos años de educación general básica del colegio consejo provincial de pichincha año lectivo 2012-2013. Tesis de grado. Quito- Ecuador: Universidad Central de Ecuador.

British Council. (2015). Inglés en el Perú. Recuperado de http://www2.congreso.gob.pe/sicr/cendocbib/con4_uibd.nsf/318A8FA6AC9F382105257F 3E00611BB9/\$FILE/Ing1\%C3\%A9s_en_el_Per\%C3\%BA.pdf

Brito, H. (1984). Hábitos, habilidades y capacidades. Revista Varona. 13(1). La Habana

Bisquerra, R. (2004). Metodología de la investigación educativa. Madrid: La Muralla

Bueno, D. (2017) Neurociencia para educadores: todo lo que los educadores siempre han querido saber sobre el cerebro. Alianza, Barcelona.

Campos, M. (2016). Motivación y aprendizaje del idioma inglés en estudiantes del nivel $V$ de un centro de idiomas, 2016. Tesis de maestría. Universidad Cesar Vallejo. Lima, Perú. 
Cassany, D. (2013). Tras las líneas. Sobre la lectura contemporánea. Barcelona: Anagrama.

Castellanos, D., Reinoso, C., y García, C. (2007). Para promover un aprendizaje desarrollador. La Habana, Cuba: Colección de proyectos.

Cerezal, J. y Fiallo, J. (2005). Cómo investigar en pedagogía. La Habana: Pueblo y Educación.

Chauca, M. (2018). Aplicación del enfoque CLIL (Content and Language Integrated Learning) para mejorar la motivación y el aprendizaje del idioma inglés en la Escuela Profesional de Ingeniería Geológica, Arequipa 2017. Tesis de grado. Universidad Nacional de San Agustín de Arequipa. Arequipa, Perú.

Cronquist, K., y Fiszbein, A. (2017). El aprendizaje del inglés en América Latina. Recuperado de https://www.thedialogue.org/wp-content/uploads/2017/09/El-aprendizaje-delingl\%C3\%A9s-en-Am\%C3\%A9rica-Latina-1.pdf

Cruz, O. (2015). Propuesta metodológica para el interés por la práctica de ejercicios físicos en los estudiantes de educación secundaria. Tesis de Maestría. Universidad San Ignacio de Loyola. Lima, Perú.

Daskalovska, N., Gudeva, L., y Ivanovska, B. (2012). Motivation and interest of the student.Procedia - Social and Behavioral Sciences, 46(1) 1187-1191. doi: 10.1016 / j.sbspro.2012.05.272

De la Puente, Y. (2015). La enseñanza del idioma inglés en el Sistema Educativo Peruano y su importancia. Conoc. Amaz. 6(2): 151-156.

Díaz, B., y Hernández, A. (2010) Estrategia Docente para un aprendizaje significativo México: Mc. Graw Hill (3ra Edición)

Domínguez, A. (2010). Construcción de los objetos del lenguaje. Madrid.

Drbseh, M. (2015). Motivation and attitudes towards learning English as a foreign language: a study of the Middle East Arab University students at Leeds University in UK. International Journal of Scientific and Research Publications 5(12) 236-257.

Eyssautier, M. (2006).Metodología de la investigación. México D.F.: Paraninfo. 
Fabregat, L., Castañeda, E., y Díaz, J. (2017). Los métodos teóricos: una necesidad de conocimiento en la investigación científico-pedagógica. Edumecentro 9 (4) 1-5.

Froufe, M. (2011).Psicología del aprendizaje. Principios y aplicaciones conductuales. Paraninfo: Madrid.

Gordillo, N. (2007) Metodología, método y propuestas metodológicas en Trabajo Social. $\begin{array}{llllll}\text { Tendencia } & y & \text { Retos } & 12(1) & 119-135 . & \text { Recuperado de }\end{array}$ https://dialnet.unirioja.es/descarga/articulo/4929312.pdf

Gonzáles, V., Castellanos, D., Dolores, M., Rebollar, M., Martínez, M., Fernández, A., Martínez, N., y Pérez, D. (2004). Psicología para educadores. Ciudad de La Habana, Cuba: Editorial Pueblo y Educación.

Grande, E. (2015). La motivación en los estudiantes de primer semestre universitario para aprender. Tesis Maestría. Tecnológico de Monterrey. Monterrey, México.

Harackiewicz, J., y Hulleman, C. (2010). The Importance of Interest: The Role of Achievement Goals and Task Values in Promoting the Development of Interest. Social and Personality Psychology Compass 4(1) 42-52 doi: 10.1111/j.1751-9004.2009.00207.x

Harackiewicz, J., Smith, J., y Priniski, S. (2016). Matters of interest.Policy Perspectives on Behavioural and Brain Science, 3 (2), 220-227. doi: 10.1177 / 2372732216655542

Hernández, R., Fernández, C. y Baptista, P. (2014). Metodología de la Investigación. (6ta edición). México D.F.: McGraw-Hill.

Hernández. J., Guerrero, G., y Tobón, S. (2015). Los problemas del contexto: base filosófica y pedagógica de la socioformación. Ra Ximhai. 11 (4) 125-140.

Ibarguen, R. (2013). Estrategia metodológica CICER propuesta para la enseñanza de las Ciencias Naturales. Tesis de maestría. Universidad Nacional de Colombia. Colombia.

Labarrere, G. (1998). Pedagogía. La Habana: Editorial Pueblo y Educación.

Legault, L. (2016). Intrinsic and Extrinsic Motivation. Recuperado de: https://www.researchgate.net/publication/311692691_Intrinsic_and_Extrinsic_Motivation 
López, D. (2016). The use of authentic videos as a teaching strategy to lower some boredom signs shown by intermediate English students at Universidad San Ignacio de Loyola when practicing grammar, in order to improve results. Tesis de Maestría. Universidad de Piura. Piura, Perú.

Lomas, C. y Tusón, A. (2012). Pensamiento narrativo y educación. Oviedo.

Lopez, D. (2016). The use of authentic videos as a teaching strategy to lower some boredom signs shown by intermediate English students at Universidad San Ignacio de Loyola when practicing grammar, in order to improve results. Tesis Maestría, Universidad de Piura. Piura, Perú.

Manrique, A. (2014). Diseño de un proyecto educativo para enseñar inglés a niños y jóvenes en edad escolar pertenecientes a la comuna 20 de Santiago de Cali. Tesis doctoral. Recuperado de https://docplayer.es/32609458-Diseno-de-un-proyecto-educativo-paraensenar-ingles-a-ninos-y-jovenes-en-edad-escolar-pertenecientes-a-la-comuna-20-desantiago-de-cali.html

Martínez, H (2014). Metodología de la Investigación con enfoque en competencias. México, D.F.: Cengage.

Maslow, A. (1954). Motivación y Personalidad. Madrid, España: Ediciones Díaz de Santos, S. A. Ministerio de Educación del Perú (2009) Orientaciones para el trabajo pedagógico. Lima: Fondo Editorial Corporación Gráfica Navarrete.

Mora F. (2017). Neuroeducación: solo se puede aprender aquello que se ama. Barcelona: Alianza. Morín, E. (1999). Los siete saberes necesarios para la educación del futuro (Trad. Mercedes Vallejos Gómez). París, Francia: Santillana/UNESCO.

Moreno W. y Velázquez, M. (2017) Estrategia didáctica para desarrollar el pensamiento crítico. Revista Iberoamericana sobre Calidad, Eficacia y Cambio en Educación REICE 5(2), 5373. https://doi.org/10.15366/reice2017.15.2.00315.

Naranjo, M. (2009). Motivación: perspectivas teóricas y algunas consideraciones de su importancia en el ámbito educativo. Revista Educación 33(2), 153-170 
Ortiz, P. (2008). Educación y formación de la personalidad. Lima, Perú.

Perkins, D. (2003). “¿Qué es la comprensión?”, en M. Stone Wiske (comp.). La enseñanza para la comprensión. Vinculación entre la investigación y la práctica, Buenos Aires: Paidós.

Pimienta J. (2012). Estrategia de enseñanza-aprendizaje. Pearson Educación. México.

Real Académica Española (2019). Diccionario de la lengua española. Recuperado de: http://www.rae.es/diccionario-de-la-lengua-espanola.

Rico, P. (2013). Proceso de enseñanza-aprendizaje desarrollador en la escuela primaria: teoría y práctica. Cuba: Editorial Pueblo y Educación.

Riopel, M. y Smyrnaiou, Z. (2016). New Developments in Science and Technology Education. Suiza: Springer.

Robbins, S. y Judge, T. (2017). Comportamiento organizacional. $17^{\circ}$ Edición. Pearson Educación. México.

Rodríguez, A. y Pérez, A. (2017). Métodos científicos de indagación y de construcción del conocimiento. Recuperada de http://www.scielo.org.co/pdf/ean/n82/0120-8160-ean-8200179.pdf

Romeú, A. (2007). El enfoque cognitivo, comunicativo y sociocultural en la enseñanza de la lengua. Ciudad Habana: Editorial Pueblo y Educación.

Rubinstein, S. (1977). Principios de psicología general. Ciudad de la Habana, Cuba: Pueblo y Educación.

Sáez, C. (2014). Neuroeducación o cómo educar con el cerebro. Evaluación de los aprendizajes y el talento humano. Lima: USIL.

Sánchez, H., y Reyes, C (2015). Metodología y diseños en la investigación científica.Lima: Universidad Ricardo Palma. Editorial Universitaria

Shabani, K. (2016) Applications of Vygotsky's sociocultural approach for teachers' professional development.CogentEducation 3 (1) 1-10.

Sierra, R. (2004). Modelo teórico para el diseño de una estrategia pedagógica en la Educación Primaria y Secundaria. Tesis de doctorado. Universidad Enrique José Varona. La Habana. 
Silvestre M. y Zilberstein J. (2002). Hacia una didáctica desarrolladora. La Habana: Pueblo y Educación.

Suryasa, W., Adhitya, G., y; Werdistira, W. (2017). An Analysis of Students' Motivation Toward English Learning As Second Language Among Students In Pritchard English Academy. Journal of Social Sciences and Humanities, 1 (2), 43-50. https://doi.org/10.29332/ijssh.v1n2.36

Toapanta, G. (2017). El podcast educativo y la destreza auditiva (listening) del idioma inglés en los estudiantes de tercer año de bachillerato general unificado de la "unidad educativa los andes”, del Cantón Santiago de Píllaro, provincia de Tungurahua. Tesis de maestría. Ambato - Ecuador: Universidad Técnica de Ambato.

Tobón, S. (2013). Formación basada en competencias: pensamiento complejo, diseño curricular y didáctica, 2da Edición. Bogotá: Ecoe.

Tobón, S., Calderón, C., Hernández, J., y Cardona, S. (2015). Sociedad del Conocimiento: Estudio documental desde una perspectiva humanista y compleja. Paradigma, 36(2), 7-36. Recuperado de https://goo.gl/hg5P6d

Urbina, B. (2016). Concepciones psicopedagógicas que pueden contribuir a fundamentar la estimulación de la motivación y su influencia en el aprendizaje del idioma inglés en estudiantes de v año, carrera inglés de FAREM-Estelí, durante el año 2015. Tesis de Maestría. Universidad Nacional Autónoma de Nicaragua. Managua, Nicaragua.

Vanden, M. (2013). Enseñanza de idiomas en la educación peruana. LEXIS 2 (1) 1-12

Velázquez M. (2014). Propuesta metodológica dirigida a la competencia comunicativa en la construcción de textos escritos en los estudiantes de sexto grado en la educación primaria. Tesis doctoral. Pontificia Universidad Católica Americana de los Estados Unidos. Tesis para obtener el grado de Doctor en Educación. Pontificia Universidad.

Velázquez, M. (20018). Reflexiones para el debate sobre los conceptos claves en la producción científica del docente investigador contemporáneo: estrategia didáctica, estrategia metodológica y alternativa metodológica. Universidad San Ignacio De Loyola. Lima, Perú. 
Valentín, M. (2017). Motivación para estudiar inglés en estudiantes de la facultad de educación de la UNCP. Tesis de maestría. Universidad Nacional del Centro del Perú. Huancayo, Perú.

Walkington C., Bernacki M. (2014). Motivar a los estudiantes al "personalizar" el aprendizaje en torno a los intereses individuales: una consideración de la teoría, el diseño y los problemas de implementación. Avances en la motivación y el logro. 18(1) 139-176. doi: 10.1108 / S0749-742320140000018004. 


\section{ANEXO1- MATRIZ METODOLÓGICA}

\begin{tabular}{|c|c|c|c|c|c|c|c|c|c|c|c|}
\hline $\begin{array}{c}\text { Problema } \\
\text { general }\end{array}$ & Problemas específicos & Objetivo general & Objetivos específicos & Categorías & Sub-categorías & Métodos & Técnicas & Instrumentos & $\begin{array}{c}\text { Unidad de } \\
\text { análisis }\end{array}$ & Población & Muestra \\
\hline $\begin{array}{l}\text { Cómo contribuir } \\
\text { a desarrollar el } \\
\text { interés por el } \\
\text { aprendizaje del } \\
\text { Inglés en los } \\
\text { estudiantes de I } \\
\text { ciclo de la Carrera } \\
\text { de Administración } \\
\text { de una } \\
\text { Universidad } \\
\text { Privada de Lima? }\end{array}$ & \begin{tabular}{|l|} 
¿Cuál es el estado actual del \\
interés por el aprendizaje del \\
Inglés en los estudiantes de I ciclo \\
de la Carrera de Administración de \\
una Universidad Privada de Lima? \\
¿Cuáles son los fundamentos \\
teóricos que sirven de base para \\
desarrollar el interés por el \\
aprendizaje del Inglés en los \\
estudiantes de I ciclo de la Carrera \\
de Administración de una \\
Universidad Privada de Lima? \\
¿Cuáles son los criterios teóricos y \\
prácticos que sirven de base a la \\
modelación de la estrategia \\
metodológica para contribuir con \\
el interés por el aprendizaje del \\
Inglés en los estudiantes de I ciclo \\
de la Carrera de Administración de \\
una Universidad Privada de Lima? \\
Cómo validar por criterios de \\
expertos la efectividad de la \\
estrategia metodológica para \\
contribuir con el desarrollo del \\
interés por el aprendizaje del \\
inglés en los estudiantes del I \\
ciclo de la Carrera de \\
Administración de una \\
Universidad Privada?
\end{tabular} & $\begin{array}{l}\text { Diseñar una estrategia } \\
\text { metodológica para } \\
\text { desarrollar el interés por } \\
\text { el aprendizaje del inglés } \\
\text { en los estudiantes de la } \\
\text { Carrera de } \\
\text { Administración de una } \\
\text { Universidad Privada de } \\
\text { Lima. }\end{array}$ & \begin{tabular}{|l|} 
Diagnosticar el estado actual del \\
desarrollo del interés por el \\
aprendizaje del Inglés en los \\
estudiantes de I ciclo de la Carrera \\
de Administración de una \\
Universidad Privada de Lima. \\
Sistematizar los fundamentos \\
teóricos que sirven de base al \\
desarrollo del interés por el \\
aprendizaje del Inglés en los \\
estudiantes de I ciclo de la \\
Carrera de Administración de una \\
Universidad Privada de Lima. \\
Determinar los criterios teóricos y \\
prácticos que sirven de base a la \\
modelación de la estrategia \\
metodológica para contribuir con \\
el desarrollo del interés por el \\
aprendizaje del Inglés en los \\
estudiantes de I ciclo de la Carrera \\
de Administración de una \\
Universidad Privada de Lima. \\
Validar la efectividad de la \\
estrategia metodológica modelada \\
para contribuir con el desarrollo \\
del interés por el aprendizaje del \\
Inglés en los estudiantes de I ciclo \\
de la Carrera de Administración de \\
una Universidad Privada de Lima.
\end{tabular} & $\begin{array}{c}\text { Estrategia } \\
\text { metodológica }\end{array}$ & $\begin{array}{l}\text { Exigencias del Proceso } \\
\text { Enseñanza-Aprendizaje }\end{array}$ & $\begin{array}{l}\text { Analítico } \\
\text { sintético }\end{array}$ & $\begin{array}{c}\text { Prueba } \\
\text { pedagógica }\end{array}$ & $\begin{array}{l}\text { Cuestionario } \\
\text { Guía de entrevista } \\
\text { semiestructurada }\end{array}$ & Alumnos & $\begin{array}{c}346 \\
\text { estudiantes }\end{array}$ & $\begin{array}{c}40 \\
\text { estudiantes } \\
3 \text { docentes }\end{array}$ \\
\hline
\end{tabular}




\section{ANEXO2- MATRIZ DE CATEGORIZACIÓN}

ESTRATEGIA METODOLÓGICA PARA DESARROLLAR EL INTERÉS POR EL APRENDIZAJE DEL INGLÉS EN LOS ESTUDIANTES DEL PRIMER CICLO DE UNA UNIVERSIDAD PRIVADA DE LIMA

\begin{tabular}{|c|c|c|c|c|c|c|c|c|}
\hline \multirow[b]{2}{*}{$\begin{array}{l}\text { Problema de } \\
\text { investigación }\end{array}$} & \multirow[b]{2}{*}{$\begin{array}{l}\text { Objetivo } \\
\text { general }\end{array}$} & \multirow[b]{2}{*}{ Categorías } & \multirow[b]{2}{*}{ Sub-categorías } & \multirow[b]{2}{*}{ Indicadores } & \multicolumn{4}{|c|}{ Instrumentos } \\
\hline & & & & & $\begin{array}{c}\text { Ítems para la } \\
\text { guía de } \\
\text { entrevista a los } \\
\text { docentes }\end{array}$ & $\begin{array}{c}\text { Ítem para el } \\
\text { cuestionario de } \\
\text { estudiantes }\end{array}$ & $\begin{array}{c}\text { Ítems para la } \\
\text { observación a } \\
\text { clases }\end{array}$ & 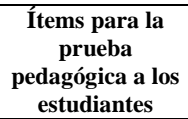 \\
\hline \multirow{9}{*}{ 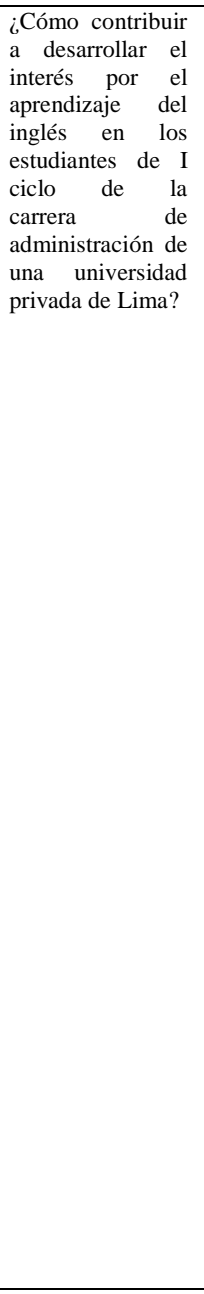 } & \multirow{9}{*}{$\begin{array}{l}\text { Diseñar una } \\
\text { estrategia } \\
\text { metodológic } \\
\text { a para } \\
\text { contribuir a } \\
\text { desarrollar } \\
\text { el interés } \\
\text { por el el } \\
\text { aprendizaje } \\
\text { del inglés en } \\
\text { los } \\
\text { estudiantes } \\
\text { de I ciclo de } \\
\text { la carrera de } \\
\text { administraci } \\
\text { ón de una } \\
\text { universidad } \\
\text { privada de } \\
\text { lima. }\end{array}$} & \multirow{7}{*}{ 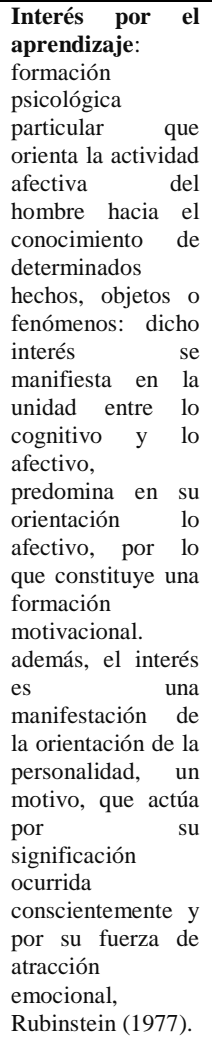 } & \multirow{2}{*}{$\begin{array}{l}\text { Base conceptual: } \\
\text { Se refiere a los principios, conceptos y explicaciones que } \\
\text { construyen el conocimiento conceptual y que no se aprenden } \\
\text { de forma literal, sino abstrayendo su significado esencial e } \\
\text { identificando las características definitorias y las reglas que } \\
\text { las componen. (Rubinstein 1977; Díaz y Hernández 2010; } \\
\text { Tabón, 2015 y Addine, 2015). }\end{array}$} & $\begin{array}{l}\text { Conoce los principios y conceptos del interés } \\
\text { por el aprendizaje }\end{array}$ & 1 & 1 & 1,3 & \\
\hline & & & & $\begin{array}{l}\text { Domina los enfoques teóricos de la enseñanza y } \\
\text { el aprendizaje. }\end{array}$ & 2 & 2 & 4 & $5,6,7,8,9$ \\
\hline & & & \multirow{2}{*}{$\begin{array}{l}\text { Base procedimental: } \\
\text { Se refiere a la ejecución de procedimientos, estrategias, } \\
\text { técnicas, habilidades, destrezas, métodos, etc. El saber } \\
\text { procedimental es práctico, porque está basado en la } \\
\text { realización de varias acciones u operaciones. Los } \\
\text { procedimientos pueden ser definidos como un conjunto de } \\
\text { acciones ordenadas y dirigidas hacia la construcción de una } \\
\text { meta determinada. (Rubinstein 1977; Díaz y Hernández } \\
\text { 2010; Tabón, 2015 y Addine, 2015). }\end{array}$} & $\begin{array}{l}\text { Motiva a sus alumnos a producir textos } \\
\text { sencillos }\end{array}$ & & \multirow[t]{2}{*}{3} & \multirow[t]{2}{*}{5} & \multirow[t]{2}{*}{$10,11,12,1314$} \\
\hline & & & & $\begin{array}{l}\text { Aplica los procedimientos a tener en cuenta en } \\
\text { la construcción de textos. }\end{array}$ & 3 & & & \\
\hline & & & \multirow{3}{*}{$\begin{array}{l}\text { Base actitudinal: } \\
\text { Se refiere a los valores, actitudes y normas, los primeros son } \\
\text { principios o ideas éticas que permiten emitir juicios sobre las } \\
\text { conductas y su sentido. Las actitudes son tendencias o } \\
\text { predisposiciones relativamente estables de las personas, para } \\
\text { actuar de cierta manera en función de los valores que asume. } \\
\text { Las normas son patrones o reglas de comportamiento que } \\
\text { hay que seguir en determinadas situaciones que obligan a } \\
\text { todos los integrantes de un grupo social. (Rubinstein 1977; } \\
\text { Díaz y Hernández 2010; Tabón, } 2015 \text { y Addine, 2015). }\end{array}$} & Participa y realiza la tarea con responsabilidad. & 4 & 4 & 6 & \\
\hline & & & & Reconoce sus logros y limitaciones. & 5 & 6 & 7 & \\
\hline & & & & $\begin{array}{l}\text { Colabora y socializa con sus compañeros en las } \\
\text { distintas actividades. }\end{array}$ & 4 & 5 & 6 & \\
\hline & & \multirow{2}{*}{$\begin{array}{l}\text { Estrategia } \\
\text { Metodológica: } \\
\text { consiste en un } \\
\text { constructo teórico } \\
\text { y didáctico que } \\
\text { tiene como fin } \\
\text { mejorar el proceso } \\
\text { de enseñanza - }\end{array}$} & \multirow{2}{*}{$\begin{array}{l}\text { Exigencias del proceso enseñanza-aprendizaje: conjunto } \\
\text { de principios didácticos y estudios actualizados de la } \\
\text { didáctica y de las ciencias pedagógicas en particular, que } \\
\text { posee como finalidad de estudio el proceso educativo; se } \\
\text { fundamentan en un educación formadora que se caracteriza } \\
\text { por la comunicación y tareas intencionadas, en donde el } \\
\text { proceder didáctico genera estrategias de aprendizaje para } \\
\text { una completa formación de la personalidad del alumno }\end{array}$} & $\begin{array}{l}\text { Emplea los principios y las categorías } \\
\text { didácticas en la enseñanza - aprendizaje. }\end{array}$ & 6 & 7 & $2,1,8$ & \\
\hline & & & & $\begin{array}{l}\text { Aplica el diagnóstico como proceso para } \\
\text { transformar al educando. }\end{array}$ & 7 & 8 & 9 & $1,2,3,4$ \\
\hline
\end{tabular}




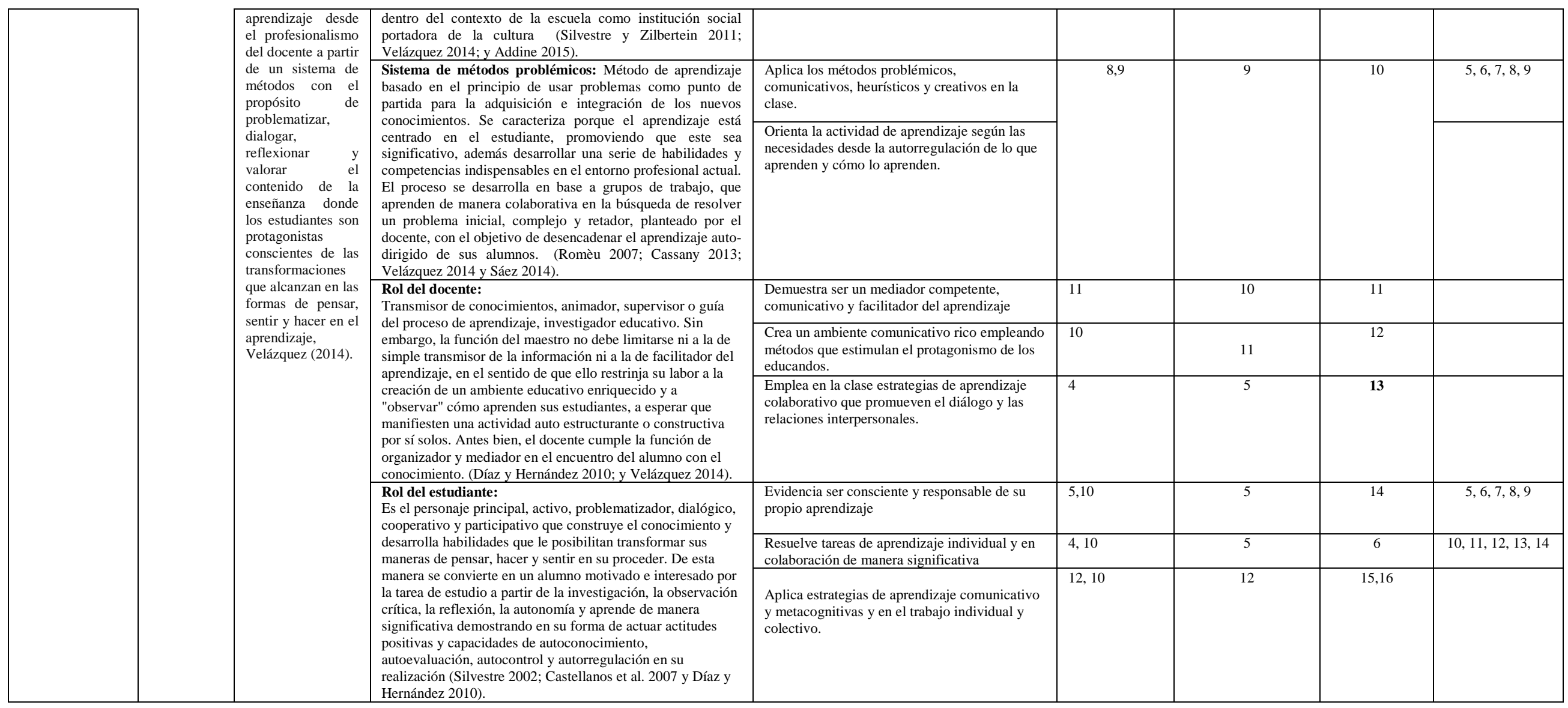




\title{
ANEXO 3. INSTRUMENTOS DE RECOLECCIÓN DE DATOS
}

\section{ENTREVISTA SEMI ESTRUCTURADA A LOS DOCENTES}

\author{
Datos informativos \\ Entrevistador \\ Lugar y Fecha \\ Duración \\ Entrevistados
}

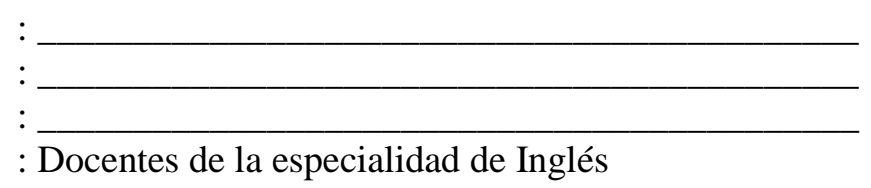

OBJETIVO: Conocer la preparación teórica y didáctica que poseen los docentes sobre el interés por el aprendizaje y los métodos de enseñanza como docentes de la asignatura de Ingles en los estudiantes de I ciclo de la Carrera de Administración de una Universidad Privada de Lima.

1. Según su experiencia como docente, ¿Cómo entiende usted el interés por el aprendizaje?

2. ¿Qué enfoques teóricos aplica en su sesión de clases con la finalidad de desarrollar en sus alumnos el interés por el aprendizaje?

3. ¿Qué métodos y estrategias emplea en la clase para motivar la construcción de textos originales respetando los elementos gramaticales presentados en clase?

4. ¿De qué manera fomenta que sus estudiantes participen colaborativamente y con responsabilidad en las actividades grupales que usted propone?

5. ¿Qué acciones realiza usted para que los estudiantes logren sus objetivos a partir del reconocimiento de sus limitaciones?

6. ¿Qué actividades significativas emplea usted en el proceso de enseñanza aprendizaje en sus clases de inglés?

7. ¿Qué tipo de evaluaciones realiza para identificar las fortalezas y debilidades de sus estudiantes con la finalidad de prevenir y corregir?

8. ¿Qué características debe tener la actividad casuística de la clase para promover el diálogo, la comunicación y el interés por el aprendizaje?

9. ¿Qué métodos de enseñanza emplea en su clase con la finalidad de promover el protagonismo, el pensamiento crítico y reflexivo y el aprendizaje significativo?

10. ¿Qué características, habilidades y actitudes de los educandos favorecen el proceso enseñanzaaprendizaje?

11. La educación actual enfatiza el papel del docente como mediador y facilitador entre el estudiante y los nuevos conocimientos, en esta línea ¿Cómo realiza usted este proceso de mediación en su sesión de clases?

12. ¿Cómo promueve usted la metacognición en tu sesión de clases? 


\section{CUESTIONARIO A LOS ESTUDIANTES \\ DATOS GENERALES:}

Carrera:

Ciclo:

Edad:_____ Sexo: Femenino ( ) Masculino ( ) Fecha:

OBJETIVO: Constatar el interés por el aprendizaje del idioma inglés en los estudiantes del I ciclo de la Carrera de Administración de una universidad privada de Lima.

Estimado estudiante, esta actividad corresponde a una investigación que se lleva a cabo para contribuir a desarrollar el interés por el aprendizaje del idioma inglés. Por ello te solicitamos que respondas conscientemente a las actividades y te damos las gracias por tu colaboración. Marca solo una de las alternativas de acuerdo a la tabla adjunta.

\begin{tabular}{|c|c|c|c|c|}
\hline NUNCA & CASI NUNCA & A VECES & CASI SIEMPRE & SIEMPRE \\
\hline 1 & 2 & 3 & 4 & 5 \\
\hline
\end{tabular}

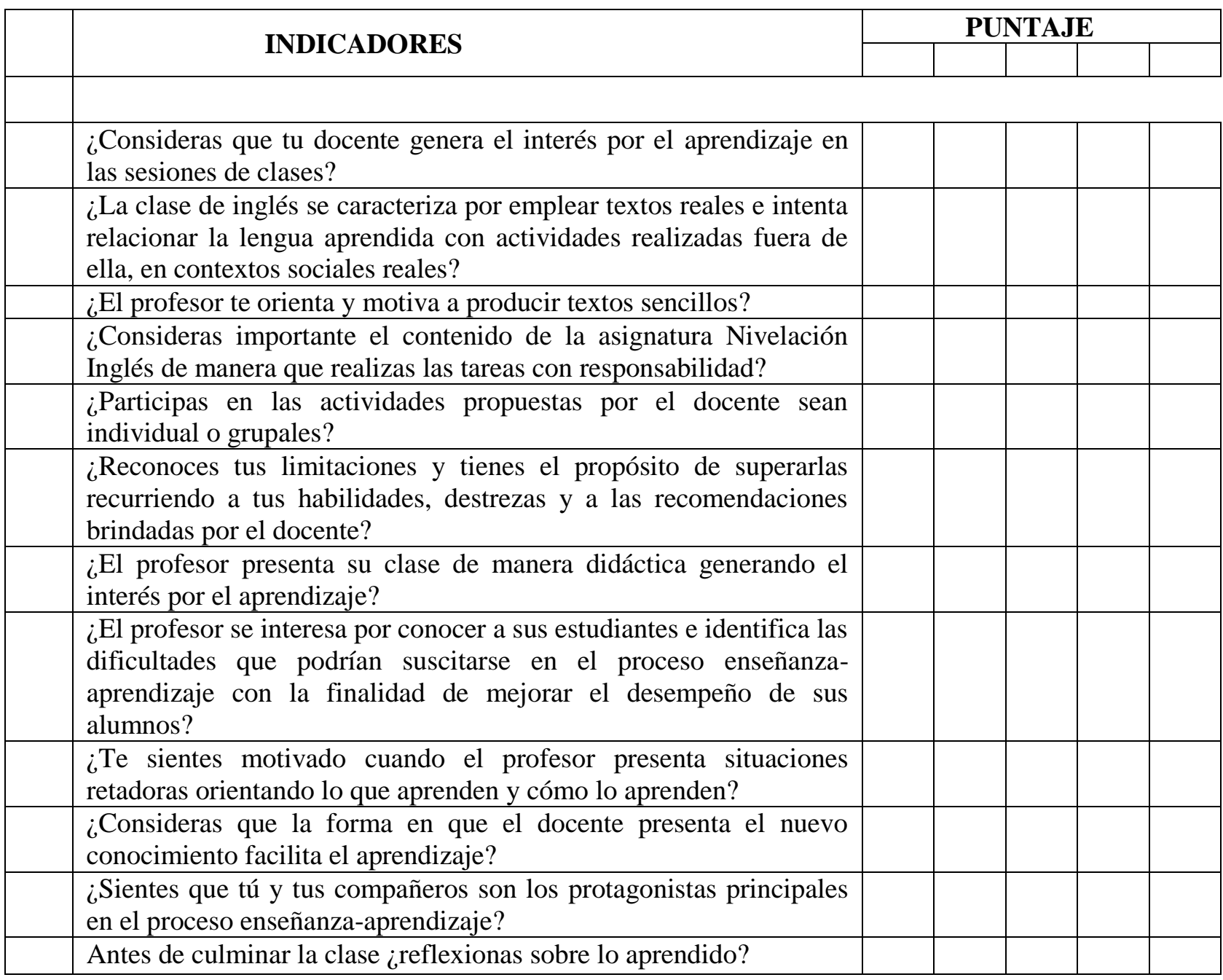




\section{GUÍA DE OBSERVACIÓN A CLASE}

\section{Datos Informativos}

Lugar y Fecha de observación:

Título de la sesión:

Duración:

Semestre:

Objetivo: Comprobar la preparación teórica y didáctica que poseen los docentes al desarrollar el proceso de enseñanza-aprendizaje de la asignatura Inglés en los estudiantes de I ciclo de la Carrera de Administración de una Universidad Privada de Lima.

\begin{tabular}{|c|c|c|c|c|}
\hline $\begin{array}{l}\text { Momentos de } \\
\text { la clase }\end{array}$ & ITEMS A EVALUAR & Sí & No & Observaciones \\
\hline \multirow{2}{*}{ INICIO } & $\begin{array}{l}\text { 1.- Los procedimientos empleados por el docente para iniciar la } \\
\text { sesión de clases llaman la atención del estudiante. }\end{array}$ & & & \\
\hline & $\begin{array}{l}\text { 2.- El docente explora los conocimientos previos que poseen los } \\
\text { educandos con relación al tema a abordar. }\end{array}$ & & & \\
\hline \multirow{11}{*}{ DESARROLLO } & $\begin{array}{l}\text { 3.-El profesor demuestra dominio en el tratamiento de enfoques } \\
\text { didáctico del contenido del tema de la clase. }\end{array}$ & & & \\
\hline & $\begin{array}{l}\text { 4.- Los estudiantes emplean diversas estrategias, presentadas por } \\
\text { el docente, para elaborar textos utilizando la gramática } \\
\text { correspondiente de manera coherente. }\end{array}$ & & & \\
\hline & $\begin{array}{l}\text { 5.- Los alumnos participan responsablemente tanto de forma } \\
\text { grupal como individual, donde prevalece el respeto, la } \\
\text { colaboración y socialización entre los alumnos y el docente. }\end{array}$ & & & \\
\hline & $\begin{array}{l}\text { 6.- Los alumnos son capaces de identificar sus limitaciones y se } \\
\text { preocupan por superarlas apelando a sus habilidades y destrezas. }\end{array}$ & & & \\
\hline & $\begin{array}{l}\text { 7.- El docente evidencia sus conocimientos teóricos de los } \\
\text { principios y categorías didácticas en del proceso enseñanza- } \\
\text { aprendizaje de manera que el alumno no sólo se siente satisfecho } \\
\text { por las clases recibidas sino que también logra los objetivos } \\
\text { esperados. }\end{array}$ & & & \\
\hline & $\begin{array}{l}\text { 8.- Se evalúa al educando con la finalidad de que el docente } \\
\text { diagnostique el nivel en el que se encuentran sus alumnos y así } \\
\text { pueda prevenir dificultades. }\end{array}$ & & & \\
\hline & $\begin{array}{l}\text { 9.- El docente aplica métodos problémicos, comunicativos, } \\
\text { heurísticos y creativos en su clase a partir de los cuales orienta lo } \\
\text { que aprenden y como aprenden sus estudiantes. }\end{array}$ & & & \\
\hline & $\begin{array}{l}\text { 10.- El docente demuestra ser un mediador eficaz, que facilita el } \\
\text { aprendizaje a través de una comunicación asertiva. }\end{array}$ & & & \\
\hline & $\begin{array}{l}\text { 11.- El alumno está expuesto a un ambiente enriquecido que } \\
\text { estimula su protagonismo en el proceso enseñanza aprendizaje. }\end{array}$ & & & \\
\hline & $\begin{array}{l}\text { 12.- Las estrategias de aprendizaje colaborativas empleadas por el } \\
\text { docente promueven el diálogo y las relaciones interpersonales. }\end{array}$ & & & \\
\hline & $\begin{array}{l}\text { 13.- El alumno demuestra ser consciente y responsable de su } \\
\text { propio aprendizaje. }\end{array}$ & & & \\
\hline \multirow[b]{2}{*}{ CIERRE } & $\begin{array}{l}\text { 14.- Se realiza la retroalimentación, aclarando las dudas que } \\
\text { surgieron en el proceso. }\end{array}$ & & & \\
\hline & $\begin{array}{l}\text { 15.- El docente aplica estrategias que promueven que el alumno } \\
\text { reflexione sobre lo aprendido en la sesión de clase de manera } \\
\text { grupal como individual. }\end{array}$ & & & \\
\hline
\end{tabular}




\section{PRUEBA PEDAGÓGICA A LOS ESTUDIANTES}

\section{DATOS GENERALES}

Carrera:

Ciclo:

Sexo: Femenino ( ) Masculino ( ) Fecha:

Part 1 Reading

EASY CHEF FORUM

What do you usually eat? How often do you eat out?

What's your favourite recipe? We want to hear from you!

In my family, we usually have a well-balanced diet. We eat vegetables, fruit and grains every day. We eat chicken about three times a week, and we eat fish once or twice a week. We sometimes have beef. We eat it once in a while at restaurants, but we don't eat out very often. We have some special days, though. Once a month, we eat out with our children at our favourite Chinese restaurants. The dumplings are delicious! And my mom comes over and makes Mexican food twice a month.

My favourite easy recipe is: Veggie Pizza

Get some Italian bread. Put vegetables on top. I use peppers, tomatoes and onions. Then add cheese and cook it in the microwave for one minute. Delicious!

Isabel's family eats vegetables seven days a week.

DOESN'T SAY

1.

RIGHT

2.

Isabel's mother makes Mexican food for the family every week.

RIGHT Isabel's family never has beef.

WRONG

DOESN'T SAY

3. Isabel can't cook Mexican food.

RIGHT WRONG DOESN'T SAY

4. Isabel eats at a Chinese restaurant every Sunday.

RIGHT WRONG DOESN'T SAY

Part 2 Use of English

1. Complete the sentences with "a" or "an". (2pts)

a) Jaime Oliver is English chef.

b) Stephen Spielberg is __ famous film director.

2.- $\quad$ Complete the sentences using the verbs in parenthesis in the correct form in simple present. (3pts)

a. Mafer's dog

b. Giancarlo (not/love) meat biscuits

c. Henry and Angie (be) brother and sister.

3.

Replace the subject pronouns by the corresponding possessive adjectives. (2pts)

a. $\mathrm{He}$ is (we)

Sheloves (she) teacher.

Write the antonym of the underline word. (2pts)

b. Lima is an ugly city.

5. Put the conversation in order (1pts)

Still or sparkling?

What would you like to drink?

Thanks very much.

Sparkling, please.

OK. Here you are.

A bottle of mineral water.

Part 3 Make sentences with these words. (Writing)

a. get - usually - I - up-seven-at -clock- o

b. $\quad$ going - to - am $-\mathrm{I}-\mathrm{be}-$ Russia - in - year - next

c. $\quad$ Carol - live - her - Tom - brother - and - London - in

d. $\quad$ Football - Pepe - play - Sunday - Morning - I - every - and

e.- stayed - a - small - and - for - we- in - hotel - went - walk - a - every morning 


\section{ANEXO 4. FICHAS DE VALIDACIÓN DE LOS INSTRUMENTOS Y ESTRATEGIA METODOLÓGICA MODELADA}

ENTREVISTA:
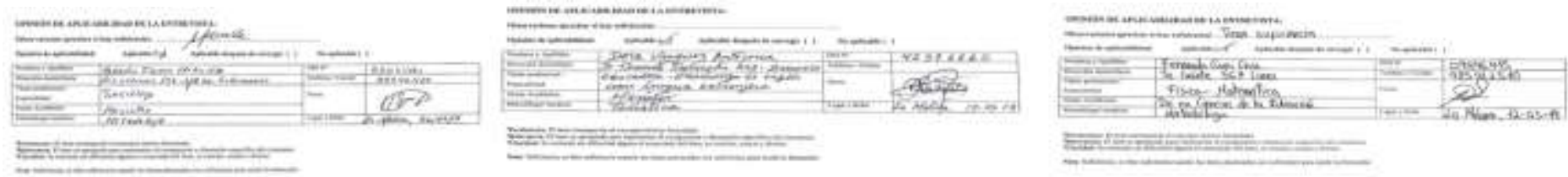

CUESTIONARIO
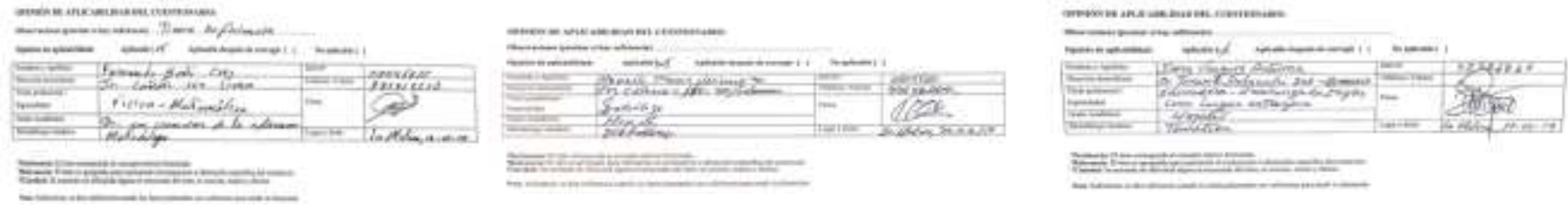

GUÍA DE OBSERVACIÓN:
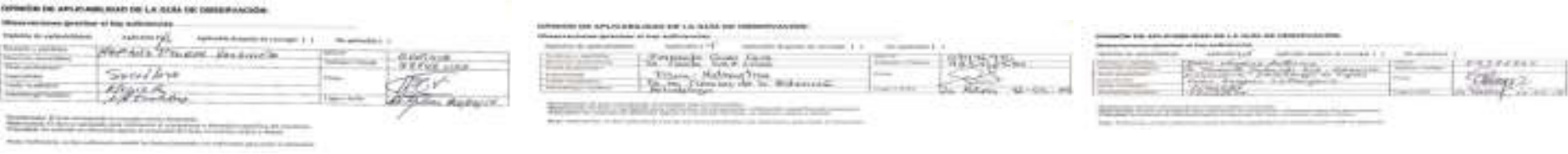

PRUEBA:

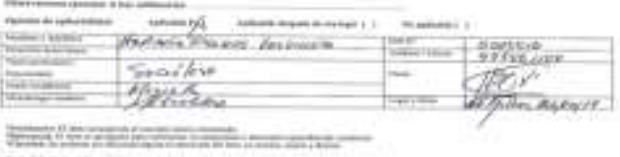

ESTRATEGIA METODOLÓGICA:
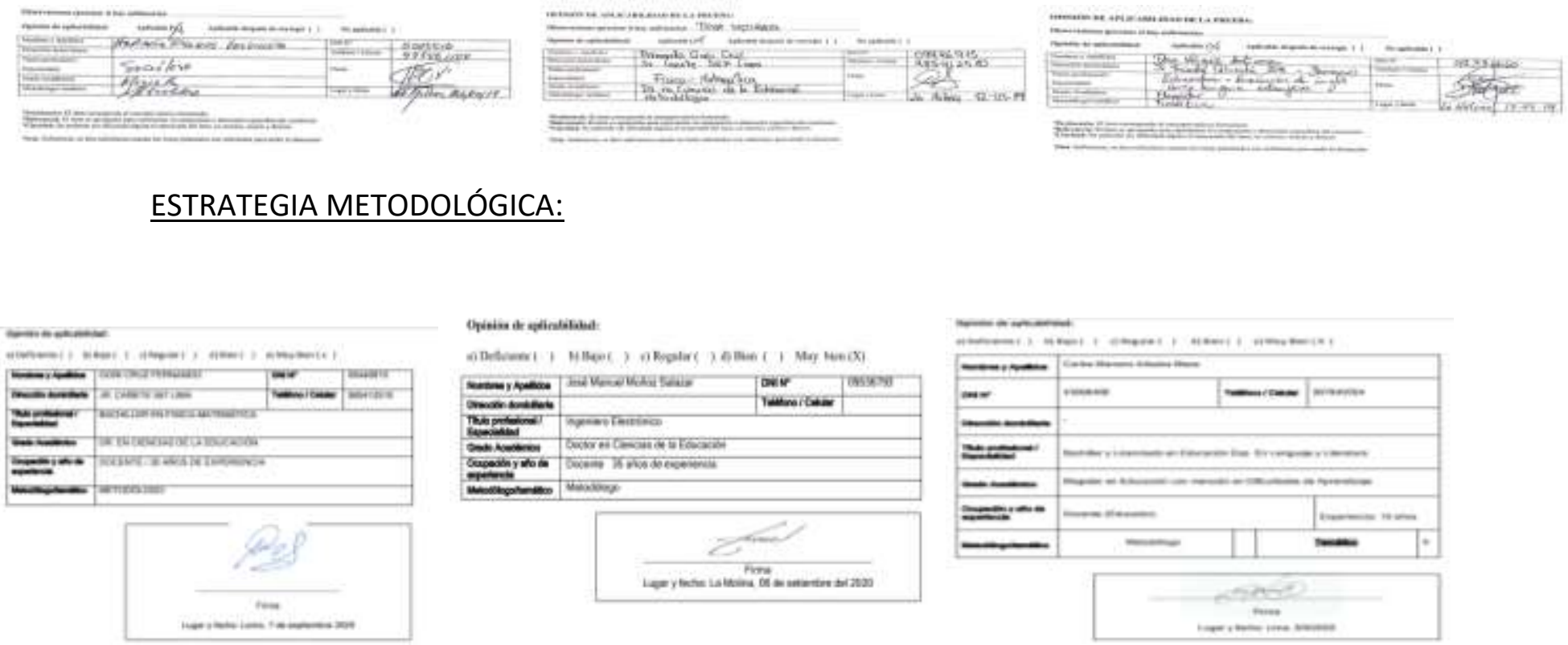

OTieis it equindabat

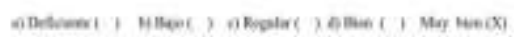
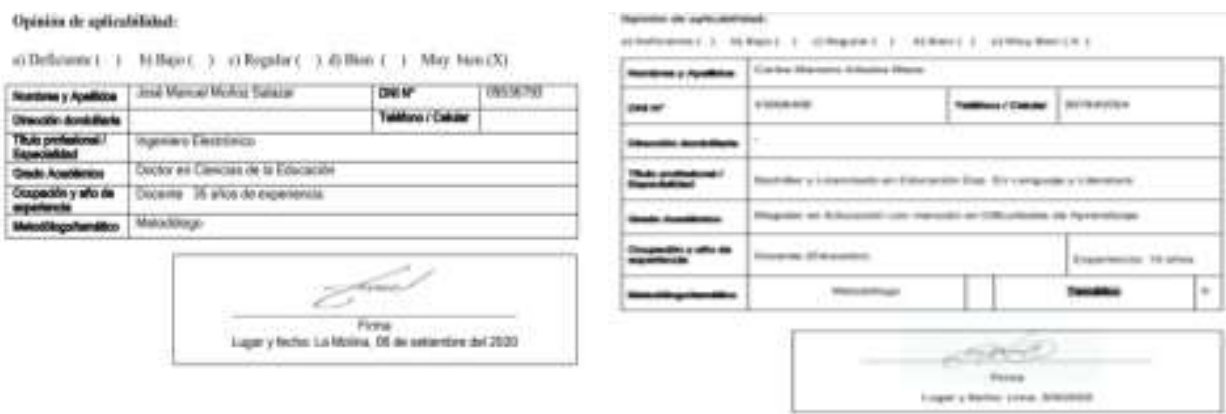


\section{ANEXO 5. ANÁLISIS ESTADÍSTICOS}

\section{ENCUESTA}

\begin{tabular}{|c|c|c|c|c|c|}
\hline & & Frecuencia & Porcentaje & Porcentaje válido & Porcentaje acumulado \\
\hline \multirow[t]{4}{*}{ Válido } & Casi Nunca & 5 & 12,5 & 12,5 & 12,5 \\
\hline & $A$ veces & 21 & 52,5 & 52,5 & 65,0 \\
\hline & Casi siempre & 14 & 35,0 & 35,0 & 100,0 \\
\hline & Total & 40 & 100,0 & 100,0 & \\
\hline
\end{tabular}

¿La clase de inglés se caracteriza por emplear textos reales e intenta relacionar la lengua aprendida con actividades realizadas fuera de ella, en contextos sociales reales?

\begin{tabular}{|c|c|c|c|c|c|}
\hline & & Frecuencia & Porcentaje & Porcentaje válido & Porcentaje acumulado \\
\hline \multirow[t]{4}{*}{ Válido } & Casi Nunca & 4 & 10,0 & 10,0 & 10,0 \\
\hline & A veces & 20 & 50,0 & 50,0 & 60,0 \\
\hline & Casi siempre & 16 & 40,0 & 40,0 & 100,0 \\
\hline & Total & 40 & 100,0 & 100,0 & \\
\hline \multicolumn{6}{|c|}{ ¿El profesor te orienta y motiva a producir textos sencillos? } \\
\hline & & Frecuencia & Porcentaje & Porcentaje válido & Porcentaje acumulado \\
\hline \multirow[t]{5}{*}{ Válido } & Casi Nunca & 7 & 17,5 & 17,5 & 17,5 \\
\hline & A veces & 22 & 55,0 & 55,0 & 72,5 \\
\hline & Casi siempre & 9 & 22,5 & 22,5 & 95,0 \\
\hline & Siempre & 2 & 5,0 & 5,0 & 100,0 \\
\hline & Total & 40 & 100,0 & 100,0 & \\
\hline
\end{tabular}

¿Consideras importante el contenido de la asignatura Nivelación Inglés de manera que realizas las tareas con responsabilidad?

\begin{tabular}{|c|c|c|c|c|c|}
\hline & & Frecuencia & Porcentaje & Porcentaje válido & Porcentaje acumulado \\
\hline \multirow[t]{5}{*}{ Válido } & Casi Nunca & 6 & 15,0 & 15,0 & 15,0 \\
\hline & $A$ veces & 19 & 47,5 & 47,5 & 62,5 \\
\hline & Casi siempre & 11 & 27,5 & 27,5 & 90,0 \\
\hline & Siempre & 4 & 10,0 & 10,0 & 100,0 \\
\hline & Total & 40 & 100,0 & 100,0 & \\
\hline
\end{tabular}

¿Participas con responsabilidad en las actividades propuestas por el docente sean individuales o grupales?

\begin{tabular}{|c|c|c|c|c|c|}
\hline & & Frecuencia & Porcentaje & Porcentaje válido & Porcentaje acumulado \\
\hline \multirow[t]{6}{*}{ Válido } & Nunca & 1 & 2,5 & 2,5 & 2,5 \\
\hline & Casi Nunca & 5 & 12,5 & 12,5 & 15,0 \\
\hline & A veces & 20 & 50,0 & 50,0 & 65,0 \\
\hline & Casi siempre & 10 & 25,0 & 25,0 & 90,0 \\
\hline & Siempre & 4 & 10,0 & 10,0 & 100,0 \\
\hline & Total & 40 & 100,0 & 100,0 & \\
\hline
\end{tabular}

¿Reconoces tus límites y tienes el propósito de superarlas recurriendo a tus habilidades, destrezas y a las recomendaciones brindadas por el docente?

\begin{tabular}{|c|c|c|c|c|c|}
\hline & & Frecuencia & Porcentaje & Porcentaje válido & Porcentaje acumulado \\
\hline \multirow[t]{5}{*}{ Válido } & Casi Nunca & 1 & 2,5 & 2,5 & 2,5 \\
\hline & $A$ veces & 22 & 55,0 & 55,0 & 57,5 \\
\hline & Casi siempre & 12 & 30,0 & 30,0 & 87,5 \\
\hline & Siempre & 5 & 12,5 & 12,5 & 100,0 \\
\hline & Total & 40 & 100,0 & 100,0 & \\
\hline
\end{tabular}


¿El profesor presenta su clase de manera didáctica generando el interés por el aprendizaje?

\begin{tabular}{llllll}
\hline \hline & & Frecuencia & Porcentaje & Porcentaje válido & Porcentaje acumulado \\
\hline Válido & Casi Nunca & 4 & 10,0 & 10,0 & 10,0 \\
& A veces & 19 & 47,5 & 47,5 & 57,5 \\
& Casi siempre & 15 & 37,5 & 37,5 & 95,0 \\
& Siempre & 2 & 5,0 & 5,0 & 100,0 \\
& Total & 40 & 100,0 & 100,0 & \\
\hline \hline
\end{tabular}

¿El profesor se interesa por conocer a sus estudiantes e identifica las dificultades que podrían suscitarse en el proceso enseñanza-aprendizaje con la finalidad de mejorar el desempeño de sus alumnos?

\begin{tabular}{|c|c|c|c|c|c|}
\hline & & Frecuencia & Porcentaje & Porcentaje válido & Porcentaje acumulado \\
\hline \multirow[t]{6}{*}{ Válido } & Nunca & 1 & 2,5 & 2,5 & 2,5 \\
\hline & Casi Nunca & 5 & 12,5 & 12,5 & 15,0 \\
\hline & $A$ veces & 12 & 30,0 & 30,0 & 45,0 \\
\hline & Casi siempre & 16 & 40,0 & 40,0 & 85,0 \\
\hline & Siempre & 6 & 15,0 & 15,0 & 100,0 \\
\hline & Total & 40 & 100,0 & 100,0 & \\
\hline
\end{tabular}

¿Te sientes motivado cuando el profesor presenta situaciones retadoras orientando lo que aprenden y cómo lo aprenden?

\begin{tabular}{llllll}
\hline \hline & & Frecuencia & Porcentaje & Porcentaje válido & Porcentaje acumulado \\
\hline Válido & Casi Nunca & 3 & 7,5 & 7,5 & 7,5 \\
& A veces & 4 & 10,0 & 10,0 & 17,5 \\
& Casi siempre & 25 & 62,5 & 62,5 & 80,0 \\
& Siempre & 8 & 20,0 & 20,0 & 100,0 \\
& Total & 40 & 100,0 & 100,0 & \\
\hline \hline
\end{tabular}

¿Consideras que la forma en que el docente presenta el nuevo conocimiento facilita el aprendizaje?

\begin{tabular}{|c|c|c|c|c|c|}
\hline & & Frecuencia & Porcentaje & Porcentaje válido & Porcentaje acumulado \\
\hline \multirow[t]{5}{*}{ Válido } & Casi Nunca & 1 & 2,5 & 2,5 & 2,5 \\
\hline & $A$ veces & 21 & 52,5 & 52,5 & 55,0 \\
\hline & Casi siempre & 12 & 30,0 & 30,0 & 85,0 \\
\hline & Siempre & 6 & 15,0 & 15,0 & 100,0 \\
\hline & Total & 40 & 100,0 & 100,0 & \\
\hline
\end{tabular}

¿Sientes que tú y tus compañeros son los protagonistas principales en el proceso enseñanza-aprendizaje?

\begin{tabular}{llllll}
\hline \hline & & Frecuencia & Porcentaje & Porcentaje válido & Porcentaje acumulado \\
\hline Válido & Casi Nunca & 4 & 10,0 & 10,0 & 10,0 \\
& A veces & 23 & 57,5 & 57,5 & 67,5 \\
& Casi siempre & 9 & 22,5 & 22,5 & 90,0 \\
& Siempre & 4 & 10,0 & 10,0 & 100,0 \\
& Total & 40 & 100,0 & 100,0 & \\
\hline \hline
\end{tabular}

Antes de culminar la clase ¿reflexiona sobre lo aprendido?

\begin{tabular}{llllll}
\hline \hline & & Frecuencia & Porcentaje & Porcentaje válido & Porcentaje acumulado \\
\hline Válido & Casi Nunca & 7 & 17,5 & 17,5 & 17,5 \\
& A veces & 20 & 50,0 & 50,0 & 67,5 \\
& Casi siempre & 7 & 17,5 & 17,5 & 85,0 \\
& Siempre & 6 & 15,0 & 15,0 & 100,0 \\
& Total & 40 & 100,0 & 100,0 & \\
\hline \hline
\end{tabular}




\section{PRUEBA PEDAGÓGICA}

\begin{tabular}{|c|c|c|c|c|c|}
\hline \multicolumn{6}{|c|}{ WRITTING } \\
\hline & & Frecuencis & Porcentaje & $\begin{array}{c}\text { Porcentaje } \\
\text { vEllido }\end{array}$ & $\begin{array}{l}\text { Porcentaj= } \\
\text { acumulado }\end{array}$ \\
\hline \multirow{4}{*}{ Wallidos } & Bajo & 17 & 42,5 & 42,5 & 42,5 \\
\hline & Medio & 17 & 42,5 & 42,5 & BE, 0 \\
\hline & Alto & (6) & 15,0 & 15,0 & 100,0 \\
\hline & Total & 40 & 100,0 & 100,0 & \\
\hline
\end{tabular}

\begin{tabular}{|c|c|c|c|c|c|}
\hline \multicolumn{6}{|c|}{ READING } \\
\hline & & Firecuencia & Porcentaje & $\begin{array}{c}\text { Porcentaje } \\
\text { valido }\end{array}$ & $\begin{array}{l}\text { Porcentaje } \\
\text { gcumulado }\end{array}$ \\
\hline \multirow{4}{*}{ Mälidos } & Bajo & 14 & 35,0 & 35,0 & 35,0 \\
\hline & Medio & 20 & 50,0 & 50,0 & 85,0 \\
\hline & Alto & b & 15,0 & 15,0 & 100,0 \\
\hline & Total & 40 & 100,0 & 100,0 & \\
\hline
\end{tabular}

GRAMMAR

\begin{tabular}{|c|c|c|c|c|c|}
\hline & & Frecuencia & Porcentaje & $\begin{array}{c}\text { Porcentaje } \\
\text { valido }\end{array}$ & $\begin{array}{l}\text { Porcentaje } \\
\text { acumuledo }\end{array}$ \\
\hline \multirow{4}{*}{ VElidos } & Bejo & 15 & 37,5 & 37,5 & 37.5 \\
\hline & Medio & 19 & $4 \pi \cdot 5$ & 47.5 & $B 5,0$ \\
\hline & Alto & e & 15,0 & 15,0 & 100,0 \\
\hline & Total & 40 & 100,0 & 100,0 & \\
\hline
\end{tabular}

TOTAL

\begin{tabular}{|c|c|c|c|c|c|}
\hline & & Frecuencia & Porcentzje & $\begin{array}{c}\text { Porcentaje } \\
\text { vallido }\end{array}$ & $\begin{array}{l}\text { Porcentaj= } \\
\text { aciumullado }\end{array}$ \\
\hline \multirow{4}{*}{ Wälidos } & Baj.jo & 16 & 40,0 & 40,0 & 40,0 \\
\hline & Medio & $1 \mathrm{~B}$ & 45,0 & 45,0 & BE, O \\
\hline & Alto & e & 15,0 & 15,0 & 100,0 \\
\hline & Total & 40 & 100,0 & 100,0 & \\
\hline
\end{tabular}

